
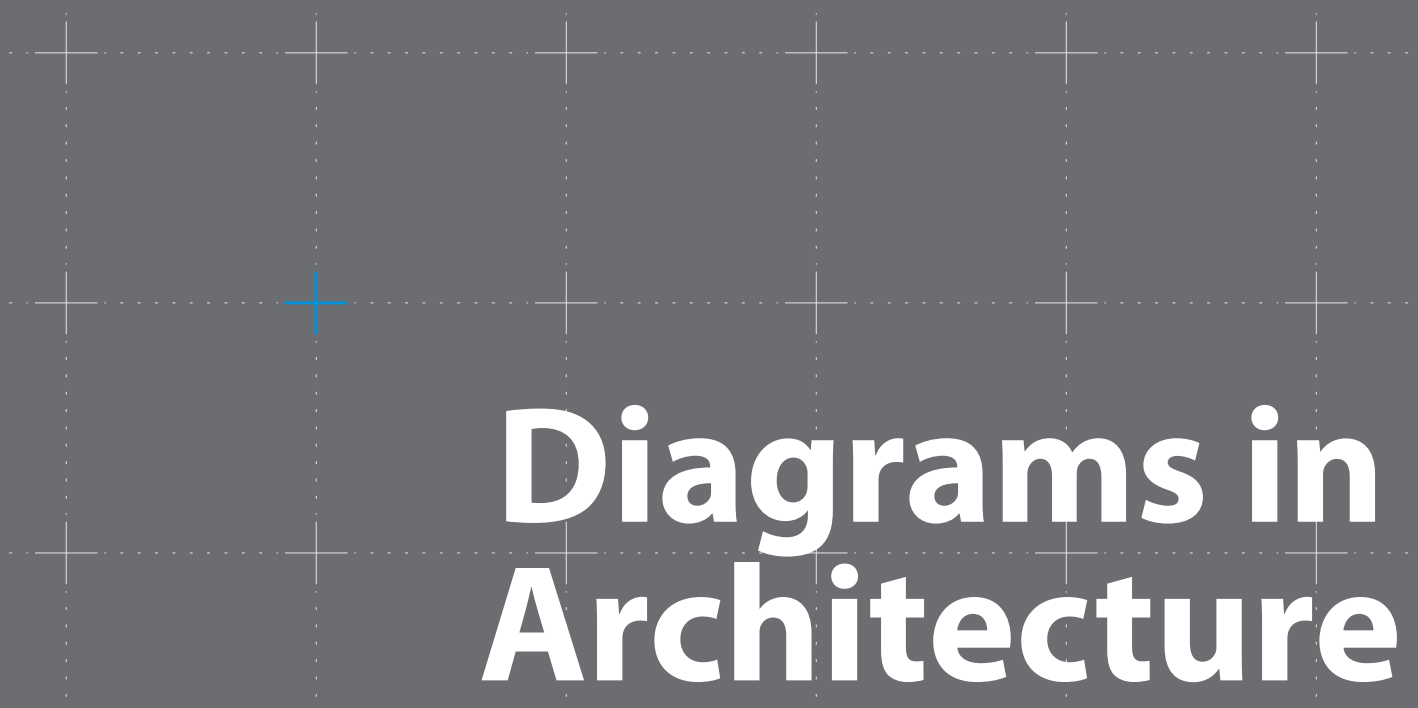

\title{
Diagrams in
Architecture
}

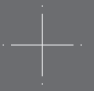

An Examination of Diagram Based Desgin Methods in Contemporary Urban Architecture Projects
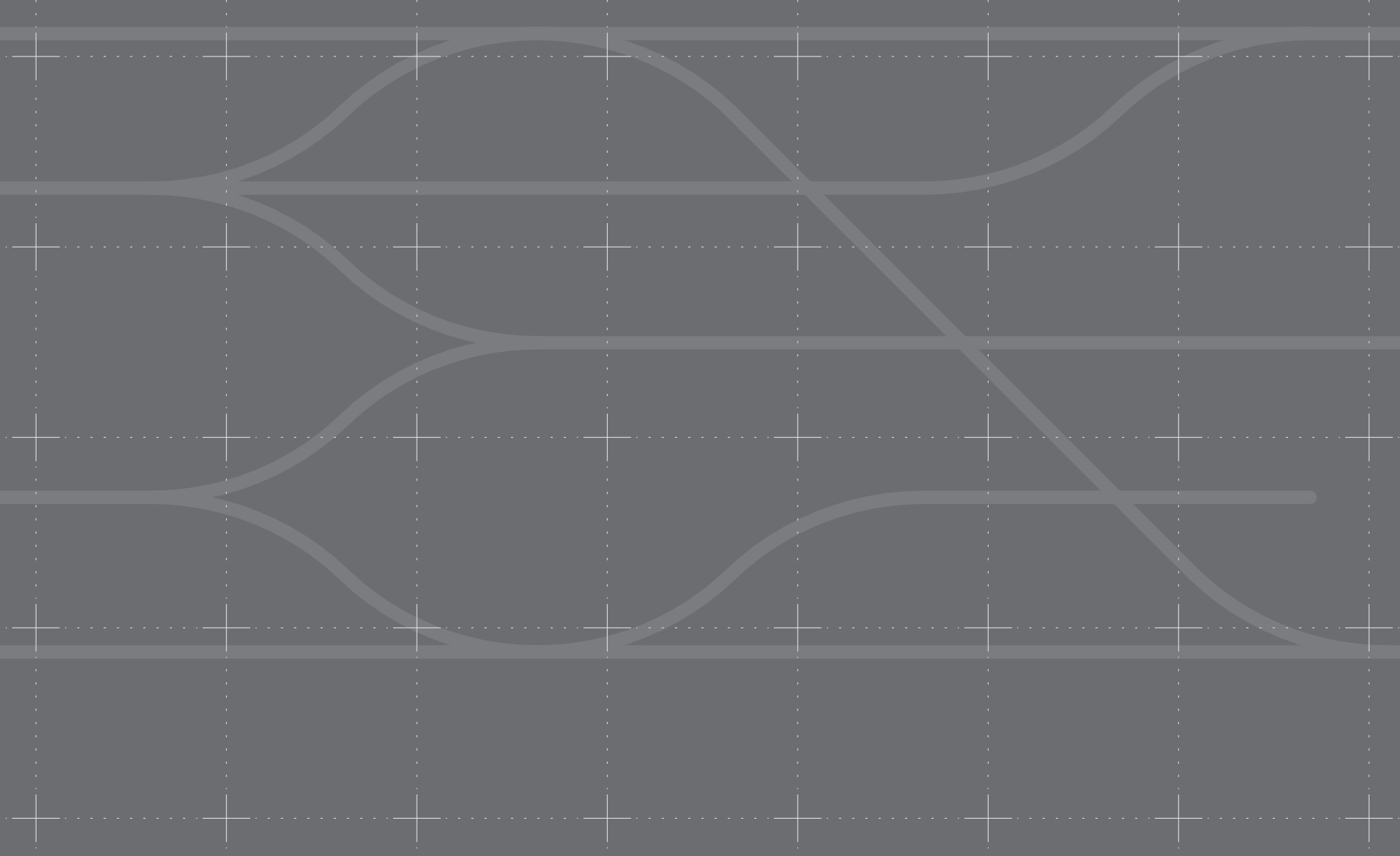

FRASER SHIELDS 



\section{Diagrams in Architecture}

An Examination of Diagram Based Desgin Methods in Contemporary Urban Architecture Projects

FRASER SHIELDS

A thesis submitted in partial satisfaction

of the requirements for the degree of

MASTER OF ARCHITECTURE (PROFESSIONAL)

at the

SCHOOL OF ARCHITECTURE

of

VICTORIA UNIVERSITY OF WELLINGTON

2012 
$+$

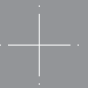

$+$

$+$

$+$

$+$

$+$

$+$

$+\quad+$

$+$

$+$

$+$

$+$

$+$

$+$

$+\quad+$

$+$

$+$

$+$

$+$

$+$

$+$

$+\cdots \cdots+$

$+$

$+$

$+$

$+$

$+$

$+$

$+\quad+$

$+$

$+$

$+$

$+$

$+$

$+$

$+\cdots \cdots+$

$+$

$+$

$+$

$+$

$+$

$+$

$+$

$+$

$+\cdots \cdots+$

$+$

$+$

$+$

$+$

$+$

$+$

$+$

$+$

$+$ 


\section{Abstract}

This research explores the relationship between the use of diagrams in architectural production and an architectural outcome which redefines conventional relationships between urban built form and open space. Several prominent architecture practices whose design methodologies are based extensively on diagrams produce architectural outcomes which relate to their surrounding physical context in unusual ways, presenting alternative solutions to conventional urban design principles and representing an emerging trend in urban design. A variety diagram types are utilised in different ways in the design processes of these key 'diagrammatic' practices.

Design proposals responding to the same brief examine the architectural and urban design outcomes of different types of diagram use. Two different diagrammatic design methodologies are executed, producing two design proposals for a complex mixed use development in central Wellington.

Each diagrammatic design methodology has different implications for the relationships between built form and open space by emphasising different factors in the design process and progressing differently from diagram into built form. One method emphasises continuity and connection, thereby minimising the typical distinctions between built form and open space. The other method emphasises a strict functional logic to produce unusual programmatic organisations which create ambiguity between the building's inside and outside. Instrumentalising diagrams in the design process aids in the management of the project's complexities, allows the design to develop in an abstract manner, and presents the often unusual design outcomes on the basis of an underlying functional logic, thereby providing a significant contribution to the realisation of new architectural and urban design solutions. 


\section{Table of Contents}

Abstract

Table of Contents IV

Acknowledgements IX IX

One | Introduction 1

Research Background 1

Research Aim 1

Research Approach 2

Scope of Research 3

Two | Literature Review 4

Introduction 5

[1] Urban Design 6

Urban Design Background 6

Boundaries: Conventional Urban Design Principles 8

Extending the Boundary: Challenging Conventional Urban Design Principles

Blurring the Boundaries: Building/Landscape Integration 15

[2] Diagrams in Architecture 18

Diagrams: Tools for Extending the Boundary 18

Three | Practice + Case Studies $\quad 24$

Introduction 25

Foreign Office Architects | Practice Study 27

$\begin{array}{ll}\text { Practice Ideology } & 27\end{array}$

Definition of Diagram 27

Diagram Value 28

Diagrammatic Design Methodology 28

Attitude Towards Ground/Landscape 29

Foreign Office Architects | Case Study 30

$\begin{array}{ll}\text { Project Overview } & 30\end{array}$

$\begin{array}{ll}\text { Project Design Methodology } & 30\end{array}$ 
Diagram Methodology

Relationship to Urban Design Principles 33

UN Studio | Practice Study 34

Practice Ideology 34

Definition of Diagram 34

Diagram Value 35

Diagrammatic Design Methodology 35

Attitude Towards Ground/Landscape 37

UN Studio | Case Study $\quad 38$

Project Overview 38

Project Design Methodology 38

Diagram Methodology $\quad 41$

Relationship to Urban Design Principles 42

MVRDV | Practice Study

$\begin{array}{ll}\text { Practice Ideology } & 43\end{array}$

Definition of Diagram 43

Diagram Value 44

Diagrammatic Design Methodology 44

Attitude Towards Ground/Landscape $\quad 45$

MVRDV | Case Study $\quad 46$

Project Overview 46

Project Design Methodology 46

Diagram Methodology 49

Relationship to Urban Design Principles 49

OMA | Practice Study $\quad 50$

$\begin{array}{ll}\text { Practice Ideology } & 50\end{array}$

Definition of Diagram $\quad 50$

Diagram Value $\quad 50$

Diagrammatic Design Methodology $\quad 51$

Attitude Towards Ground/Landscape $\quad 52$

OMA | Case Study

Project Overview $\quad 53$

Project Design Methodology 
Diagram Methodology 54

Relationship to Urban Design Principles 55

Case Studies | Discussion $\quad 56$

Diagram Type Summary $\quad 56$

Diagram Use Summary $\quad 58$

Unconventional Diagram Use 59

Common Unconventional Diagram Use 60

$\begin{array}{ll}\text { Four } \mid \text { Pre-Design } & 64\end{array}$

Pre-Design | Introduction $\quad 65$

Design Testing 65

Design Background 65

Design Brief 66

$\begin{array}{ll}\text { Pre-Design | Site Analysis } & 67\end{array}$

Urban Context $\quad 67$

$\begin{array}{ll}\text { Site Context } & 68\end{array}$

$\begin{array}{ll}\text { Site Photographs } & 70\end{array}$

Existing Building - The Oaks Retail Complex 71

Wellington 2040

\begin{tabular}{l|l} 
Five $\mid$ Design Execution & 74
\end{tabular}

Abstract/Instrumentalising | Design Execution 75

Introduction $\quad 75$

Design Execution $\quad 76$

$\begin{array}{ll}\text { Resulting Form } & 78\end{array}$

Abstract/Instrumentalising | Design Outcome $\quad 80$

$\begin{array}{ll}\text { Design Summary } & 80\end{array}$

Analytic/Literal | Design Execution 88

Introduction $\quad 88$

Design Execution $\quad 88$

Resulting Form 94

Analytic/Literal | Design Outcome 96

Design Summary 96

\begin{tabular}{ll|l} 
Design Execution | Discussion & 104
\end{tabular} 
Design One: Areas of Unconventional Building/Open Space Relationships

Design One: Role of diagrams in Design Process

Design Two: Areas of Unconventional Building/Open Space Relationships

Design Two: Role of diagrams in Design Process

Role of the Designer in the Different Methodologies

Architectural Outcomes of the Different Methodologies

Limitations of the Different Methodologies

Findings for the Instrumentality of Diagrams

Six $\mid$ Conclusions

Conclusion One: Different Types of Diagrammatic Practice

Conclusion Two: Different Unconventional Urban Design Outcomes

Conclusion Three: Contribution of Diagrammatic Design

Methodologies in the Realisation of Unconventional Urban Design Outcomes

Limitations and Further Research

Final Conclusion

Bibliography

List of Figures 
Diagrams in Architecture 


\section{Acknowledgements}

I would like to thank my family, especially my parents, Helen and Hugh, for their support and encouragement throughout my time at university, and for pushing me to recognise the importance of a good education. It is thanks to the values which they have passed on to me that I today have the drive and passion for learning required to complete this research.

I would secondly like to thank my supervisor, Chris McDonald, for his thorough feedback and thoughtful guidance, and for maintaining a healthy and ultimately valuable scepticism of my still-emerging area of research.

Lastly I would like to thank my friends and research studio colleagues whose couch conversations and innumerable tea breaks provided the welcome distractions necessary to maintain a MArch (Prof) student's sanity. 


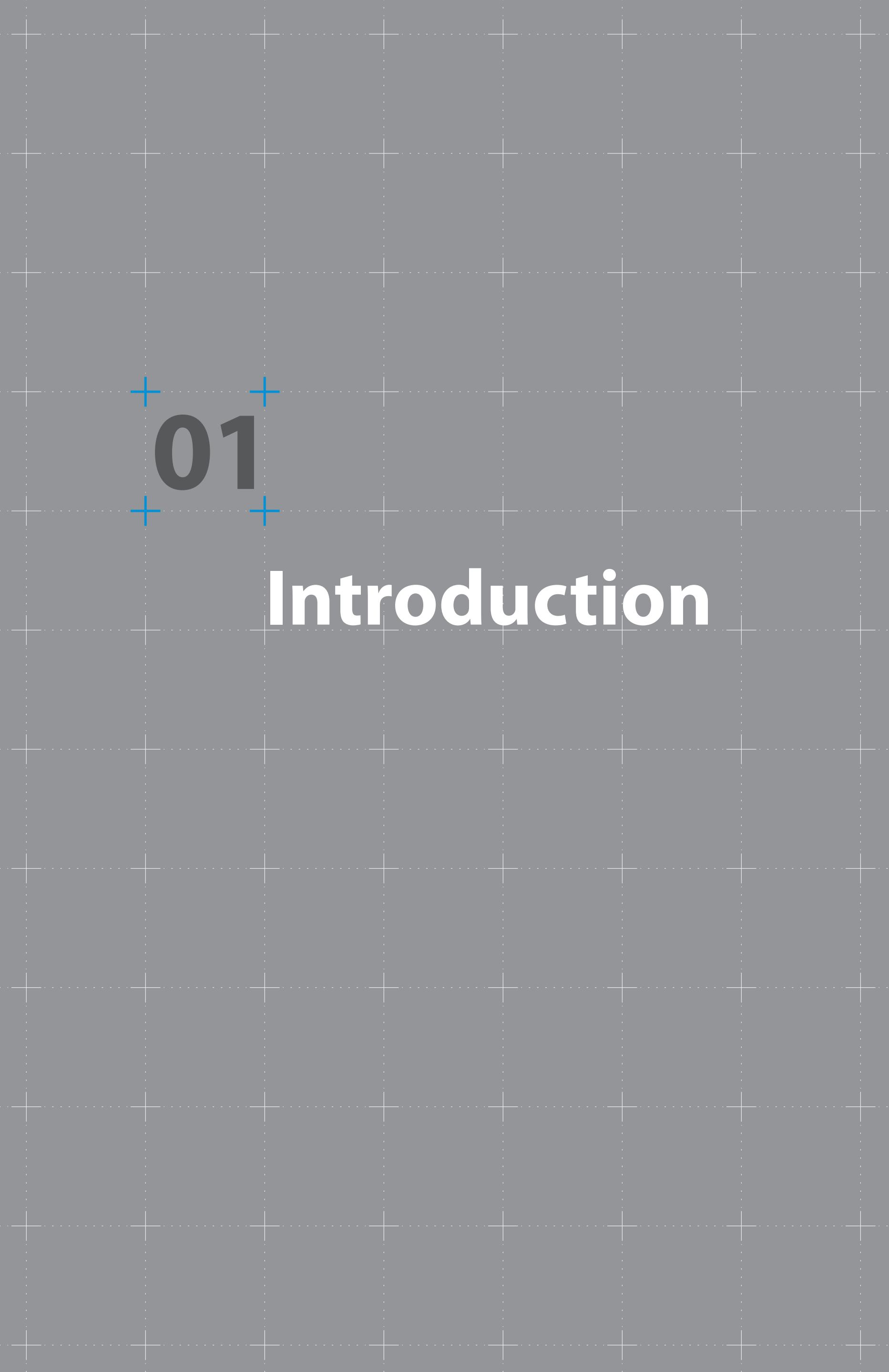




\section{Introduction}

\section{Research Background}

Diagrams have been used in architecture for centuries, however only attracted significant written attention as recently as the 20 th Century, gaining prominence in the 1980s. Despite their widespread use and long history in architecture there are surprisingly few publications dedicated to the topic of diagrams in architecture, perhaps due to an emphasis on text and images and a prioritised interest in product over process. Because of this, significant gaps exist in the knowledge that surrounds the use of diagrams in architecture.

Many contemporary architectural projects designed by key 'diagrammatic practices' - those practices who utilise diagrams extensively in their design methodologies - seem to challenge contemporary urban design principles prescribed by urban design texts and publications. These practices utilise diagrams in new ways to generate and explain new conceptions for the physical boundaries of architecture and its relationship with what has conventionally been called the outdoor public realm. No examination of how these 'diagrammatic' design methodologies impact on the design of urban architecture projects, specifically how they influence the architecture's relationship between built form and open space, has been published. This represents a serious gap in the knowledge of how diagrams can be utilised in urban architecture projects to generate new possibilities and strategies for urban design and the design of buildings in urban contexts.

\section{Research Aim}

The aim of this thesis is to explore the use of 'diagrammatic' design methods in urban architecture projects. It focuses on the instrumentality of diagrams in generating new possibilities for architecture which challenge conventional urban design principles concerning the relationship between buildings and open space. 


\section{Research Approach}

Chapter 2 reviews literature concerning contemporary urban design principles and theory. It focuses particularly on how the current theory addresses the physical boundaries between built form and open space, and establishes a set of 'conventional' urban design principles on the topic. Rival views which challenge these 'conventional' principles are then examined to identify emerging alternative conceptions of built form/open space relationships. Texts include urban design guides and recent books published on the topic.

The second part of the chapter reviews literature concerning the use of diagrams in architecture and provides the theoretical basis for contemporary thinking on their use. It outlines various definitions of architectural diagrams and identifies their function and value in architectural production. The research identifies four key architectural practices which feature prominently in literature concerning both emergent urban design trends and diagrams in architecture. Texts include periodical articles and edited books on the topic.

Chapter 3 presents practice and case studies of the four key architectural practices identified by the literature review. The diagrammatic concepts of each practice are examined and a case study of one key project from each practice is executed. The case studies examine the diagrammatic design methodology of each of the projects, and identify the areas of emergent urban design trends for each design. Following the practice and case studies a discussion identifies the different types of diagrams used by the practices and identifies two different types of 'unconventional' diagram use, common amongst the key practices.

Chapter 4 outlines the role of design for the research and presents the design brief and site analysis required before undertaking the design phase of the research.

Chapter 5 presents the design phase of the research which responds to a theoretical design brief for a mixed use building in a central urban site. A diagrammatic design methodology based on each of the two types of diagram use identified by the case studies is executed, generating two different design proposals in response to the brief.

The second part of the chapter identifies the findings for the design phase of the research. Areas of unconventional urban design outcomes in each design proposal are identified, and the role of diagrams and the designer in each of the methodologies is discussed. The differences in architectural outcomes and limitations of the different diagrammatic design methodologies are also discussed. Following these areas of discussion, findings on the instrumentality of diagrams in producing unconventional urban design outcomes are identified, relating to the aim of the research.

Chapter 6 presents the conclusions for the research which are informed by the 
literature review, practice and case studies, and the design execution. Three major conclusions are formulated for this research. Limitations and areas of further possible research are also identified.

\section{Scope of Research}

The primary area of interest for this research is urban buildings which present a rival conception of built form/open space relationships to those identified as 'conventional' according to urban design texts. The research does not argue that all urban architecture projects could or should challenge conventional urban design principles, only that for certain projects these emerging strategies could produce new and different architectural and urban design outcomes. With a focus on newness and difference and the difficult task of determining suitable criteria for analysis, the research does not seek to argue points concerning the urban quality of the design outcomes.

The scope of the research is limited by the availability of published material, especially concerning the processes of design. A more detailed analysis of a lesser number of practice and case studies is relied upon for drawing conclusions for the research. 


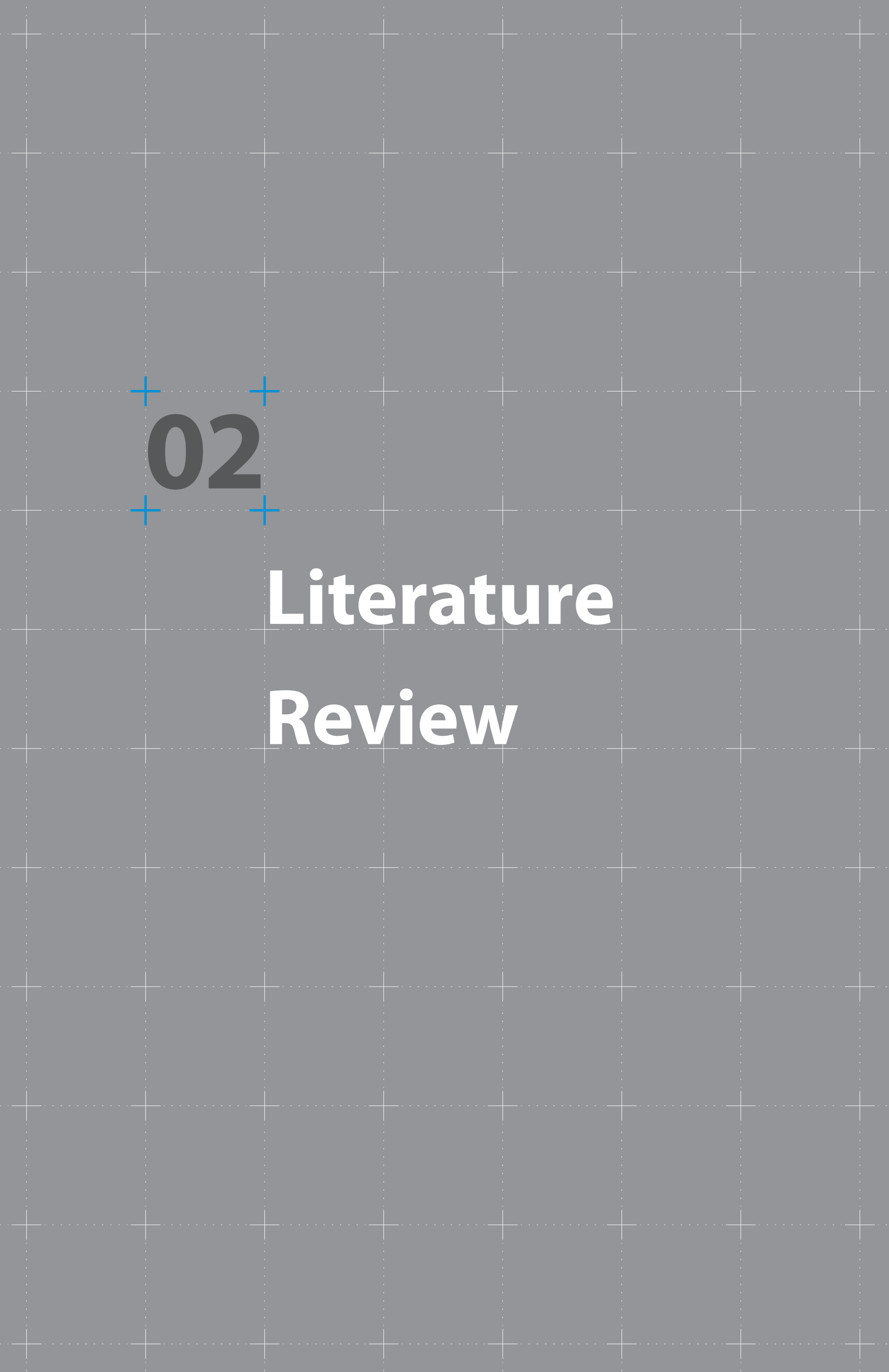




\section{Literature Review Introduction}

The literature review is structured as two streams of research; urban design and diagrams in architecture.

Part one, Urban Design, is divided into three sections: Urban Design Background identifies how urban form has changed over the last century and the impact of these changes on urban public space. Boundaries: Conventional Urban Design Principles identifies conventional urban design principles advocated by recent urban design movements and publications, especially their principles regarding the relationship between buildings and open space. In Extending the Boundary: Challenging Conventional Urban Design Principles, emergent rival urban design movements and practices are identified and the ways in which they challenge conventional urban design principles are examined, especially those regarding the relationships between buildings and open space.

Part two, Diagrams in Architecture examines literature concerning the use of diagrams in architecture and provides the theoretical basis for their use in the profession. Various definitions of diagrams are examined and their functions and values in the architectural design process are identified. The architectural qualities characteristic of buildings produced via diagrams are also identified. Texts include periodical articles and edited books on the topic. 


\section{[1] Urban Design}

\section{Urban Design Background}

Traditional and Modern City Form.

Urban space systems within cities can essentially be understood in two different ways. The first is where buildings define space and the second is where buildings are objects-in-space (Carmona, Tiesdell, Heath, \& Oc, 2010). The former is typically referred to as traditional urban space, and the latter Modern urban space.

Traditional urban space can be considered as the urban space which evolved prior to large scale industrialisation and urbanisation. Before the industrial revolution urban development was limited by transport methods, availability of construction materials, building methods and the absence of mechanical building technologies such as lifts (Carmona et al, 2010). Urban form during this time was characterised by continuous compact low rise buildings forming small scale urban blocks which defined and enclosed urban space into definite spatial types such as streets and squares. Rowe (as cited in Carmona et al, 2010), describes this urban form in terms of 'texture', where a continuous matrix of background buildings define urban space; only buildings of significance where separated from the background urban structure.

Modern urban space planning emerged in opposition to traditional urban form. It was driven both by "...horror at the squalor and slums of nineteenth century industrial cities, and by perception of the start of a new age - the Machine Age" (Carmona et al, 2010, p. 21). Le Corbusier (as cited in Carmona et al, 2010) likened the traditional street to a trench, describing it as oppressing, constricting and enclosing. In opposition to the traditional city, Modern city form was characterised by buildings as freestanding objects in landscape settings; sculptural objects standing freely space. Using figure-ground diagrams, Rowe and Koetter showed how traditional and modern cities were essentially an inverse of one another: one represented solid buildings placed in a void; the other, voids removed from a solid building mass (as cited in Carmona et al, 2010). According to Carmona et al, (2010) modernist urban space was intended to "...flow freely around buildings rather than being enclosed and contained by them," (p. 85) allowing light in and air to circulate. The form of the buildings were determined primarily by the functions of the internal spaces 
which they housed, resulting in buildings which related poorly to the il-defined public space which surrounded them.

\section{Reactions to Modern Urban Space.}

Modernism's emphasis on 'object' buildings in space resulted in sterile urban environments which, according to Lang (as cited in Carmona et al, 2010) were a "...failure in terms of the lives of those who inhabited them" (p. 12). Gehl (2010), suggests the problem was viewing urban development from an aerial perspective, thereby ignoring the small scale human landscape experienced by the users of the spaces. He suggests that Modern city spaces were too large and amorphous, streets too wide and sidewalks too long and straight.

In the early 1960s Modernist ideas of urban space began to be questioned with increasing force resulting in a number of criticisms and reactions to the prevailing Modern urban development practices. This reaction was led by a group of writers including Jane Jacobs, Kevin Lynch, Christopher Alexander and Jan Gehl who became influential in the newly formed discipline of urban design. Much of their writing attacked the fundamental concepts of modernist urban planning, and instead proposed a social usage approach to urban planning, emphasising the way in which people use space and perceive a sense of place rather than the design of buildings as objects alone (Carmona et al, 2010).

\section{Urban Design's Place-Making Tradition.}

Since the 1990s a place-making tradition in urban design has emmerged and exists as the prevailing approach to urban design today, informing conventional urban design principles. This approach is rooted in the social urban design tradition of the 1960s, and concerns both the physical design of urban spaces as well as urban spaces as behavioural settings. The place-making tradition informs most definitions of urban design today, a useful example of which comes from the Commission for Architecture and the Built Environment (CABE) (2000) in the United Kingdom:

Urban design is the art of making places for people. It includes the way places work... as well as how they look. It concerns the connections between people and places, movement and urban form, nature and the built fabric, and the processes for ensuring successful villages, towns and cities. (p. 8)

As part of the place-making tradition, the significance of urban design and the built environment is its ability to influence the human activity and social life it supports. Although not able to determine actions or behaviour, Carmona et al (2010) suggest "...urban design can be seen as a means of manipulating the probabilities of certain actions or behaviours occurring” (p. 134). According to Gehl (2010), human activity is directly related to the design quality of the 
urban environment. Good urban design can thereby enable urban spaces to realise their full potential by increasing density of use.

A number of urban design manifestos have emerged as part of the place-making tradition, seeking to identify the qualities of successful urban social places and 'good' urban form. Notable examples include Responsive Environments, and attempts by Kevin Lynch, Allen Jacobs and Donald Appleyard, Francis Tibbalds, and the Congress for New Urbanism.

\section{Boundaries: Conventional Urban Design Principles}

\section{Buildings Defining Public Space.}

An important quality of successful urban spaces identifiable in a number of place-making manifestos is built form providing definition to urban public space. Allan Jacobs and Donald Appleyard's 'Toward an Urban Design Manifesto' (1987) (as cited in Carmona et al, 2010) identifies five prerequisites of a 'sound' urban environment, one of which is a manmade environment, particularly buildings, defining public space as opposed to buildings existing in space. The Congress for New Urbanism's 'Charter for New Urbanism' (1993) (as cited in Carmona et al, 2010) also advocates the design of urban places framed by architecture, and advocates that cities should be shaped by physically defined public spaces. Buildings defining outdoor public spaces is now accepted as a conventional principle of urban design and is published in recent 'official' urban design guides such as those by CABE (2000) and the English Partnerships and the Housing Corporation (2007).

The urban design principle of buildings defining urban public space exists in opposition to Modern urban planning as it focuses predominantly on the spaces between buildings rather than the buildings themselves. Trancik (2007), suggests that by conceiving as public space as 'figural volume' the unworkable relationships between Modern buildings and public space can be reversed. This strategy sees a reversal of the conception of the role of buildings from 'objects' to 'texture', where the relatively anonymous buildings described by Kelbaugh (as cited in Carmona \& Tiesdell, The Morphological Dimension, 2007) as being 'background' or 'collateral' play an important role in defining public space; they "...gain their strength from the public space they define" (p.61). According to Trancik (1986), well defined outdoor spaces are as necessary as good buildings, which should define exterior space rather than displace it. $\mathrm{He}$ proposes people's reaction to a space is largely determined by the way it is enclosed, likening the external spaces of a city to the 'rooms' which people relate to on a daily basis. Buildings establish the 'walls' to these external rooms.

\section{Positive Space; Definite Boundaries.}

To help describe the visual qualities of external (outdoor) space, Alexander (as cited in Carmona et al, 2010) proposed that they be considered in terms 
of 'negative' and 'positive' space; this terminology is now widely adopted in urban design publications. Positive space relates to that of traditional city form and is characterised by clear definition and a sense of enclosure; negative space relates to Modern city form and is shapeless and inconceivable, possessing no perceivable boundary or enclosure. Gehl (2010) identifies an example of negative space as being bounded on all sides by traffic, and describes their function as impoverished compared to spaces where life is reinforced by buildings. Positive urban space is a key facet of conventional urban design principles, forming an important part of good urbanism (Llewelyn-Davies, 2007; Carmona, Tiesdell, Heath, \& Oc, 2010).

Positive urban space possesses the qualities of clear definition and enclosure. It features a distinct and definite shape and character, and has a positively defined function with no leftover or ambiguous space and a clear distinction between public and private areas. Enclosure is provided by clearly perceivable boundaries which limit the visual field and provide the space with a sense of containment and a threshold between 'inside' and 'outside', a principle which, according to Gehl (2010), makes a "...vital contribution to spatial experience and to the awareness of individual space as a place" (p. 75). According to Carmona et al (2010), three enclosing elements exist - “...the surrounding structures (the walls to the space), the floor; and the imaginary sphere of the sky overhead" (p. 176). In opposition to a prioritised sense of enclosure, Hillier (as cited in Carmon et al, 2010), identifies fault in many contemporary public spaces as being too enclosed compared to allowing visual permeability into the space. He proposes a more important quality of public space is its connectedness or 'integration' with the surrounding city.

\section{Building Facades: Walls of Outdoor Rooms.}

Building facades convey a building's identity and character. Buchanan (1998) argues it is the role of the facade to go beyond visual and physical definition of public space to create a sense of place, helping to define the character of the adjacent space and articulate its function. He suggests important qualities of facade articulation and composition are visual rhythms, mass and materiality, and expression of structure, which all help to engage the viewer to interact with the facade.

\section{Edges: Buildings' Social Contribution to Public Space.}

Urban buildings do more than simply provide definition, enclosure and character to public space, as CABE (2007) points out, “...the social responsibility of buildings to contribute positively to civic life has often been neglected” (p. 86). The notion of buildings contributing positively to their urban environment is reiterated in the Urban Design Compendium's summary of 'urban architecture' as: 
perspective, the success of a building is determined by its ability to make a positive contribution to the public realm - to face the street, animate it and make sure that all adjacent open space is positively used. It is this interaction between buildings and the public domain - this edge - that determines the relationship between inside and outside, built and open, public and private, individual and community. (p. 89)

This summary adopts the terminology of Gehl and Alexander; referring to this boundary between built form and open space, public and private, as 'edge'. Conceptualised as edge rather than boundary, the building/open space interface takes on a social role rather than simply providing visual definition to the space. The design of this interface between built form and public space has an influence on the social life of the space (Gehl, 2010; Carmona, Tiesdell, Heath, \& Oc, 2010). According to Gehl and Alexander, the edge is a defining factor in the success or failure of public spaces, noting that the social life of public spaces gravitates towards the edges: "If the edge fails, then the space never becomes lively" (Alexander et al as cited in Carmona et al, 2010, p. 214). Gehl (2010) describes this phenomenon as 'edge effect'.

Gehl (2010) defines edges in terms of 'soft' or 'hard'; the former characterised is by transparent facades, large windows and many openings, the latter by blank walls. Studies conducted on the impact of edge quality on city life point to a direct connection between soft edges and lively cities (Gehl, 2010). Rather than treating the edge as a line or boundary, Alexander et al (as cited in Carmona et al, 2010) recommend conceiving it “...as a 'thing', a 'place', a zone with volume to it" (p. 214), and suggest the edge of a space can be enhanced by providing opportunities for sitting. The edge 'zone' acts as an interface between life inside buildings and life outside in city spaces. Gehl (2010), recommends opening up this interface so the internal and external spaces can work together. Madanipour (as cited in Carmona et al, 2010), suggests “...the more ambiguous and articulate the boundary, the more civilised a place appears to be. When the two realms are separated by rigid walls, the line of interaction becomes arid, communication limited and the social life poorer for that" ( $\mathrm{p}$. 215). A key strategy for ensuring 'soft' edges is to locate activities for the public on the ground floor, creating an 'active' frontage. Making a frontage 'active' adds interest, vitality, and life to the public realm through increased human presence. Active frontages are characterised by:

- Frequent doors and windows with few blank walls

- Narrow frontage buildings, giving vertical rhythm to the street scene

- Articulation of facades, with projections such as bays and porches incorporated

- Lively internal uses visible from the outside, or spilling onto the street (Llewelyn-Davies, 2007) 
To encourage the social life of public spaces, the ground floor should house activities which contribute to, as well as benefit from, interaction with the public realm, contributing to its vitality.

\section{The Public Realm.}

The public realm can be considered as the sites and settings of public life. Historically this referred primarily to the physical world, however now extends beyond the physical as public life increasingly exists through the internet.

The physical public realm is defined by Carmona et al (2010) as "...the series of spaces and settings - which may be publically or privately owned - that support or facilitate public life and social interaction" (p. 137). They also note it could be considered as all the spaces shown as white in a figure-ground diagram, which includes interiors of key public buildings. The public realm extends to all the spaces accessible to and used by the public however is not always clearly defined and absolute. Rather, the relative publicness of a space can be ambiguous and depends on its qualities of ownership, access and use. External public space which is not privately owned represents public space in its purest form, whereas internal privately owned quasi-'public' space such as shopping malls exists at the other end of the spectrum and for many observers represent a decline of the public realm.

\section{Topography of the Public Realm.}

Gehl (2010) describes one quality of an inviting urban environment as one which exists on a single level, providing better opportunities to engage with fellow pedestrians. Loukaitou-Sideris (as cited in Carmona et al, 2010), describes sunken or elevated plazas as 'cracks' in the urban environment which disrupt pedestrian activity. Considering this, Gehl (2010) recommends stairs should be avoided wherever possible as they present a physical and psychological obstacle to pedestrian movement and are more difficult than staying on the same level or alternatively being transported up or down mechanically. If stairs are necessary they can be thoughtfully designed using 'staircase psychology,' whereby the climb is divided into smaller sections so pedestrians do not get to see the full course of the climb at any point. One example of successful stair design in public space is the Spanish Steps in Rome, where the climb is combined with interesting experiences and social interaction. Ramps are a more desirable option for pedestrians than stairs however do not always possess the same opportunity as stairs to provide character.

Although Gehl (2010) recommends public space remains on one level, he does recognise "Topography and height differences...provide good opportunities to add value. Any differences in height can enhance experiences for pedestrians compared to walking on flat surfaces" (p. 177). If appropriately managed, topographical differences can provide drama at eye level and contribute positively to the urban environment. 


\section{Extending the Boundary: Challenging Conventional Urban Design Principles}

The previous section identified conventional urban design principles concerning the relationship between buildings and open space which arose in opposition to Modern urban form. These principles can be summarised as follows:

- Built form providing definition and enclosure to urban public space rather than buildings standing in space

- Clear distinction between public and private areas

- 'Soft' edges

- Conceptualising the building/open space edge as a zone with thickness; not just a line

- Interaction between activities inside and outside buildings through active frontages

- Minimum topographical variation in urban public space

This section identifies rival urban design movements and practices which have emerged in opposition to, or as an alternative or extension of conventional urban design principles. Rival conceptions of boundaries between buildings and open space and building/open space duality are examined to identify emerging trends in urban architecture.

\section{Integral Urbanism.}

Integral urbanism is an emergent urbanism reacting against both Modern and Postmodern urban form, seeking to 'heal wounds' inflicted on the landscape by these movements. The principles of Integral Urbanism represent a synthesis of the 'most compelling' aspects of contemporary trends in urban design and architecture, so represent some of the most current and emergent ideas in urban design. As its name suggests, Integral Urbanism seeks to integrate a wide range of systems present in urban design, namely: Functions or uses, urban and suburban, public and private, centre and periphery, horizontal and vertical, architecture and landscape, figure and ground, indoor and outdoor, people, design professions, theory and practice, process and product, system and serendipity (Ellin, 2006). As well as synthesising some of the most recent urban architecture and urban design trends, Integral Urbanism is important in the discussion of the relationship between buildings and open space as its principles have a specific focus on borders, edges and 'in-between' spaces as concepts and as actual places.

According to Nan Ellin, the goal of Integral Urbanism is to achieve 'flow', which is characterised by places that are animated, spirited, soulful and lively. Five qualities for places to be in flow are identified, and include: hybridity, connectivity, porosity, authenticity and vulnerability: 
Hybridity and connectivity are about bringing activities and people together at all scales (from local to global). Porosity is about the nature of the relationship between these. Authenticity is about engaging real social and physical conditions with an ethic of care, respect, and honesty. Vulnerability is about relinquishing control while remaining engaged, valuing process as well as product, dynamism, and reintegrating space and time. (Ellin, 2006, p. 136)

The qualities most important to the relationship between buildings and open space are hybridity, connectivity and porosity, as they deal with the bringing together of a variety of activities and the nature of the relationship between them. These qualities are relevant as many emergent urban architecture projects seek to combine activities in new and unexpected ways, developing new conditions for urban architecture.

\section{Hybridity and Connectivity.}

Hybridity and connectivity seek to bring activities and people together rather than isolating separate functions. These qualities treat people and nature and, importantly, buildings and landscape as symbiotic rather than oppositional (Ellin, 2006). Many architects and architectural theorists recognise the value of hybridity, including most notably Steven Holl, Roger Trancik, and Rem Koolhaas (Ellin, 2006). Koolhaas (as cited in Ellin, 2006) describes how “... programmatic elements react with each other to create new events" (p. 20), referring to this as 'programmatic alchemy'. Koolhaas also introduced hybrid terms that connect separated phenomena, most notably 'SCAPE', which, according to Ellin (2006), erases "...distinctions between figure and ground inside and outside, centre and periphery" and "...allows for the convergence of architecture, landscape, and infrastructure" (p. 54).

The dissolving of the distinctions between building and landscape is an important development for urban architecture as it has definite implications on the conventional duality between buildings and open space and the boundaries present between built and unbuilt. Mark Lee (as cited in Ellin, 2006) introduced the term 'topological landscape' to describe the hybrid condition between architecture and landscape. He explains that rather than represent "... spaciousness by merely dissolving spatial confines, the topological landscape actively seeks to redefine new boundaries while simultaneously transgressing established ones ... It is not a stable entity but a performative state..." (p. 35).

Connectivity is another important term, and sometimes principle generator, of urban design interventions (Ellin, 2006). Architect Alex Wall (as cited in Ellin, 2006) notes a rise in interest of designing 'flexible, multifunctional surfaces' which create connections between different programmes and users over time. UN Studio's design for Arnhem Central transport interchange in Holland is an example of a building generated by circulation which employs flexibility 
of surfaces. Conventionally, circulation is thought of primarily in terms of horizontal movement, however by thinking about it vertically as well, qualities of hybridity and connectivity can be generated in section also.

\section{Porosity.}

Porosity seeks to preserve the integrity of that which is brought together by hybridity and connectivity by allowing a level of accessibility between the different systems through permeable membranes (Ellin, 2006). As porosity deals with the relationship and interaction between different systems, it has a focus on the nature of edges, boundaries, and borders. This quality introduces the condition of translucency to the urban environment which allows articulated interaction between elements but not free flow (as with Modernism through transparency) or exclusion (as with Postmodernism through fortification). According to Ellin (2006), too much porosity or no porosity diminishes quality of life, however the combination of concealment and revelation in a translucent urbanism adds accessibility, interest and life to the city.

Ellin recognises sixteen different categories of porosity, most importantly, visual, functional and urban porosity. Visual porosity allows visual but not physical access to a space and is most commonly accomplished with the use of glass, or, more recently, metallic wire mesh screens, slatted wood and sandblasted glass. Functional porosity allows access to a place or modulates access to it, and is commonly achieved with 'permeable' building edges featuring balconies, arcades and outdoor seating. Urban porosity is "...achieved when permeable membranes separate and unite buildings from and with the surrounding physical and cultural landscape" (Ellin, 2006, p. 77), and is achieved through strategies such as interpreting indoors with outdoors and buildings with cityscapes, creating hybrid conditions between public and private space. Porosity engages with the articulation of boundaries and is concerned with bringing places together whilst preserving the integrity of each, in doing so enhancing the social experience by bringing differences of people and places together.

\section{Summary.}

Integral urbanism is important to consider as it represents a synthesis of some of the most compelling trends in contemporary urban design. With a focus on borders and edges, the principles advocated by this urbanism have clear implications on how the relationship between buildings and open space are considered in urban design. These principles can be summarised as:

- Integration of public/private, horizontal/vertical, indoor/outdoor

- Minimising distinction between figure and ground, integrating architecture, landscape and infrastructure

- Hybridization of functions - bringing people and activities together 
- Permeable building edges and translucency

These principles represent a rival conception of building/open space duality as prescribed by conventional urban design principles. Rather than a clear distinction between buildings and open space, these principle seek to integrate buildings with their urban contexts, blurring the boundaries between building and landscape, indoors and outdoors, and public and private. In the following section, architectural implications of these principles will be identified and summarised.

\section{Blurring the Boundaries: Building/Landscape Integration}

\section{Origins of Building/Landscape Integration.}

The most compelling emergent urban design trend identified as part of Integral Urbanism is the integration of architecture and landscape. Rather than present a clear duality between buildings and open space and a clear articulation of the boundary between the two, some emergent projects seek to integrate building and site together; the building forms an extension to its surrounding landscape.

Taking this integration to the extreme, some projects aim for a complete fusion of the individual building with the site. According to Mallgrave and Goodman (2011), “...these projects would attempt to blur the boundaries between figure and ground becoming themselves, reconstituted, folded, and punctured versions of the ground surface" (p. 171), thereby blurring the boundaries between architecture and landscape. They suggest it is possible to trace this line of thinking to Deleuze's Le Pli (The Fold) which appeared in French in 1988 and was translated to English in 1993, and was interpreted by architects as the idea of formal continuity through physical folds. Greg Lynn (as cited in Mallgrave \& Goodman, 2011) argued that folding in architecture allowed the integration of unrelated elements within a new continuous mixture.

This line of thinking can be traced back further still to the 1960s and the work of Architecture Principe formed by Claude Parent and Paul Virilio, whose work it is suggested anticipated the recent exploration of folding and the integration of building with landscape (Alison, Jones, Spiller, \& Vaughan, 2006). In the view of Parent and Virilio, the Modern city was unable to master the incompatibility between the fixity of stop and the fluidity of circulation; an incompatibility they saw as paralysing to Modern architecture. To combat this, they proposed a new form of urbanism where oblique angles and tilted planes would animate and set in motion its inhabitants with the aim of stimulating human social activity. In this theory of urbanism the ground was no longer conceived as absolute and was rather conceived as an architectonic manipulation (Alison, Jones, Spiller, \& Vaughan, 2006). 


\section{Building/Landscape Integration: Terms and Definitions}

A number of different terms and definitions exist which describe the integration of architecture with the landscape; building with site. In his 1993 essay "Towards a New Architecture", Jeffrey Kipnis introduced the notions if InFormation and DeFormation, the former being the fusion of different programmes and forms into a Modernist monolith. The latter, DeFormation, represents the 'new' of the essay's title and is described as “...the generation of novel forms that in themselves lead to new programmes, ultimately effecting political and social changes" (Mallgrave \& Goodman, 2011, p. 163). DeFormation leads to smoothness, continuity and folding, and in the words of Kipnis (as cited in Mallgrave \& Goodman, 2011), a new 'abstract monolithicity'.

Mark Lee introduced the term 'topological landscape' to describe hybrid conditions between architecture and landscape (Ellin, 2006). According to Lee, the aim of this architecture is not to represent spaciousness by diminishing enclosure, but rather seeks to redefine boundaries by going beyond the established principles of building/open space duality.

Rem Koolhaas of OMA introduced the hybrid term 'SCAPE' which encompasses townscape and landscape, minimising the distinctions between figure and ground and inside and outside, allowing for the convergence of architecture, landscape and infrastructure (Ellin, 2006). Floris Alkemade, also of OMA, refers to the interrelationship between levels as 'ground level manipulations,' where building levels are not separated by a two dimensional surface but rather flow into each other by raising, lowering, bending and folding, resulting in a more intensive use of surface area (von Meijenfeldt $\&$ Geluk, 2003); a principle which could easily be applied to buildings and their surrounding context.

Aaron Betsky uses the term 'landscrapers' in his 2002 book of the same name to describe buildings which "...unfold the land, promising to lay a new ground on which we can erect an architecture of the land” (p. 13). Looking to the future, he suggests building/landscape integration could see the disappearance of distinct architectural objects in favour of "...fluid, open-ended structures that rise naturally from the land” (p. 139) which remain open to interpretation and use. He suggests such structures could make us regain a sense of reality of place as we become aware of the ground we inhabit in a culture more dependent on the abstraction of digital manipulation and virtual spaces, and maintains that the edges of these forms will be progressively omitted by the movement of information and people.

\section{Practitioners of Building/Landscape Integration}

Common architectural practitioners whose projects seek to integrate buildings with landscape identified in Ellin (2006), Betsky (2002), and Mallgrave \& Goodman (2011) include London based Foreign Office Architects (FOA), 
and Dutch practices MVRDV, UN Studio and the Office for Metropolitan Architecture (OMA) led by Rem Koolhaas. According to Betsky (2002), Koolhaas "...makes buildings as landscapes in which the land becomes a building face and the interior is only a seamless convolution of the exterior's order into labyrinth caves" (p. 143). This strategy has resulted in the layercake structure of the Seattle public library, as well as the continuous surface of ramped floors of the Jussieu library project of 1993. It is from OMA's Jussieu project that Mallgrave and Goodman (2011) argue that perhaps one of the most influential buildings of this type descends; the Yokohama ferry terminal completed in 2002 by FOA:

Their project...aimed to extend the surface of the earth surrounding the terminal up and over the building itself, transforming the roof into a park. Into and upon this undulating park-like surface they introduced a series of interwoven, looping pathways that would create a nonlinear circulation system for the pier. ...The pleats and folds of the roof create a landscape of varied but continuous spaces, while simultaneously forming the building's structural system... (Mallgrave \& Goodman, 2011, p. 172)

According to Betsky (2002), MVRDV have designed some of the most fantastically complex building/landscape hybrids, including the Villa Vpro and the Dutch Pavilion, the latter of which is described as a layer-cake of synthetic landscapes. UN Studio's Arnhem stations has been described as “.... landscape of continual curves that will dip down for us to walk on, rise up to shelter us, and open up to allow us to move through..." (Betsky, 2002, p. 139). These four identified practices, Foreign Office Architects, UN Studio, MVRDV and OMA, feature prominently throughout the remainder of the research. 


\section{[2] Diagrams in Architecture}

\section{Diagrams: Tools for Extending the Boundary}

A significant observation about the four emergent urban design practitioners identified in the previous section is that they have all, in some way or another, utilised diagrams extensively as part of their design methodologies. Based on this observation, the research aims to identify the nature of the relationship between 'diagrammatic' design methodologies and their architectural outcomes which reinterpret conventional urban design principles as they relate to building/open space duality.

This section examines literature concerned with the use of diagrams in architecture. Relatively little has been written on the topic, and that which is written finds little definitive consensus, resulting in a number of ambiguities on the topic. The purpose of this section is to provide a brief overview of the use of diagrams in architecture rather than an exhaustive analysis of their use and definition; this would require an extensive piece of research in its own right. A more detailed treatment of the subject will occur in the practice and case studies which follow.

\section{Diagrams: Rise of Importance.}

Diagrams in architecture are as old as architecture itself, with examples dating back to prehistoric artefacts. Their use has been a staple of architectural texts at least as far back as Vitruvius' 'Ten Books on Architecture' (c 25 BC), which featured basic geometric diagrams. Based on the diagram's long history of use in architecture it is surprising there is not more criticism and research into their relationship with architecture; their theorisation remains incomplete. Despite being often fundamental to works of architecture, they usually remain hidden and difficult to interpret and decipher; their status is relegated below that of written text, perspective drawing and scale model.

In contrast with their historically relegated status, the diagram has now infiltrated every aspect of architectural theory (Garcia, 2010), becoming a leading term in architecture's theoretical discourse (Somol, 2010). Robert Somol (2010) argues that over the second half of the twentieth century the fundamental technique and procedure of architectural knowledge shifted from the drawing to the diagram, and maintains that architects of the neo-avant-garde are drawn to 
the diagram over drawing or text. Although there are practical reasons behind the rise of the diagram such as changes in the architect's work conditions in a 'fragmented and ever changing' post-industrial society, those who promote the diagram in architecture see it as a return from the significance of form to a rehabilitation of function and reality (Confurius, 2000). There have been many strong claims made of the 'emancipating' effects of diagrams, but regardless of the motivations behind their use, diagrams are valuable and used in seemingly every aspect of architecture today (Garcia, 2010).

\section{Diagram: Definition.}

An important problem facing any project related to the history or theorisation of diagrams is the definition of 'diagram' itself. A diverse range of definitions for the diagram exist which consequently leads to very different conceptualisations of their properties, function and use (Garcia, 2010). There is little consensus on how to definitively distinguish between diagrams and other related concepts such as drawings, sketches, illustrations, visualisations, models, maps, processes and metaphors (Garcia, 2010). These overlapping terms and concepts bring confusion and ambiguity to the understanding and definition of diagrams and dilutes the meaning of the term.

Most definitions of the diagram in architectural theory draw on the works of Charles Sanders Peirce (1839-1914), Michel Foucault (1926-84), and Gilles Deleuze (1925-95) with Felix Guattari (1930-92). Influenced by Foucault and his writing on the panopticon, Deleuze and Guattari's A Thousand Plateaus (1988) remains the most influential writing forming the basis for almost all contemporary theory on diagrams in architecture, specifically their concept of the diagram as 'abstract machine' (Garcia, 2010):

An abstract machine in itself is not physical or corporeal, any more than it is semiotic; it is diagrammatic... It operates by matter, not by substance; by function, not by form... The diagrammatic or abstract machine does not function to represent, even something real, but rather constructs a real that is yet to come, a new type of reality". (Gilles Deleuze and Felix Guattari, A Thousand Plateaus, as Cited in Allen, 1998)

In a definition influenced by the writing of Deleuze and Guattari, Anthony Vidler (2004) suggests the diagram specifies “...the relations between unformed/unorganised matter and unformalised/unfinalised functions" (p. 24), maintaining the importance of the diagram lies in its function rather than the qualities of its appearance. He goes on to propose the diagram is “...a neutral zone, where certain relations are mapped precisely but without aura, with no qualitative information" (p. 36). Architect and theorist Stan Allen (1998) defines the diagram as "...a graphic assemblage that specifies relationships between activity and form, organising the structure and 
distribution of functions” (p.17). Mark Garcia (2010) suggests “...a diagram is the spatialisation of a selective abstraction and/or reduction of a concept or phenomenon. ... diagram is the architecture of an idea or entity" (p. 18). This research does not seek to formulate its own definitive definition of the diagram, however it is clear from these published definitions that literature on the topic is concerned principally with diagrams of a functional nature - those relating function with form. The varying qualities and purposes of diagrams are examined below to identify their value within the context of architecture.

\section{Architectural Diagrams: Function and Value.}

Influenced by Deleuze and Guattari's concept of the diagram as 'abstract machine,' Stan Allen (1998) suggests the primary utility (or function) of the diagram is as an abstract means of thinking about organisation, which, in the context of architecture, applies to both programme and its distribution in space. The abstracted nature of the diagram is fundamental to its instrumentality in architecture; it is described by Robert Somol (2010) as a "...tool of the virtual rather than the real” (p. 89). The value of the diagram's abstraction lies in its momentary and flexible configurations of potential relationships, which allows for continual modification, transformation and mutation. As such, the diagram presents an open, generative process of design which frees the designing process from formal decisions and delays formal considerations for as long as possible; the design does not tend toward fixed formal typologies so allows for greater diversity (Confurius, 2000).

Another important function of the diagram in architecture is its ability to organise a variety of different types of information within a single graphic configuration. It functions as an instrument of visualisation which mediates between the 'disordered complexity of the information society' and the demands of the architectural project (Confurius, 2000). The diagram makes visible the various complexities of matter and activity surrounding the project and allows this diverse field of information to be related. As such, Stan Allen (1998) suggests “...diagrams are architecture's best means to engage the complexity of the real" (p. 17).

Diagrams also function to shift architecture away from the ambiguities of personal poetics (Allen, 1998), minimising the importance of the architect as a creative individual. Gerrit Confurius (2000) suggests this "...reflects the spirit of the time" (p. 5); the architect becomes an organiser and channeller of information (Somol, 2010). Rather than a product of creative genius, architecture is presented as something that is socially constituted by the various 'forces' surrounding the project - economic, political, local and global. In this model, Robert Somol (2010) suggests “....architecture is understood as a discursive-material field of cultural-political plasticity" (p. 90). 
'Diagram Architecture.'

Toyo Ito coined the term 'diagram architecture' in 1996 while writing about the architecture of Kazuyo Sejima. Stan Allen (1998) adopts the same term, and describes diagram architecture as "... an architecture that travels light... No complex mysteries to untangle, no hidden messages to translate, no elaborate transformational process to decode..." (p. 18), and explains:

- It is concerned with function and the architecture's ability to multiply effects and scenarios; not embedded content and questions of meaning and interpretation

- It establishes a loose fit of programme and form, creating maximum performative effects with minimum architectural means

Both Allen and Robert Somol (2010) make the distinction between working 'diagrammatically' and simply working with diagrams. According to Somol, working diagrammatically "...implies a particular orientation, one which displays at once both a social and disciplinary project... Diagrammatic work is projective in that it opens new, or more accurately, 'virtual' territories for the practice" (p. 90). He goes on to suggest the work of diagrammatic practices attempts to displace design with the diagram, and deliver "...form without beauty and function without efficiency" (p. 90).

The prominent use of diagrams in architecture and the increasingly diagrammatic nature of architecture are not without opposition. Some find the prominent use of diagrams disturbing as the technique acts in opposition to architecture's traditionally dominant methods and hierarchies. Common criticisms of diagrams identified by Mark Garcia (2010) include: Diagrams lack the aesthetic qualities of drawings; they deal poorly with multisensory and phenomenological content; they are ideological, they are not logically or clearly connected with the final building they are associated with; they do not fully engage with society and social issues; and they are used pointlessly to determine architecture. These criticisms raise questions of the significance of diagrams and any future innovations still left for diagrams.

\section{Contemporary Diagram Practice.}

Contemporary diagrammatic practices have developed critical designs and theories that engage with these criticisms. New theories and methods related to diagrams have been sourced from outside of architecture, leading to methodologies based on multiple disciplines and medias (Garcia, 2010). This new generation of diagrammatic practitioners is exemplified by the Dutch practices of OMA (led by Rem Koolhaas), UN Studio, and MVRDV, and British practice Foreign Office Architects (FOA). These practices feature prominently in literature concerning diagrams in architecture, and as noted previously, they are all practices which challenge the conventional principles of urban design, blurring the boundaries between buildings and open space. 
This consistency of practices begs the question: is there a connection that exists between a diagrammatic design methodology and architectural outcomes which reconceptualise the architectural boundary, seeking to integrate building with landscape? If this exists, what is the nature of the connection? Is a diagrammatic methodology causal to the generation of emergent urban design outcomes and architecture, or is it utilised as an instrument to achieve a predetermined design intention?

While it would be impossible to prove the existence of a causal relationship, closer examination of the design methodologies of these four key practices in the following chapter offers important insight on the role and significance of diagrams in generating architecture. The role of diagrams in each practice's design methodologies is examined via case studies which examine the connection between diagrams and architecture. 


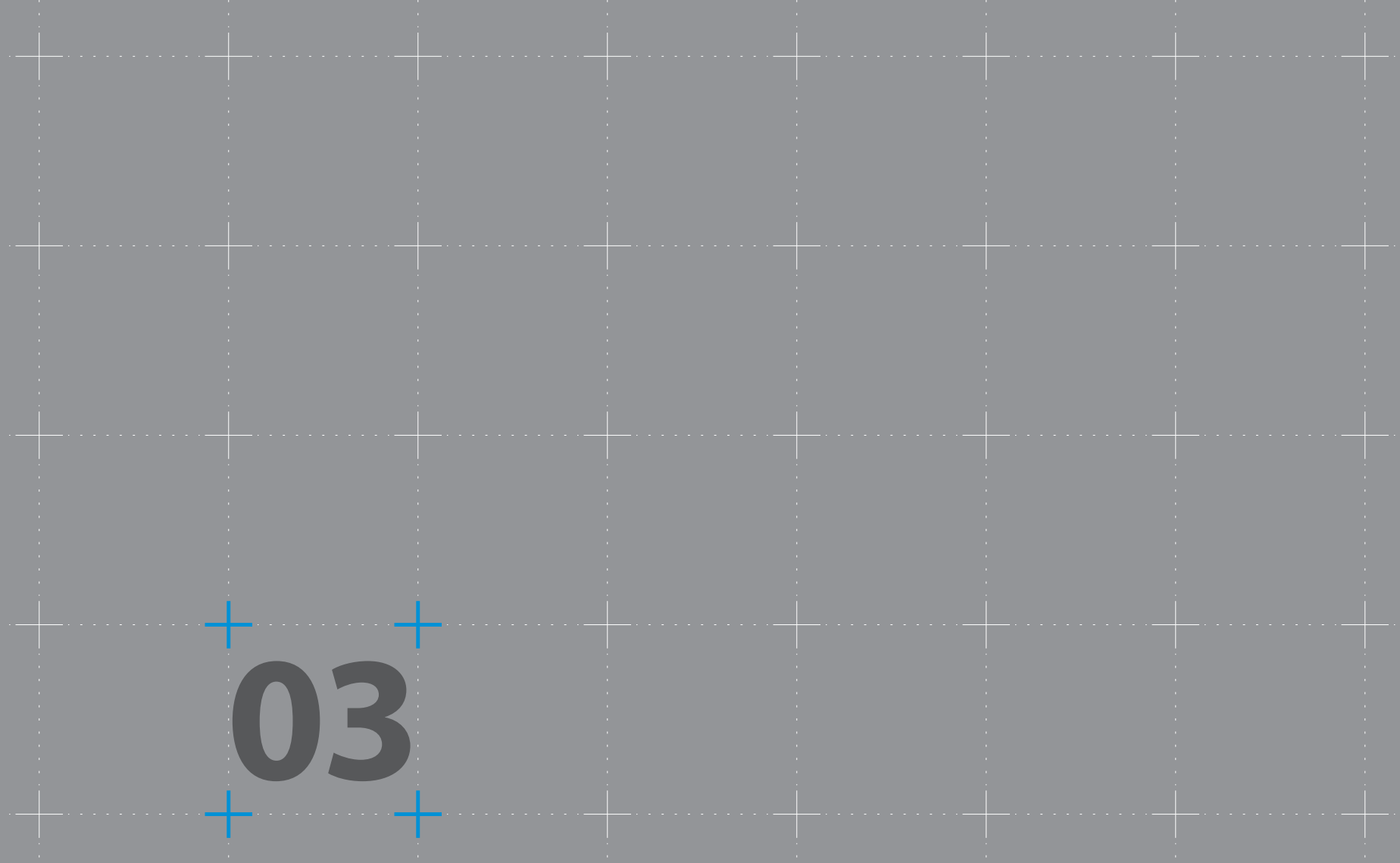

\section{Practice +}

\section{Case Studies}
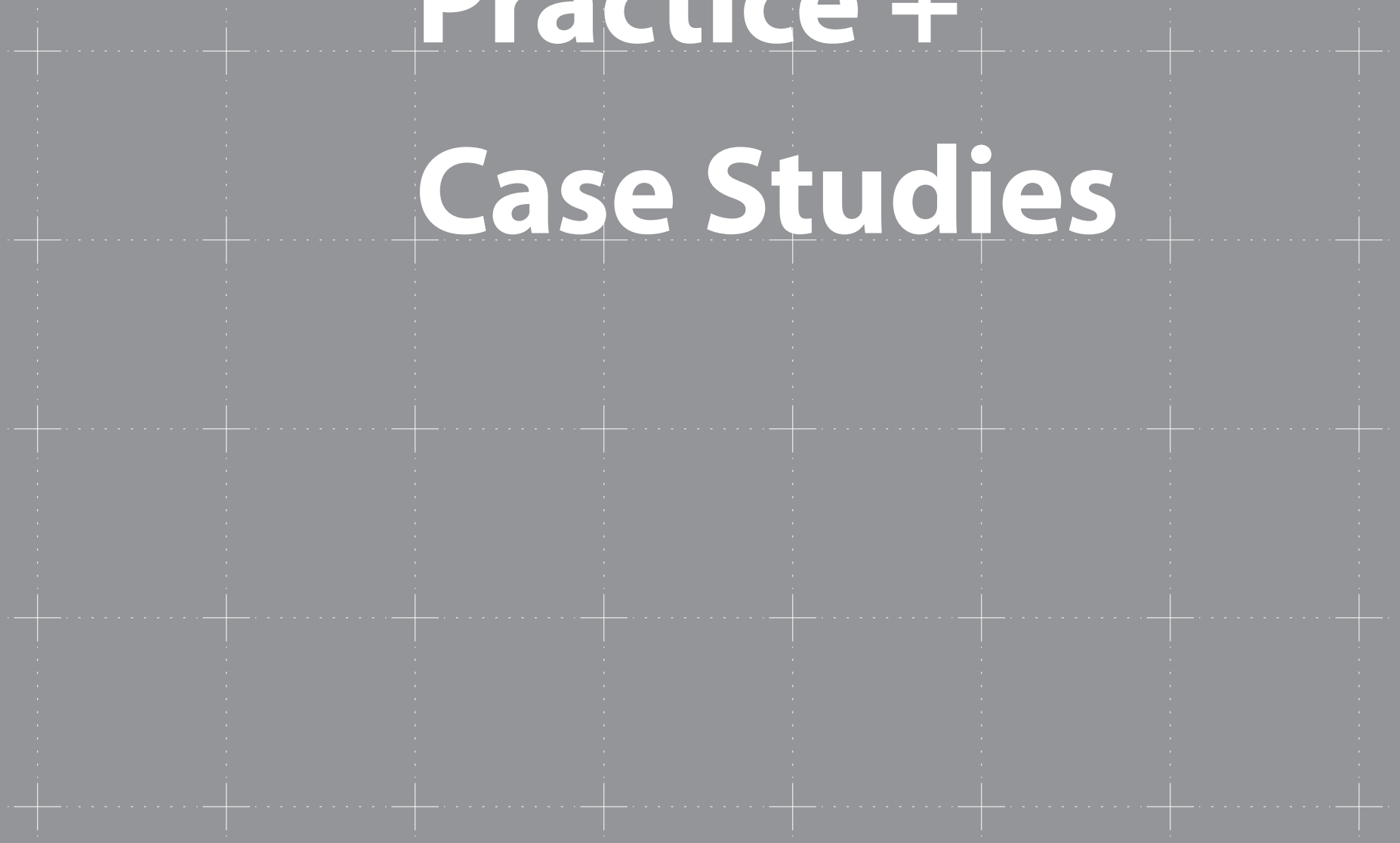

$+$
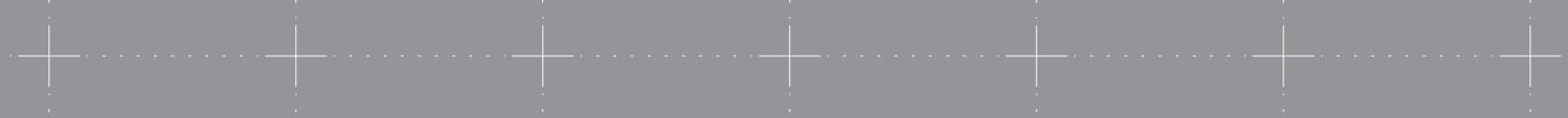


\section{Practice + Case Studies | Introduction}

The literature review identified conventional and emergent urban design principles and trends which relate to the interface between urban buildings and public open space, and identified several key practices whose work exemplifies these emergent trends. It then examined the use of diagrams in architecture and identified the same practices as key 'diagrammatic' practices. The four practices which feature prominently in each stream of research and are therefore most suited for further examination into the relationship between the two research streams are Foreign Office Architects (FOA), UN Studio, MVRDV and the Office for Metropolitan Architecture (OMA). A practice study and project case study has been undertaken for each of these four key practices to begin to explore possible relationships between the two streams of research: emergent urban design trends and 'diagrammatic' design practice.

The practice studies examine literature written by the practitioners, interviews with the practitioners and literature written by others about the practices. Each practice study is divided into five sections:

Practice Ideology - Identifies the key values and interests of the practice and provides a good background and context for the study.

Definition of Diagram - Identifies the practice's definition or conception of architectural diagrams.

Diagram Value - Identifies the value of diagrams as part of the practice's design methodology.

Diagrammatic Design Methodology - Identifies the role of diagrams in the practice's design methodology - how the practice utilises diagrams.

Attitude Towards Ground/Landscape - Identifies the practice's attitude towards the ground and landscape. This section provides valuable background insight for a later case study investigation into one of the practice's projects which relates to its 
surroundings in an unconventional way.

The general findings from the practice studies are refined by a case study of one project from each of the four key practices, where more specific findings into the role of diagrams in each design process are identified. The projects have been selected based primarily on the availability of published information about the project's design process. Each case study is divided into four sections:

Project Overview - A brief description of the project

Project Design Methodology - A step-by-step summary of the design methodology used to generate the project, including diagrams. The design steps involving the use of diagrams are written in black, while other influences are identified by grey italic. The project is summarised as it is presented in published literature - as a step-bystep, linear process. The reality of each project's development will of course be far less straightforward, no doubt featuring branching ideas and areas of development, of which only the strongest survive to be retrospectively published as the project's design process.

Diagram Methodology - Refines the project's design process into a step-by-step design methodology.

Relationship to Urban Design Principles - Briefly analyses the project against the urban design principles identified in the literature review to identify the ways in which the project deviates from urban design convention, especially the relationship between the building and its adjacent open space.

A discussion section lastly identifies findings from the practice and case studies, examining further the various ways diagrams are used in the design process. These findings will inform the execution of the design phase of the research which is featured in the following chapter. 


\section{Foreign Office Architects | Practice Study}

\section{Practice Ideology}

The founding partners of Foreign Office Architects, Farshid Moussavi and Alejandro Zaera-Polo share a principle interest in the processes of architectural production and observe a progressive shift towards a focus in architecture on methodology and instrumentality (Zaera-Polo, 2010). For the pair, architectural process is more interesting than architectural ideas which they associate with pre-existing codes and systems and critical practice, which often relies on straightforward ideological statements, metaphors and architectural reproductions (Moussavi \& Zaera-Polo, 2002). The practice's focus on devising new and experimental architectural processes is driven by the desire to explore emergent possibilities and discover new aesthetics and forms for architecture (Moussavi \& Zaera-Polo, 2004). A central issue for the practice is generating coherent, non-representational forms which create projective arguments and transcend cultural constructs in an increasingly hybridised world due to globalisation (Zaera-Polo, 2010). Their work is characterised by complex surfaces, however an interest in the 'engineering of material life' rather than form is what they hope distinguishes their work from other complex-surface architecture (Moussavi \& Zaera-Polo, 2002).

\section{Definition Of Diagram}

Moussavi and Zaera-Polo define the diagram as...

...a tool that describes and prescribes performances in space. It does not necessarily contain metric or geometric information: those emerge once the diagram starts processing matter. A diagram is usually specific to a space; it may be a specific location, a scale, a temporal frame, but it always has a spatial correlation... The diagram relates to processes that may occur not only in three-dimensional space but in several other dimensions of reality (Zaera-Polo, 2010).

They also explain that "a diagram is able to absorb and embody increasing levels of complexity and information, without necessarily altering the nature of its performance" (Moussavi \& Zaera Polo, 2006). 


\section{Diagram Value}

Diagrams are valued as an instrumental part of Foreign Office Architects' design methodology. For the practice, diagrams, as opposed to drawings which they see as being constrained to architectural conventions, do not play a representational role for their architectural object and instead mediate between the physical constructs and concepts on an organisational level (Zaera-Polo, 2010). Rather than symbolic operations, they claim working diagrammatically produces organisations capable of multiple readings (Zaera-Polo, 2010). In the diagrammatic design process, the project retains its virtualities and allows for re-evaluation and evolution of the project (Zaera-Polo, 2010), retaining the capacity to trigger new possibilities for as long as possible (Moussavi \& Zaera Polo, 2006). The capacity to trigger or generate the new is what the practice seems to value most about the diagrammatic design methodology; the diagram is utilised as a projective rather than representational tool which they claim produces new organisations, sensations and moods, allowing for "...the emergence of another possible world" (Zaera-Polo, 2010, p. 239).

\section{Diagrammatic Design Methodology}

Foreign Office Architects utilise diagrams as a tool to describe and prescribe performances in space. For the practice, it is crucial that the performance is clearly determined. They explain that operating diagrammatically should not be confused or unclear; rather, it is about knowing precisely the level of knowledge and determination that can be exerted on the project at any one time (Moussavi \& Zaera Polo, 2006). Moussavi explains that each project is 'grown' rather than deployed, as its working diagram is manipulated, analysed, and injected with further parameters (Kleinman, 2006). This explanation re-emphasises the practice's process-based and evolutionary approach to design, suggesting that a project may start very simply and gain complexity as its organisational diagram embodies more information as the project progresses. Such information is known to include raw contextual data concerning circulation, use, topography, demographics and building and shipping logistics, which is distilled into generative models and diagrams (Kleinman, 2006). According to Moussavi and Zaera-Polo (2006), it is in the middle of the design process that the strategies and aims of the project need to be deployed - not at the beginning or end. This would suggest a highly rational approach to the design process, where perhaps the more experimental parameters or influences unique to the project are deployed only after the more fundamental parameters surrounding the pragmatics of the project - its fundamental 'performances' - have been prescribed by an organisational diagram. These fundamental parameters may provide a context or framework for the project which is then subjected to the additional parameters determined to achieve the strategies or aims of the project.

Moussavi and Zaera-Polo (2010) identify the most common problem with 
contemporary experimental architecture as literally turning the 'space' of the diagram or graph into the space of the drawing, and therefore the building. They explain that in principle the diagram doesn't need to be similar in form to the spatial or functional organisation it prescribes: “...a very simple diagram may generate very complex organisations" (Zaera-Polo, 2010, p. 239). In the diagrammatic methodology of the practice, additional information is added to the diagram before the building's final form is determined. The diagram requires several forms of mediation to become a drawing and enter the 'real space', gaining coarseness and complexity as it processes the building's constructional and material factors (Zaera-Polo, 2010). Moussavi and ZaeraPolo recognise a prototypical aspect of diagrammatic design methodologies, in the sense that a project's diagrams can be applied to other contexts. It is through the process of mediation between the diagram and the building's final form that the building develops in a particular way to become unique to that location (Kleinman, 2006). The computer is described by Zaera-Polo (2010) as "....an ideal instrument for the production of the virtual" (p. 238), and is utilised extensively in the mediation process.

\section{Attitude Towards Ground/Landscape}

According to Moussavi and Zaera-Polo (1998) “...we can no longer rely on the classical relationship between building and ground, or on the conventional definition of the ground as delimited, stable, horizontal, determined and homogenous" (p. 36). This attitude brings forth a new conception of the ground which they refer to as 'new grounds' - which is described as having a complex, active, and operative nature, and being 'hollow' and 'diagonally' structured (Zaera-Polo \& Moussavi, 1998/1999). Many of the practice's projects involving complex topological surfaces reflect this redefinition of the ground. These structures are characterised by an ambiguity between surface and space, ground and envelope, three dimensional and two dimensional, and are presented as an alternative to the traditional opposition between the ground and the architectural figure (Zaera-Polo \& Moussavi, 1998). Significantly, Moussavi and Zaera-Polo (1998/1999) claim that only through the use of certain tools and techniques have they been able to produce such organisations, and that certain structures actually start to arise from these practices. Such a claim would suggest the architects believe in a strong contributing connection between a diagrammatic design process and a redefinition of the ground as an architectural element. 


\section{Foreign Office Architects | Case Study}

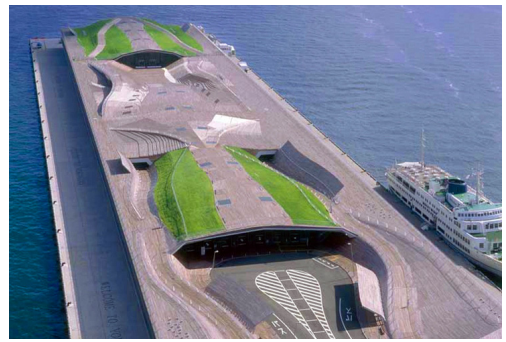

Figure 3.1. Yokohama International Port Terminal, arial perspective.

(n.d.). Retrieved January 26, 2012, from http://www.idesignarch.com/ wp-content/uploads/2010/08/YokohamalnternationalPortTerminal-1.jpg.

\section{Project Overview}

The project is for a new international port terminal for the city of Yokohama, Japan. The project is developed on the basis of a particular spatial performance rather than as a formal or cultural statement, creating the experience that you are never returning or retracing your steps.

\section{Project Design Methodology}

The project seeks to explore the possibility of transport infrastructure as a field of movements rather than a 'gate,' challenging the strongly oriented linear space typical of the existing typology. The project centres around the possibility of generating organisation from a circulation pattern.

I. A circulation diagram structured around a series of interlaced loops that allow for multiple return paths and avoid circulatory 'dead-ends' was created - the 'no-return' diagram. This diagram provides the building with a particular spatial performance.

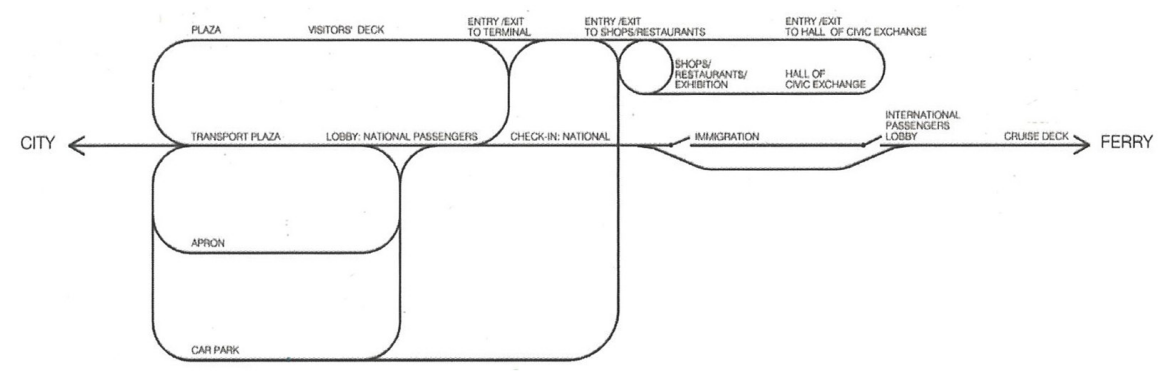

Figure 3.2. No-Return Diagram

From The Yokohama Project: Foreign Office Architects (p. 10), by Moussavi, F., \& Zaera-Polo, A, 2002, Barcelona, Spain: Actar.

The architects wanted a flat building which didn't appear on the skyline; an idea consistent with not wanting to create a 'gate'. This led to the conceptualisation of the building as a ground, hybridising an enclosure with a topography. They decided the building would be a warped surface; this required relating the no-return diagram with surface geometry. 
II. A surface was associated with every line segment of the no-return diagram, and a surface bifurcation to every bifurcation of the line.

Site massing was determined, based on the maximum allowable footprint to keep the building as low as possible, and the requirement for straight boarding decks $15 \mathrm{~m}$ from the edge of the pier.

III. Each surface applied to the segments of the no-return diagram was allocated a size in square metres, which, divided by the width of the pier provided the length of every surface between bifurcations.

IV. A three-dimensional version of the no-return diagram emerged, resembling a 'lasagne' of warped surfaces [Figure 3.3]. The diagram absorbed certain ergonomic requirements such as ceiling heights, to give an approximation of the final form [Figure X].

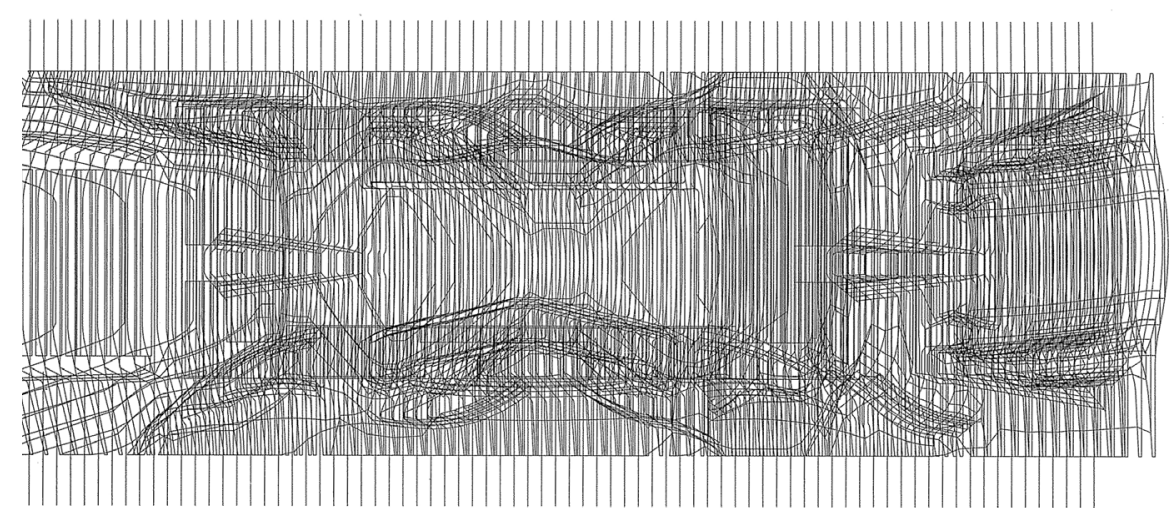

Figure 3.3. Three-Dimensional No-Return Diagram

From The Yokohama Project: Foreign Office Architects (p. 41), by Moussavi, F., \& Zaera-Polo, A, 2002, Barcelona, Spain: Actar.

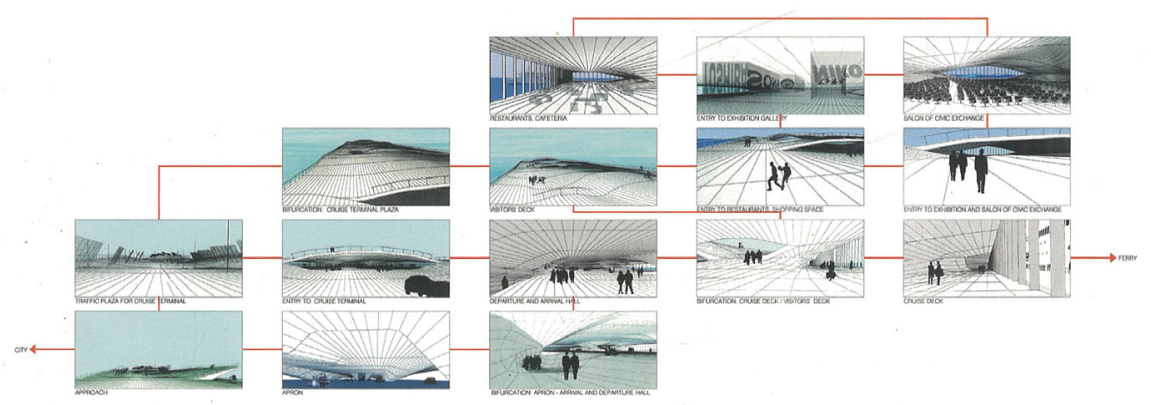

Figure 3.4. Three-Dimensional No-Return Diagram developed to show inhabitation

From The Yokohama Project: Foreign Office Architects (p. 10), by Moussavi, F., \& Zaera-Polo, A, 2002, Barcelona, Spain: Actar.

The architects wanted a column-free construction, as columns would have turned back to the idea that the architecture is deployed on the diagram a posteriori, and wasn't consistent with the aim to produce space and organisation literally out of the circulation diagram.

V. A structural strategy for the resulting form was created [Figure 3.5]. Folded surfaces were used, blending circulation and structure together in a

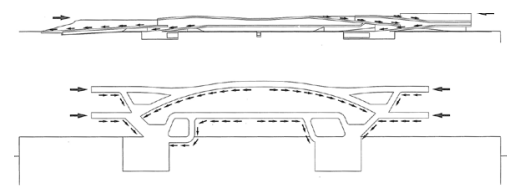

Figure 3.5. Diagram of building structural strategy

From The Yokohama Project: Foreign Office Architects (p. 15), by Moussavi, F., \& Zaera-Polo, A, 2002, Barcelona, Spain: Actar. 


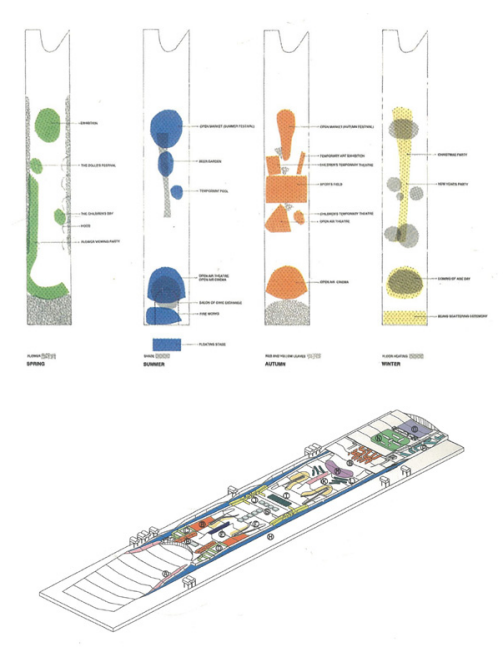

Figure 3.6. Diagram showing distribution of secondary programme

From The Yokohama Project: Foreign Office Architects (p. 19), by Moussavi, F., \& Zaera-Polo, A, 2002, Barcelona, Spain: Actar. metamorphic manner.

VI. Secondary programme was deployed as though it were furniture placed onto the building's warped surface, and was located based on desired relationships with the various circulation flows of people [Figure 3.6].

Through this process a basic building 'embryo' emerged, loosely resembling the form of the final building.

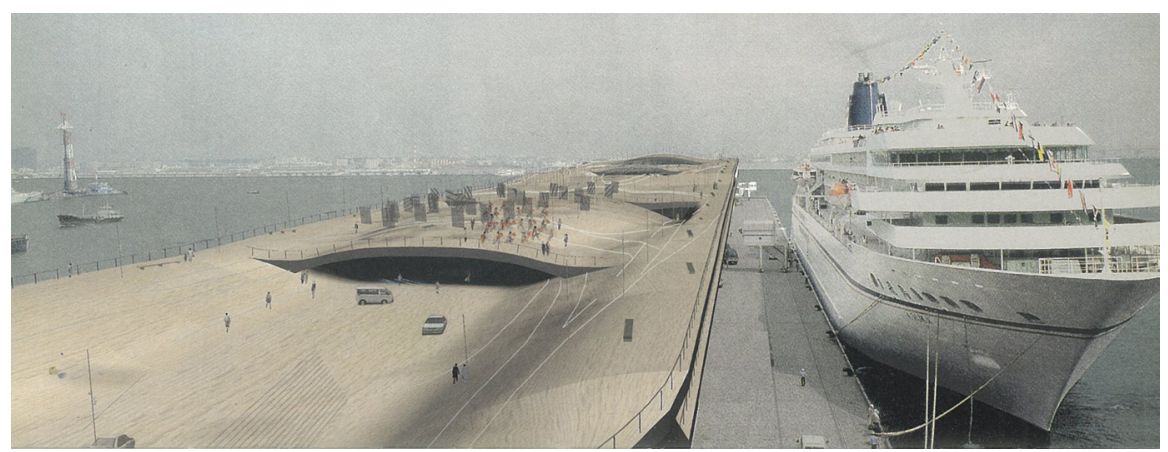

Figure 3.7. Early building development

From The Yokohama Project: Foreign Office Architects (p. 19), by Moussavi, F., \& ZaeraPolo, A, 2002, Barcelona, Spain: Actar.

Over a period of several years this basic design was intensively developed and subjected to the various inputs and influences required for such a complex building to be realised [Figure 3.8]. The architects refer to the project as being 'grown' rather than designed.

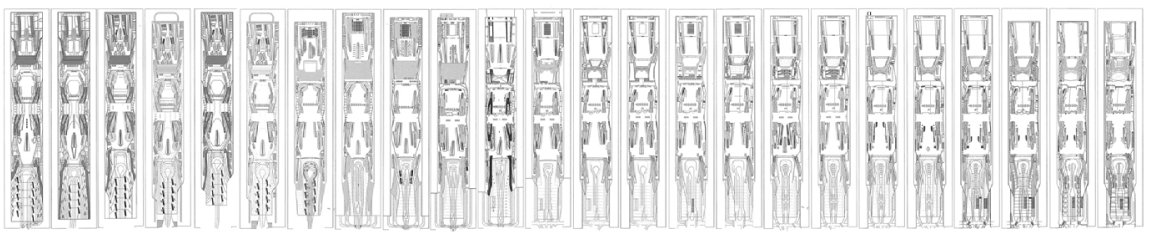

Figure 3.8. Building plans showing design evolution from January 1996 (far left) to January 2000 (far right).

From The Yokohama Project: Foreign Office Architects (p. 55-59), by Moussavi, F., \& ZaeraPolo, A, 2002, Barcelona, Spain: Actar.

\section{Diagram Methodology}

The following is a step by step summary of the methodology utilised by Foreign Office Architects for the design of the Yokohama International Port Terminal, a project which explored the possibility of generating architecture from circulation.

\section{Identify goals for circulation}

I. Develop Circulation diagram

II. Associate surfaces with circulation diagram

Determine allowable site massing and location of fixed programmes within this 
massing

III. Scale the associated surfaces according to programmatic requirements

IV. Manipulate the diagram in three dimensions, relating different surfaces to one another

V. Identify structural strategy for resultant form

VI. Further develop the distribution of programme within the resultant form

This process generates a flexible form and organisation which is subject to further development

\section{Relationship to Urban Design Principles}

Conventional urban design principles prescribe that buildings provide definition and enclosure to urban public space and possess a clear distinction between public and private areas. A key aspect of this principle is the distinct duality between built form and open space. Yokohama International Port Terminal represents a challenge to these conventions by breaking down the distinctions between the typically private built form, public open space, and the landscape in which the building stands. The building rises from its urban setting at the base of the pier to provide the visitor with gently sloping ramps up to the building's public roof level [Figure 3.9]. Pedestrian circulation up to this level blends seamlessly with the building's urban surroundings, minimising the distinction between figure and ground. The undulating, warped surfaces of the roof provide visitors with an artificial landscape protruding into the bay, creating a public space rich in aesthetic interest and topographic variety, whilst also helping to structure the building. Public circulation paths ramp and swerve long the length of the building, creating continuity and connection between the building's interior and exterior and between its various levels and integrating horizontal and vertical movement and structure [Figure 3.10]. The Yokohama International Port terminal is one of the most successful and influential contemporary exemplars of an urban building integrated with a public landscape.

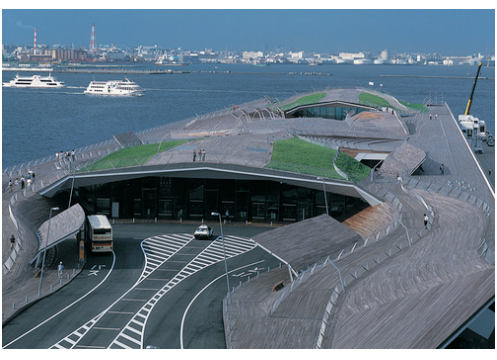

Figure 3.9. Yokohama International Port Terminal ramping from urban surroundings.

(n.d.). Retrieved January 26, 2012, from http://archis.org/action/2010/01/16/ reasoning-with-waves-and-the-diagrams/.

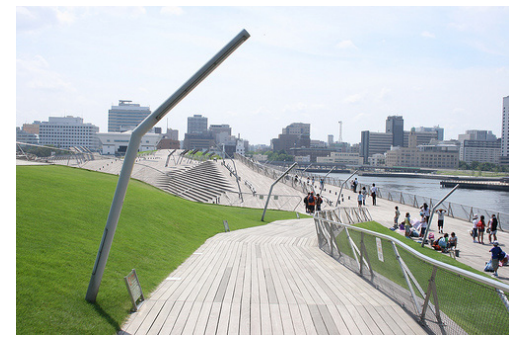

Figure 3.10. Yokohama International Port Terminal, ramped circulation.

Sayo, M. (Photographer). (2008). Retrieved January 28, 2012, from http://www.flickr.com/photos/lilmissayo/3164457942/ 


\section{UN Studio | Practice Study}

\section{Practice Ideology}

Ben van Berkel and Caroline Bos' Amsterdam based UN Studio is one of the most explicitly diagrammatic architecture practices. The pair express a distrust of contemporary theory-driven architecture whose concepts, design decisions and processes they claim are articulated by post-rationalisations (Berkel \& Bos, 1998, p. 19). The practice is opposed to a representational approach to architectural production and claim that buildings designed in this way cannot escape existing typologies, which they say leads to meaningless repetition (Berkel \& Bos, 2010). Rather than a representational approach, the practice has developed an experimental, instrumental design technique. This technique, driven by diagrams, does not proceed as literally from pre-existing architectural signs so provides an escape or 'liberation' from typology that drives the forwardlooking vision of the practice in its quest for the 'new' in architecture (Berkel $\&$ Bos, 2010).

\section{Definition of Diagram}

UN Studio have a highly instrumental, process-based idea of the diagram, interpreting its use in practice as a 'proliferating machine' (Berkel \& Bos, 1998). They describe them as generative, productive, projective and interactive tools capable of creating innovative efficiencies and 'instrumental meanings' (Berkel $\&$ Bos, 2010). They explain that the diagram is not a metaphor, but is rather an 'abstract machine' that is both content and expression, whose meanings are not fixed: "Diagrams are packed with information on many levels. A diagram is an assemblage of solidified situations, techniques, tactics and functionings" (Berkel $\&$ Bos, 2010, p. 224). Their different notions of diagrams include ideograms, line diagrams, operational diagrams and 'image diagrams' - reproductions of paintings or random images which are used in a diagrammatic manner to suggest possible, virtual organisation. Read diagrammatically, these images become infrastructural, and can be read as maps of possible movement (Berkel \& Bos, 2010). 


\section{Diagram Value}

The diagrammatic design methodology is valued by UN Studio for its nonrepresentational, process driven approach to the design development. Their 'abstract machine' does not function to represent an existing situation but is rather instrumental in the production of new ones. They explain that external concepts are introduced to the design in a specific shape; as figure, not as image or sign. This delayed 'intrusion of signs' provides architecture with a forward looking alternative to a representational design technique, and prevents typological fixation. Rather than resorting to typologies, diagrams provide the practice with the tools to generate new, instrumental meanings for architecture, as they introduce into the work "...qualities that are unspoken, disconnected from an ideal or ideology, random, intuitive, subjective, not bound by linear logic - qualities that can be physical, spatial, or technical” (Berkel \& Bos, 2010, p. 224).

\section{Diagrammatic Design Methodology}

In the early diagrammatic work of Berkel and Bos, the diagram was a 'found' element existing outside of the project, which was used to introduce themes and organisations into a project. The primary role of the diagram was to generate ideas for the organisation of the project, without acting symbolically or metaphorically. Highly abstract organisational diagrams where sometimes established in advance of other programmatic aspects such as building form or use to establish a direction for the design, providing a 'mould' for the project's analysis.

When appropriate diagrams for a project could not be found Berkel and Bos began to construct their own. These diagrams where not concerned with building typologies, or strict parameters such as floor area, but where rather used to relate project information such as user categories with time, accentuating the effects of the interaction between the different actors. By relating different information, hard parameters for the project were constructed out of the 'soft notion of flow' (Berkel \& Bos, 2007).

Berkel and Bos identify three stages to the diagram: selection, application, and operation. Each stage is referenced to Deleuze, from whose writing they interpret three different 'moods' or 'tonalities' of the diagram, summarised as: the figure of the diagram is not representational, diagrams can be playfully selected and applied, and time and matter can be introduced to the diagram. It is worth quoting at length Berkel and Bos's description of their diagram methodology:

In architecture, it goes something like this: the project is set on its course. Before the work diverts into typology a diagram, rich in meaning, full of potential movement and loaded with structure, which connects to some 
important aspect of the project, is found. The specific properties of this diagram throw a new light on to the work. As a result, the work becomes unfixed; new directions and new meanings are triggered. The diagram operates like a black hole, which radically changes the course of the project, transforming and liberating architecture (Berkel \& Bos, 2010).

The search for a diagram is instigated by specific questions relating to the project such as its location, programme or construction rather than on the basis of representational information (Berkel \& Bos, 2010), however there need not always be an overlap between the specific project and the field where it looks for inspiration (Berkel \& Bos, 2007). The process of selecting one diagram over another is not described, as Berkel and Bos explain the focus of the practice is how the diagram is instrumentalised rather than how it is selected (Berkel $\&$ Bos, 2007). Its application is described as the "...insertion of an element that contains within its dense information something that our thoughts can latch on to, something that is suggestive, to distract us from spiralling into cliché" (Berkel \& Bos, 2010, p. 227). They explain that instrumentalising the diagram is the most difficult part to understand, setting the 'abstract machine' in motion and allowing the transformative process to begin, interweaving time and action (Berkel \& Bos, 1998). The practice does not utilise the diagram as a morphogenetic device for the overall form of the building; the diagram is not a blueprint or a working drawing as it exists only at a more abstract level (Berkel $\&$ Bos, 2010).

Through the repeated use of specific diagrams their application in the design process became more refined (Berkel \& Bos, 2007). This repetition occurred at a highly abstract level of the design process and allowed for certain diagrams to be manipulated and applied in different ways. Through repetition, the use of specific diagrams became integrated into a broader 'design model'. For example, the diagrams of the Moebius strip, Klein bottle, trefoil and spiral are all variations of the 'mathematical design model' which can be used in various ways in different projects: "Diagrams turned design models are profoundly abstracted, yet fully formed, basic design concepts that are developed further by working out a catalogue of options and transformations, culminating in distinctive projects" (Berkel \& Bos, 2007). They are 'packages' of organisational or compositional principles which exists at an abstract level, independent from any site specific information and often involve organisational schemes or matrixes with lists of parameters showing possible interactions between elements (Berkel \& Bos, 2007). Design models enable a cyclical design procession, where new inputs can be evaluated and the design allowed to evolve and grow. The architects claim they condense complexity as information such as routing, construction and programme are already contained within each model.

Some of the practice's most important design models are the mathematical model, the V model, and the blob-to-box model. Mathematical models are 
based on mathematic knots such as the Moebius strip, the Klein bottle and the double helix. For Berkel and Bos, these diagrams possess topological qualities, movement, direction and combinatorial and serial themes through which they relate to architecture, though never literally. Rather, they are read and translated in many different ways - for example as construction, landscape, routing, material, spatiality, or atmosphere (Berkel \& Bos, 2007). The V model is used to address the issue of stacking programmes, and is used to fuse together different use typologies whilst existing simultaneously as construction and useable space. Its application seeks to intensify the uses of diagonally inclined architectural forms (Berkel \& Bos, 2007). The blob-to-box model introduces the principle that an organisation can change from a box to a freer, more fluent system (Berkel \& Bos, 2007). Berkel and Bos describe the implications of the blob-to-box model as going from: oppositions to connectivity, unit-based to time-based, static programme to programme of flows, rigidity to flexibility, generic to specific, and transcendence to engagement (Berkel \& Bos, 2006).

\section{Attitude Towards Ground/Landscape}

UN Studio do not write extensively about their attitude towards the ground and landscape, however it is clear from their projects that their building interiors are conceptualised as or at least feature qualities of landscapes, extending the buildings' surroundings within. Arnhem Central station (further examined in the following case study) is one particularly strong example of this strategy, described by the architects as a "landscape of interrelated movements" (Berkel \& Bos, 1998, p. 22). 


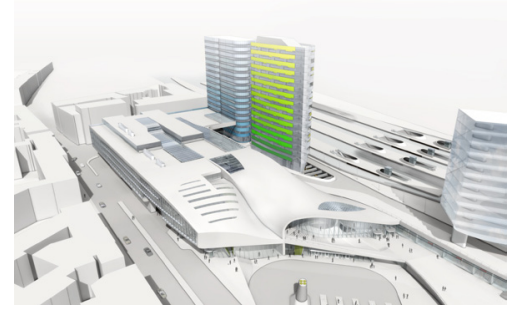

Figure 3.11. Arnhem Central Design Proposal, arial view.

UN Studio (n.d.). Retrieved January 26, 2012, from http://www.unstudio. com/projects/arnhem-central-masterplan.

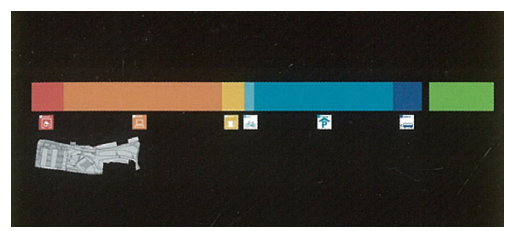

Figure 3.12. Scaled diagram showing floor areas of programmes to be accommodated on site.

From UNStudio: Design Models: Architecture Urbanism Infrastructure ( $p$. 275), by Berkel, B. v., \& Bos, C, 2006, London, United Kingdom: Thames \& Hudson.

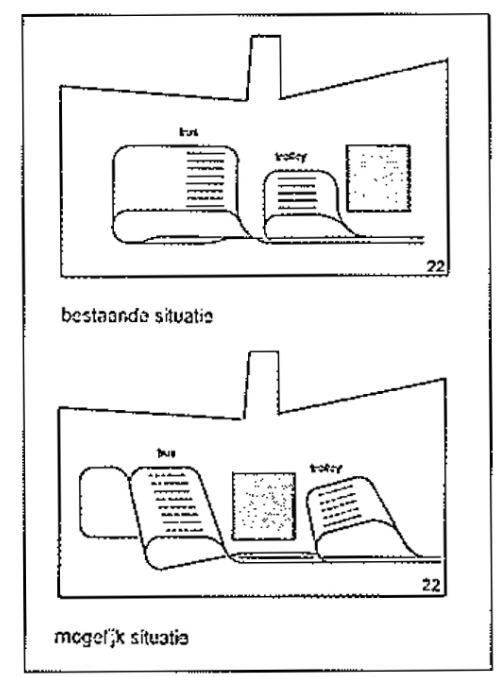

Figure 3.13. Diagram showing separation of bus services

From "Rational in Retrospect: Reflections on the Logic of Rationality in Recent Design," by Schumacher, P, 1999, AA Files , 38, p. 33.

\section{UN Studio | Case Study}

\section{Project Overview}

Arnhem Central is a complex infrastructural project - a transport interchange which integrates train, bus, taxi, car, bicycle, and pedestrian movement. The enclosed pedestrian zone which mediates between the various modes of transport forms the most complex element of the project, and is the focus of this case study.

\section{Project Design Methodology}

I. The problem of fitting $160,000 \mathrm{~m} 2$ of programme onto a $40,000 \mathrm{~m} 2$ site is visualised on a scaled diagram [Figure 3.12].

The decision was made to separate the regional and trolley bus services and use the central space to configure the pedestrian flows between them.

II. A diagram illustrates the basic organisational outcome of this decision [Figure 3.13]. The separate bus services are shown with a square representing the pedestrian area which mediates between them.

III. A network graph displays the connections to be constructed between the various modes of transport [Figure 3.14]. Each mode is represented as a node scaled in size based on its number of passengers. The hierarchy of links is represented by line weight.

IV. The original network graph is transposed onto a scaled plan of the site [Figure 3.15]. The density of originating pedestrian traffic and transfer traffic is quantified.

The previous two network graphs present the problem of the transport interchange in diagrammatic terms of nodes and links between nodes.

V. The scaled network graph was then developed into a 'branching figure', which Schumacher (1999) observes as a leap from a language of straight lines, paths and nodes to one of branches featuring irregular curves [Figure 3.16]. This diagram appears to be focused on movement and pedestrian flows between the different programmatic elements. 


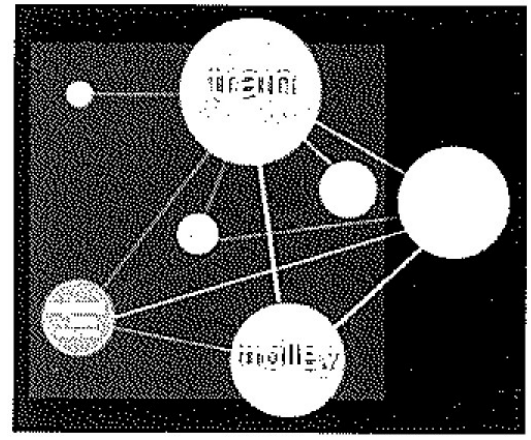

Figure 3.14. Network graph

From "Rational in Retrospect: Reflections on the Logic of Rationality in Recent Design," by Schumacher, P, 1999, AA Files , 38, p. 33.

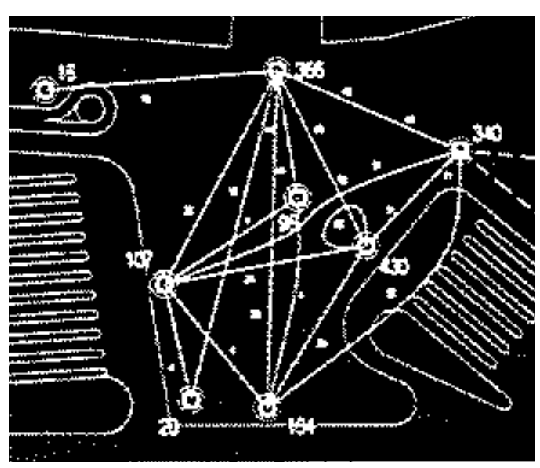

Figure 3.15. Network graph transposed onto the site

From "Rational in Retrospect: Reflections on the Logic of Rationality in Recent Design," by Schumacher, P, 1999, AA Files 38, p. 33.

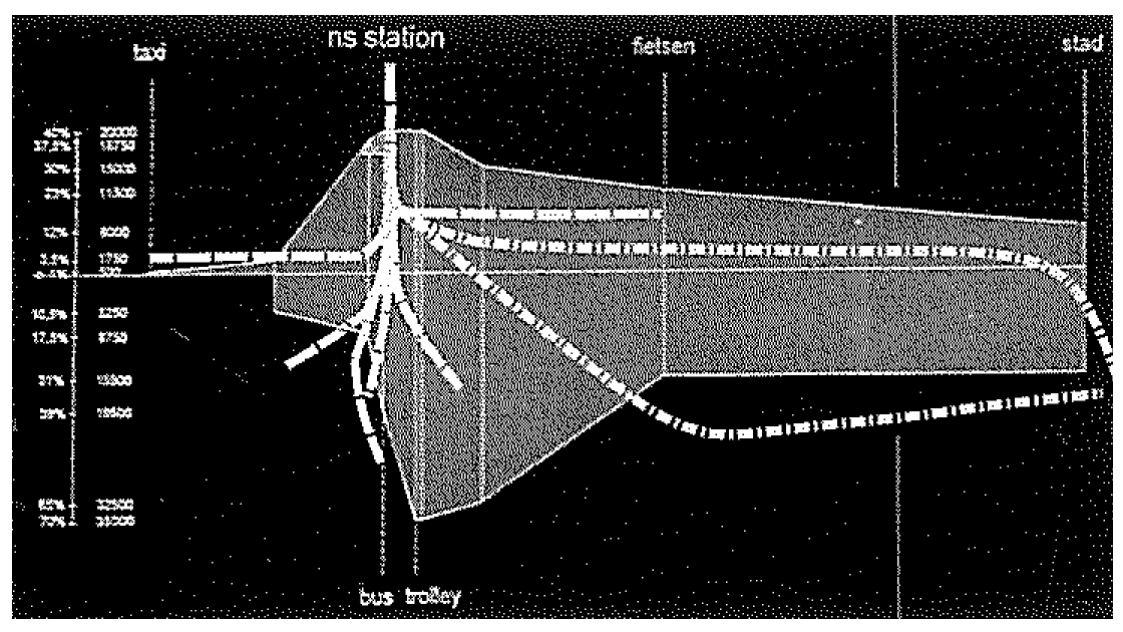

Figure 3.16. 'Branching figure' diagram

From "Rational in Retrospect: Reflections on the Logic of Rationality in Recent Design," by Schumacher, P, 1999, AA Files , 38, p. 34.

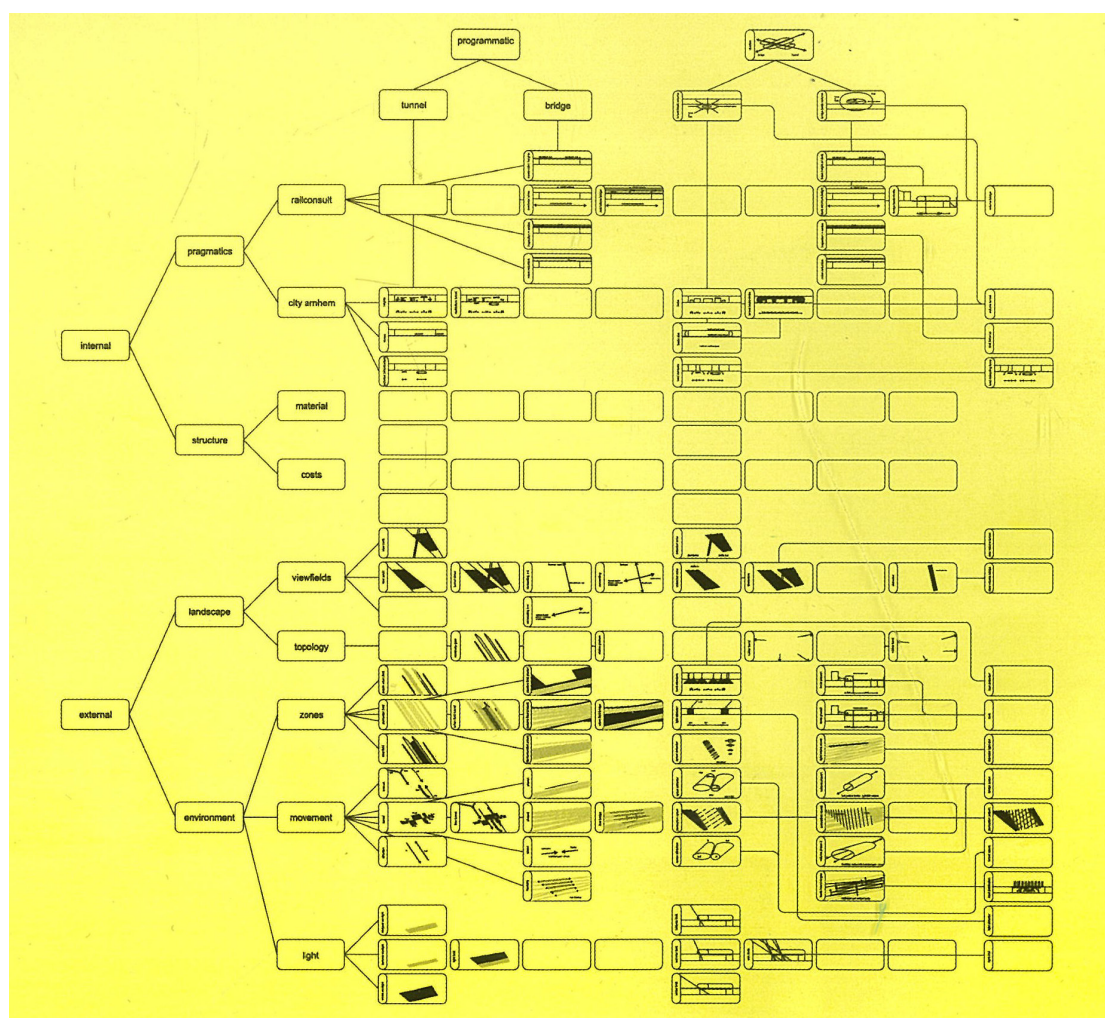

Figure 3.17. Schematic matrix of internal and external forces, regulations and other constraints

From UNStudio: Design Models: Architecture Urbanism Infrastructure (p. 275), by Berkel, B. v., \& Bos, C, 2006, London, United Kingdom: Thames \& Hudson. 


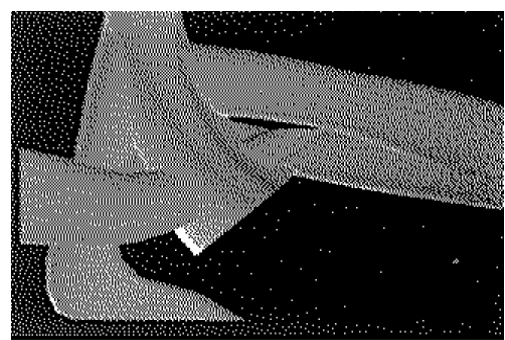

Figure 3.19. Three-dimensional 'cone' diagram

From "Rational in Retrospect: Reflections on the Logic of Rationality in Recent Design," by Schumacher, P, 1999, AA Files, 38, p. 35.

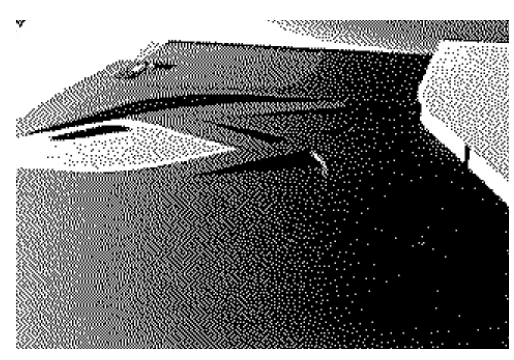

Figure 3.20. Single surface diagram creates a 'movement landscape'

From "Rational in Retrospect: Reflections on the Logic of Rationality in Recent Design," by Schumacher, P, 1999, AA Files, 38, p. 35.
The method of translation between the network graph and 'branching figure' diagram is not described by the architects, however Schumacher (1999) suggests the strategy of 'branching' could have been selected from a variety of other possible organisations, e.g. linear, grid, ring. Figure 17, published seven years later in Design Models (2006) would suggest Schumacher was correct in suggesting this strategy of selection from a range of possibilities. The schematic matrix is used to generate an overview of the potential of combining different parameters, however it is unclear exactly where this fits into the design process at Arnhem.

VI. The 'branching figure' diagram is developed into a three-dimensional diagram showing the vertical relationships of pedestrian flows transposed onto the site.

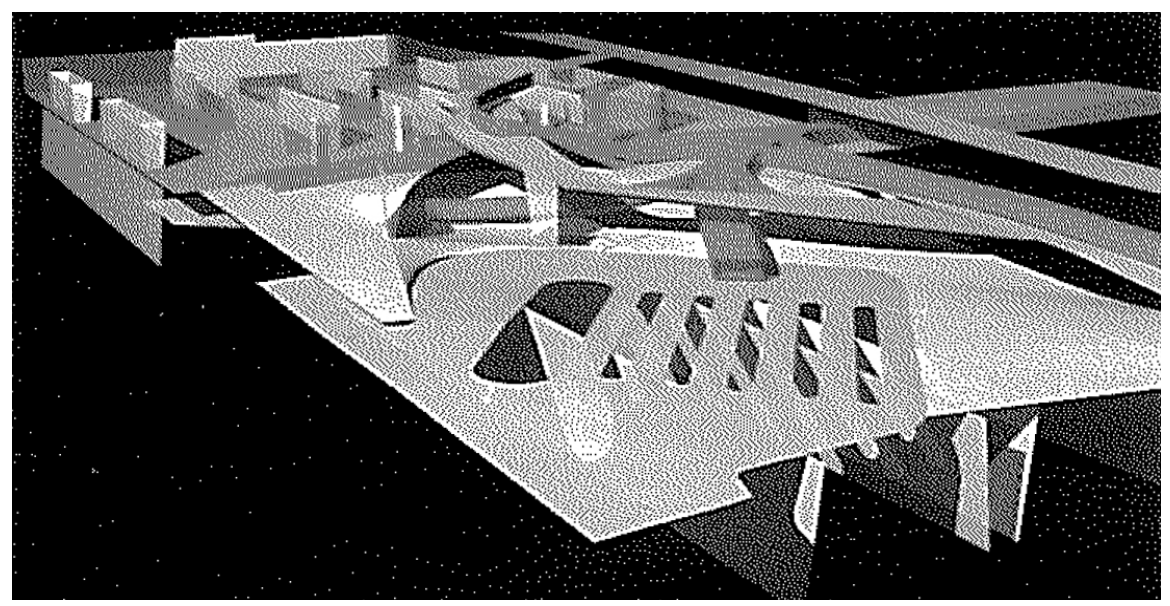

Figure 3.18. Three-dimensional branching diagram transposed onto site

From "Rational in Retrospect: Reflections on the Logic of Rationality in Recent Design," by Schumacher, P, 1999, AA Files, 38, p. 34.

VII. The branching diagram is developed into several three-dimensional models; the first, smoothly bent 'cones' which intersect, merge and branch, allowing pedestrian flows to be funnelled and spread smoothly [Figure 3.19]. The 'cones' are presumably scaled in relation to pedestrian flows identified by the network graph.

VIII.The second model presents the transfer of pedestrian flows as a single surface which peels smoothly at different levels [Figure 3.20]. Unlike the 'cone' diagram, the single surface doesn't delimit the space of movement or enclose the separate flows, creating what Schumacher (1999) terms a 'movement landscape'.

The translation of the branching figure diagram into various three-dimensional diagrammatic languages triggers new possibilities for the physical realisation of the project's organisation. For example, the single surface diagram opens up new possibilities for the project by providing the advantage of increased transfer surface and avoidance of bottlenecks due to lifts and staircases. User disorientation due to stacked spaces is also avoided. 
IX. A diagram external to the project is then introduced as an infrastructural element. This is the Klein bottle (an example of one of the practice's 'mathematical models') which is used as an organisational model for passenger movement [Figure 3.21]. The element is treated as a diagram, connecting the different levels of the station in a hermetic way whilst also triggering new structural and spatial possibilities for the project.

The architects explain the Klein bottle diagram was not a serendipitous find, but was discovered as part of a search for a new way of understanding the station area; an understanding that was provided by mathematical knots (Berkel \& Bos, 1998)

X. A diagram emerges as a hybrid of the three-dimensional 'cone' diagram and the single surface diagram, which are stitched together using the organisational and spatial language of the Klein bottle diagram. A topographic landscape of curves is created.

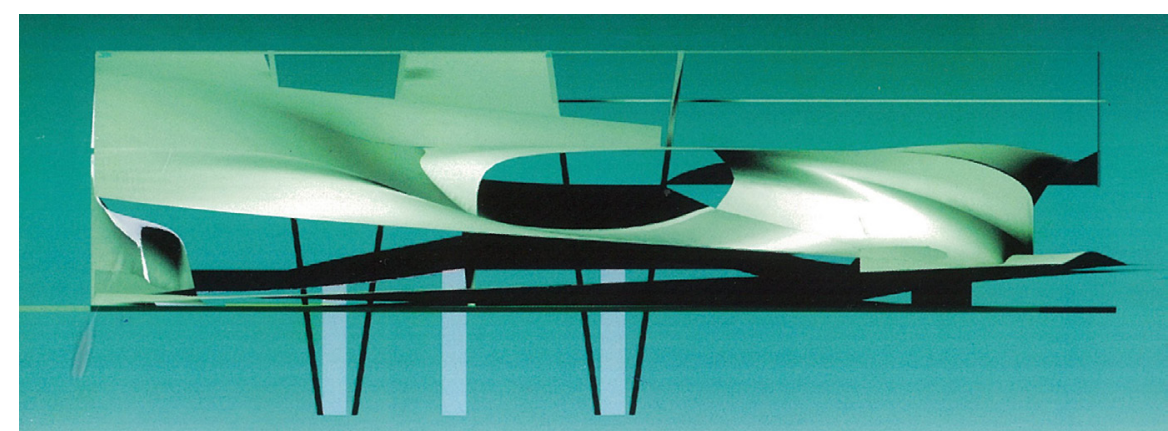

Figure 3.22. Hybrid diagram encompassing the 'cone' and single surface diagrams, related to one another using the Klein bottle diagram

From UNStudio: Design Models: Architecture Urbanism Infrastructure (p. 274), by Berkel, B. v., \& Bos, C, 2006, London, United Kingdom: Thames \& Hudson.

This hybrid diagram provides the basic form and organisation of the pedestrian transfer hall, which is further developed to become the final form of the building. The diagram is also a good illustration of the practice's retrospectively formulated 'design models' (as described in the UN Studio practice study). Visible in the diagram are the 'V', Blob-to-Box and Klein Bottle design models, illustrated by Figure 3.23.

\section{Diagram Methodology}

The following is a step by step summary of the methodology utilised by UN Studio for the design of Arnhem Central. The study of pedestrian movements forms a cornerstone of the design.

I. Visualise programme area and ratios on a scaled diagram in relation to site Determine fundamental programme distribution on site

II. Diagram the basic organisational outcome of the fundamental distribution of programme, identifying organisational challenges and opportunities for innovation

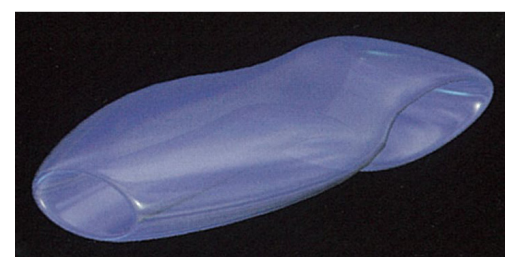

Figure 3.21. Klein bottle introduced as diagram

From UNStudio: Design Models: Architecture Urbanism Infrastructure ( $p$. 274), by Berkel, B. v., \& Bos, C, 2006, London, United Kingdom: Thames \& Hudson.

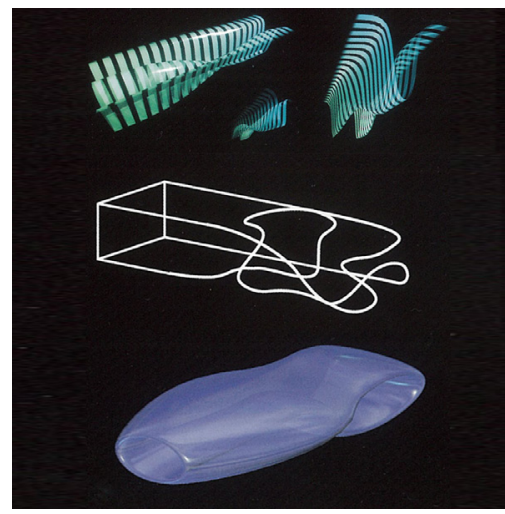

Figure 3.23. Diagrams of the ' $V$ ', blobto-box and Klein bottle design models

From UNStudio: Design Models: Architecture Urbanism Infrastructure ( $p$. 274), by Berkel, B. v., \& Bos, C, 2006, London, United Kingdom: Thames \& Hudson. 


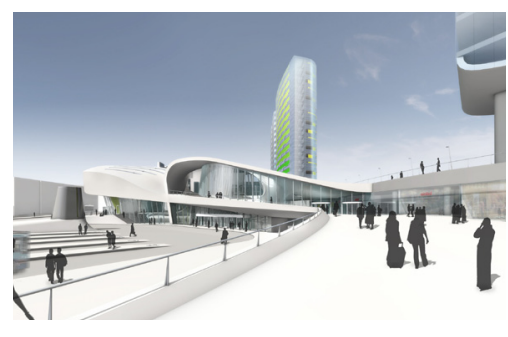

Figure 3.24. Arnhem Central Design Proposal, ramping from urban surroundings.

UN Studio (n.d.). Retrieved January 26, 2012, from http://www.unstudio.com/ projects/arnhem-central-transfer-hall

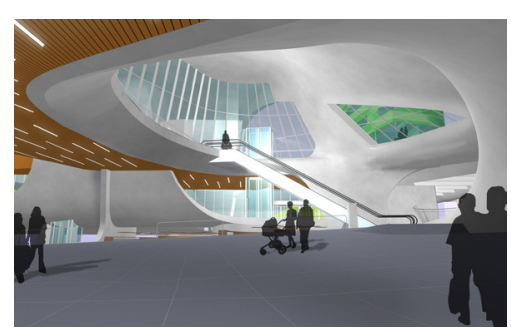

Figure 3.25. Arnhem Central Design Proposal, transfer hall.

UN Studio (n.d.). Retrieved January 26, 2012, from http://www.unstudio.com/ projects/arnhem-central-transfer-hall
III. Prepare network graph, scaled to illustrate key information (passenger numbers in the case of Arnhem) with hierarchy of relationships identified

IV. Transpose network graph onto site, quantifying key influences where possible

Select a more detailed organisational strategy from a variety of possible strategies (a branching strategy in the case of Arnhem), whose interaction with other project influences could be explored in a schematic matrix

V. Translate organisational strategy onto a scaled diagram of the site

VI. Develop the diagram of the organisational strategy into a three-dimensional diagram

VII. Translate this diagram into a variety of diagrammatic languages (Cones and single surface in the case of Arnhem).

Experiment with the organisational possibilities these other diagram 'worlds' trigger for the project, and somehow select the strongest strategies

VIII.Identify a diagram external to the project which can be used in an infrastructural manner to relate different influences of the project and introduce it to the organisation of the project (In Arnhem, the Klein bottle is used to relate the 'cone' and single surface diagrams and also triggers further organisational possibilities)

This process generates a flexible organisation and form which is subject to further development

\section{Relationship to Urban Design Principles}

Rather than a clear distinction between built form and the ground, the transfer hall of Arnhem Central ramps upwards from its urban surroundings, blending the pedestrian approach to the building with its urban landscape [Figure 3.24]. The building's ramped pedestrian surfaces are continued through to the building's interior, minimising the distinction and sense of threshold between the building's various indoor levels and its outdoor urban surroundings. Within the vast space of the transfer hall the pedestrian surfaces begin to warp, merge and spiral, creating an internal landscape of curved surfaces and movement whose topological variation is central to the organisation of the space [Figure 3.25]. Horizontal and vertical movement and structure are integrated into a series of warped surface which also curve up to create enclosure for the building. 


\section{MVRDV | Practice Study}

\section{Practice Ideology}

Central to MVRDV's practice is the belief that the reality in which they operate is to a large degree quantifiable. Bart Lootsma (2003) identifies the origins of this rigorous academic basis of MVRDV's working method in the office of OMA, where Maas and van Rijs worked with Koolhaas in the 1980s. Through their analytical approach the design emerges as though it were the solution to a mathematical equation (Adam, 2002), appearing as the concretisation of abstract statistical information. Their work does not depend on theoretical justifications but is rather presented as an examination of the data surrounding the project. Stan Allen (1997) describes their work as “...a systematic effort to find the cracks in the system where something new can happen in spite of its overarching logic" (p. 33). Maas explains their practice is projective as it is concerned with developing tools to investigate and construct the future (Van Sande \& Schoonjans, 2007). The focus of the practice is not on the aesthetic aspect of their architecture, which is described by Lootsma (2003) as the most neglected and uninspired aspect of their work, and is mainly rectangular and practically Modernist. Instead the practice is heavily concerned with issues such as density, mixed functions, juxtaposed programmes, floor plan variation and the building as an extension to the (urban) landscape (Lootsma, 1997).

\section{Definition of Diagram}

MVRDV uses a variety of diagrams and diagrammatic techniques. A central diagrammatic technique of the practice is the construction of 'Datascapes', which are described by Bart Lootsma (1997) as:

...visual representations of all the quantifiable forces that may influence the work of the architect or even steer or regulate it... Each datascape deals with only one or two of these influences and reveals their impact on the design process by showing their most extreme effects (p. 38).

Statistic information surrounding a project is turned into a Datascape which operates as a diagram, displaying the limitations of the project, and in many cases generates schemes that appear to come close to architectural projects, although they are not (Lootsma, 1997). 
The practice's diagrammatic techniques have also extended to the development of software such as the 'Functionmixer' which operates diagrammatically, building an abstract world based on the optimisation of a range of parameters chosen by the operator.

Datascapes and Functionmixer could be considered as analytical or optimised diagrams, however the practice also uses diagrams in a conceptual manner. Maas explains that diagrams are used to condense the information of a project into a central, essential concept, which is often coupled to a word such as bend, flip, lift, stretch or squeeze, to enhance the communication of the diagram (Van Sande \& Schoonjans, 2007). This technique was utilised in the design of their Dutch Pavilion, which was constructed as a "...direct and unfiltered translation from diagram into architecture" (Mallgrave \& Goodman, 2011).

\section{Diagram Value}

Datascapes provide MVRDV with a tool to analyse and visualise the various forces surrounding a project, which are often so complex that statistical techniques are seen as the only way to fully understand the situation of the project and decide on a direction. When visualised through Datascapes, a more complex version of the site plan emerges, displaying the possibilities and constraints imposed by society on the project. This presents a highly rational approach to the design process, where the artistic role in architectural design is limited and mostly supplanted with explanatory diagrams, tables and charts. In spite of this logical and rational approach, surprising solutions emerge. Datascapes are utilised to describe the problem in new ways, exaggerating the constraints of the project and forcing it to extremes where known solutions are incapable of solving the problem and new and unexpected forms are generated (Allen, 1997). Conceptual diagrams are valued by the practice as a method of clarifying and maintaining consistency with a central concept and tracking developments throughout the design process.

\section{Diagrammatic Design Methodology}

MVRDV publicise very little about their process of design and talk little about the art of design - which plays a very small part in their projects. Most information about their design methodology comes from interviews and critics writing about their work. MVRDV have however published information about some of the tools and techniques which play an important role in their design methodology, particularly their use of datascapes, which are essentially used to translate mapped data into architecture.

MVRDV's projects typically start with extensive research and the assembly of massive quantities of data, not concerned with the determination of the building's form but focusing on understanding the situation of the project. The research is often on a range of topics which could include natural conditions 
like sun and wind, legislation such as minimum working conditions, economic influences and urban issues such as settlement patterns and density. Once collected, the statistical information is assembled into datascapes which visualise the complex constraints surrounding the project. The data can be presented in any number of ways, but it is up to the architects to decide the most useful form for it to take for the purposes of the project. The form of the constructed datascapes are superficially simple with regard to the information they contain, and often resemble architectural projects and have been interpreted and criticised by some critics as such, although they are not. After visualising the data, the architectural problem is identified and analysed and visions, directions and possibilities for the project are determined.

Datascapes make visible the often contradictory forces which play a role in the project, so the design develops as a process of negotiation and confrontation between the different constraints, possibilities and participants in the design process. This process of negotiation can function to generate the building itself or help illustrate the possibilities and limitations of the project.

The building form emerges as a result of the datascapes being loaded with programmes, illustrating at the same time the restrictions and possible outer limits of the design. The creativity and inventiveness of the project is not expressed in the creation of new forms but rather as the re-formulation of the existing constraints, causing new and unexpected solutions and performative complexities to emerge: “...a stubborn logic yields fresh, improbable results" (Allen, 1997, p. 29).

\section{Attitude Towards Ground/Landscape}

A central concern of MVRDV is the increasing population density of the Netherlands, which is approaching that of Japan. As a consequence the boundary between the city and the landscape is becoming increasingly blurred, leading to the observation of the urban phenomenon termed by the practice as 'interiorisation'. Interiorisation occurs when buildings are constructed close to one another and space between them takes on an interiorised identity, expressed through an increased sense of enclosure and a more intensive design and use of the space. The practice observes in these instances the building's facade beginning to 'disappear,' resulting in hybrids between buildings and the surrounding urban fabric (Mansilla \& Tunon, 1997). In this context the architectural project is seen less as the insertion of a building on the site, as it is the construction of the site itself through the architecture (Allen, 1997). This idea is manifest architecturally in the projects of MVRDV as the prolongation of the site or ground floor into the building, and a continuation or gradual transition between indoor and outdoor, public and private, introducing landscape into the architecture. Their buildings often feature intermediate 'third' spaces which exist as neither indoor nor outdoor in the residual space leftover after the stacking of programmes which facilitate transversal interior 
views through complex cross-sections, enlivening users' perceptions of the space (Mansilla \& Tunon, 1997).

\section{MVRDV | Case Study}

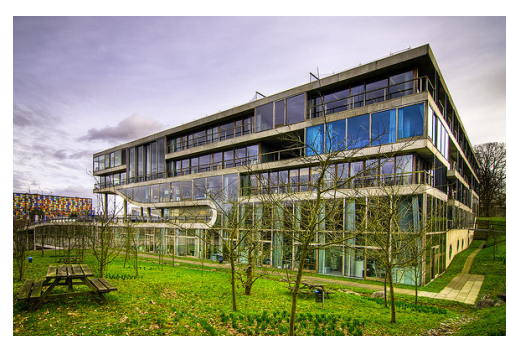

Figure 3.26. The Villa VPRO

Leng, J. (Photographer). (2008). Retrieved January 26, 2012, from http://www.flickr.com/photos/ ettubrute/2357171915/

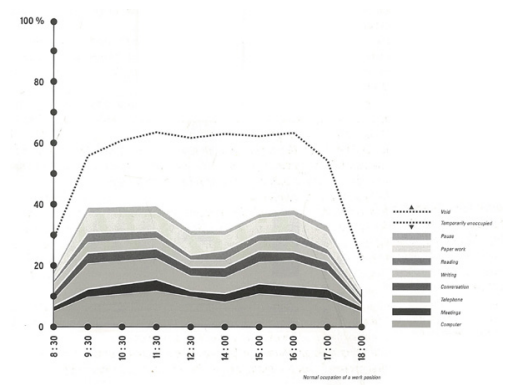

Figure 3.27. Graph showing the percentage of time spent doing certain activities during a normal working day

From MVRDV at VPRO (p. 47), by Salazar, J. (Ed.), 1999, Barcelona: Actar.

\section{Project Overview}

The Villa VPRO is a new headquarters for a not-for-profit broadcasting organisation in the Netherlands, which was previously housed in eleven separate villas. The project seeks to maintain the informal and varied working spaces of the villas at the increased scale of the an office building.

\section{Project Design Methodology}

MVRDV publish very little about their process of design, so based on published material it is not possible to reconstruct a step-by-step design methodology for their projects. Their projects are described as emerging out of a process of negotiation between different influences rather than as a result of a more linear and well-defined design process.

Instead of a step-by-step methodology, this case study will identify several of the diagrammatic techniques used to generate the design outcome. The Villa VPRO project is not the most 'diagrammatic' of MVRDV's projects, however has the most published information on its process of design.

\section{Project Aim:}

The project seeks to preserve the characteristics of the organisation's existing villas at the enlarged scale of an office building - specifically compactness (no corridors), the stacking of spaces and relationship to landscape. The desire for compactness was likely a pragmatic concern also to minimise circulation space and promote communication. The requirement for more flexible working spaces was also identified based on research into changing work habits [Figure 3.27].

\section{Building Footprint:}

Volume and plan layout studies illustrate the footprints and layouts possible to achieve the desired $9,000 \mathrm{~m} 2$ floor area [Figure 3.28, Figure 3.29]. The footprints 
were informed by town planning restrictions such as zoning, plan boundaries and building heights, as well as the wish to make the smallest possible intrusion on the site.

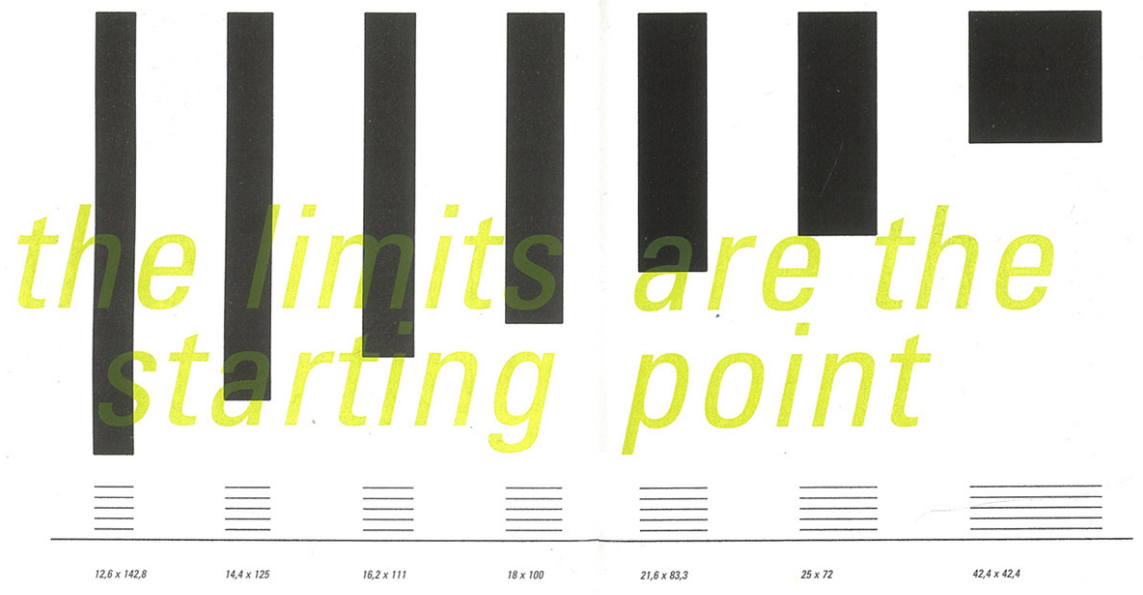

Figure 3.28. Building volume study

From MVRDV at VPRO (p. 48, 49), by Salazar, J. (Ed.), 1999, Barcelona: Actar.

A square building footprint was selected which provided the greatest compactness but also created a building which was very deep in plan - possibly the deepest office building in the Netherlands according to the architects.

\section{Light+air+view:}

The deep plan presented a challenge for getting light and air into the depths of the building and allowing views out to the landscape. Rather than a conventional court solution which would not have met the project's requirement for compactness, a 'precision bombardment' of penetrations in the building's volume was conceived [Figure 3.30].

The resulting form is described by the practice as an 'office landscape', where the difference between the inside and outside blurs (Salazar, 1999). The views and patio areas created by the subtracted voids compensate for the depth of the building.

The process for determining the size and shape of the voids is not detailed, however could be based on a negotiation of parameters such as programmatic requirements for daylight and air or separation of the building's internal programme with other design influences.

\section{Conceptual Diagram:}

As a continuation of the reduced distinction between inside and outside due to the building's subtracted voids, the concept of the building as the landscape is visualised via a simple conceptual diagram [Figure 3.31].

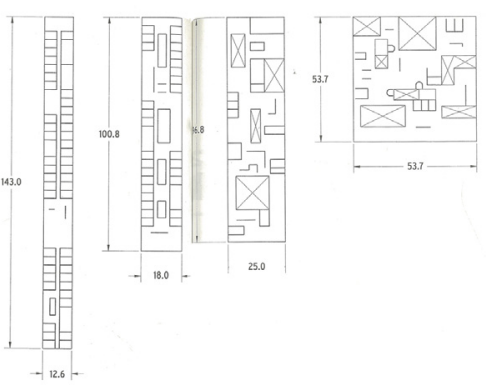

Figure 3.29. Plan layout study showing the possible plan configurations of the various possible building footprints

From FARMAX: Excursions on Density (p. 684, 685), by Mass, W., van Rijs, J., \& Richard, K. (Eds.), 1998, Rotterdam: 010 Publishers.

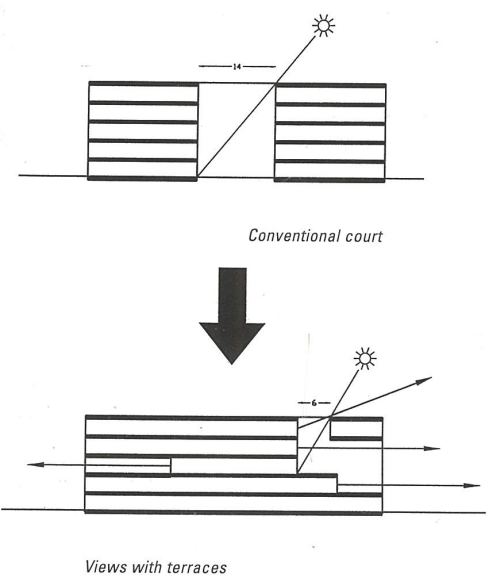

Figure 3.30. Conventional court versus 'precision bombardment' of penetrations

From MVRDV at VPRO (p. 51), by Salazar, J. (Ed.), 1999, Barcelona: Actar.

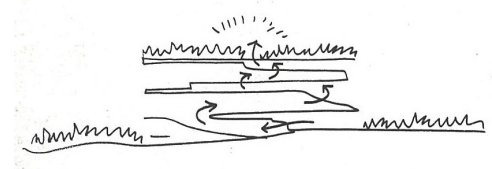

Figure 3.31. Conceptual diagram showing the idea of building as landscape

From murdv Maas vanRijs deVries 1991-1997 (p. 88), by Maas, W., de Vries, N., \& van Rijs, J, Croquis , 86. 


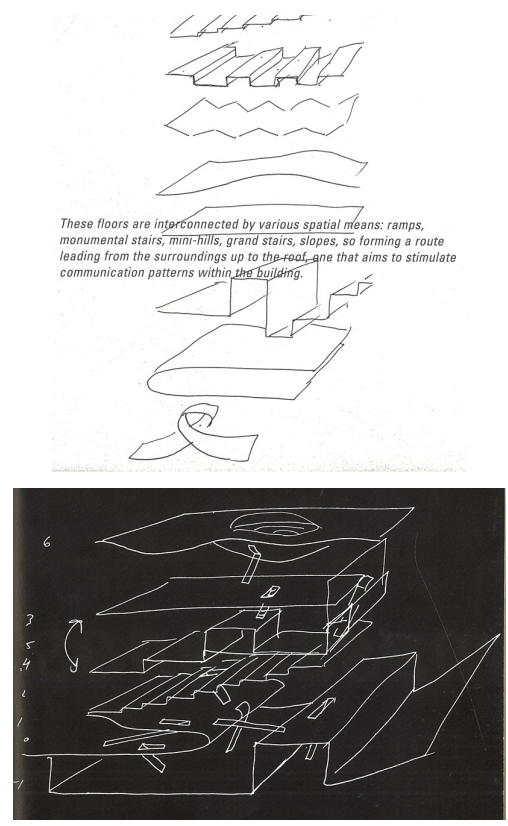

Figure 3.32. Diagrams showing the various spatial means of connection which are transposed into built form very directly

From MVRDV at VPRO (p. 66, 67), by Salazar, J. (Ed.), 1999, Barcelona: Actar.

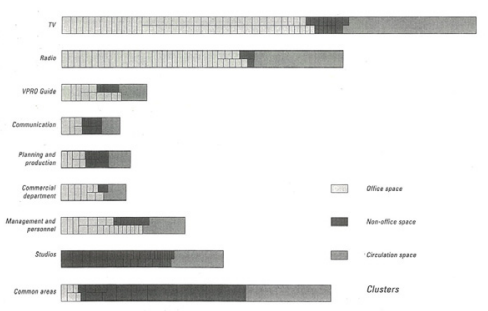

Figure 3.33. Diagrammatic break down of programmed floor areas, showing the office, non-office and circulation space of each

From MVRDV at VPRO (p. 70), by Salazar, J. (Ed.), 1999, Barcelona: Actar.
Spatial Moulding:

The floors of the building are connected by various spatial means in an effort to stimulate communication between the levels. Diagrams illustrate the various possible strategies for connecting floors and their location within the building [Figure 3.32]. The diagram of each strategy is transposed into built form in a very literal sense, resulting in unorthodox spatial connections unlikely to be achieved by working within conventional means of architectural design. The varying connections between floors create a variety of office types throughout the building.

Distribution of Programme:

The different programmes are broken down into office space, non-office space and circulation space [Figure 3.33] and distributed throughout the building, 'urbanising' the floors.
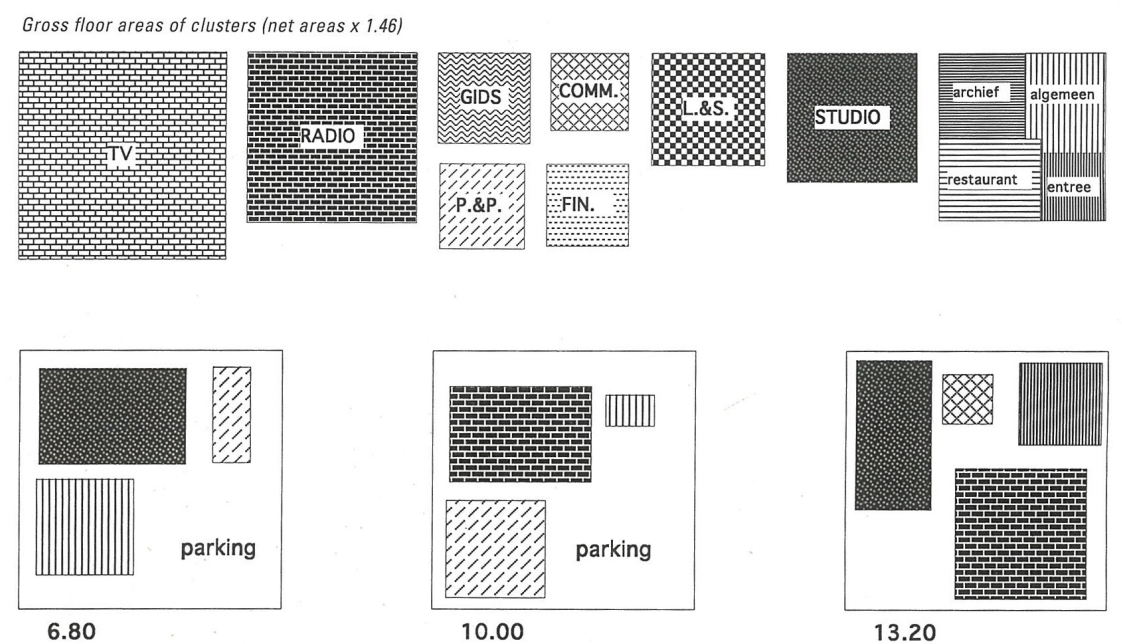

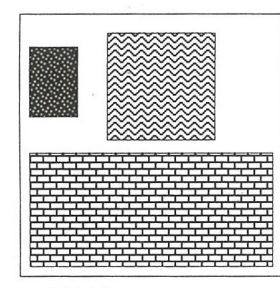

16.40

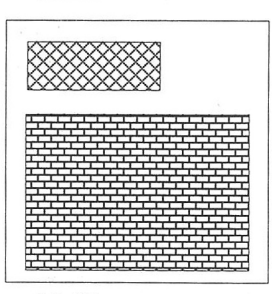

19.60

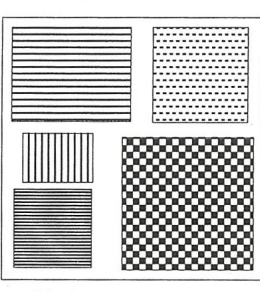

22.80
Figure 3.34. Distribution of programme throughout the building

From MVRDV at VPRO (p. 72), by Salazar, J. (Ed.), 1999, Barcelona: Actar.

Structure:

The building is supported by a regular grid of columns with cross-bracing resisting lateral loads. This strategy was selected to provide maximum flexibility for the floor plans and maximum transparency. The process of structuring the building is not documented, however it is possible the grid of columns with cross bracing was selected from a variety of different structural possibilities e.g. structural walls and moment frames. 


\section{Building Envelope:}

The building frontage is described by the architects as the outcome of a datascape of requirements (Salazar, 1999). The building envelope is made up of thirty-five different sorts of glass, positioned according to the requirements of colour, reflectivity, heating and cooling demands and degree of transparency for the rooms behind them. This mix of glass types creates a rose window effect for the facade.

\section{Diagram Methodology}

The following is a broad summary of MVRDV's process of design as identified in the practice study and is not specific to the Villa VPRO project.

I. Perform extensive research not necessarily aimed at the determination of final form, but rather understanding the situation of the project.

II. Assemble the data into datascapes - visual representations of the constraints of the project. The method of representation is up to the designer.

\section{Identify, architectural problem, direction and aims of the project}

III. Execute a process of negotiation and confrontation between the often contradictory datascapes. This process can generate an organisation or form for the building or at least displays the outer limits of the project.

\section{Relationship to Urban Design Principles}

Of the four case studies, the Villa VPRO appears as the most conventional in terms of its architectural style and construction. It is also the only case study which exists in a non-urban setting, located in a business park surrounded by forest. This being the case, an analysis against criteria formulated for buildings in an urban setting will not be entirely suitable for this case study. The building displays similar architectural characteristics as some of the other case studies however, which are consistent with emergent urban design trends and could be deployed in urban locations.

The building seeks to minimise its impact on the landscape and appears from the outside as a densely packed volume realised in relatively conventional construction and materials, standing quite distinct from its surroundings. This seemingly dense volume is penetrated with a series of unusually deep holes or voids, which create intermediate spaces that are neither inside nor outside the building, generating ambiguity and integration between inside and out [Figure 3.36]. The voids provide light and air to the depths of the building, and also provide greater visual accessibility into the centre of the building and between its various levels. Physical accessibility is also increased through unconventional connections between the building's floorplates [Figure 3.37], appearing as though conceptualised as landscapes and capped by an accessible green roof.

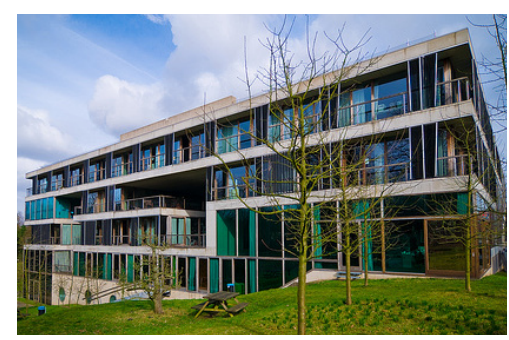

Figure 3.35. Rose window effect due to the use of different types of glass

Leng, J. (Photographer). (2008). Retrieved January 26, 2012, from http://www.flickriver.com/photos/ ettubrute/tags/netherlands/

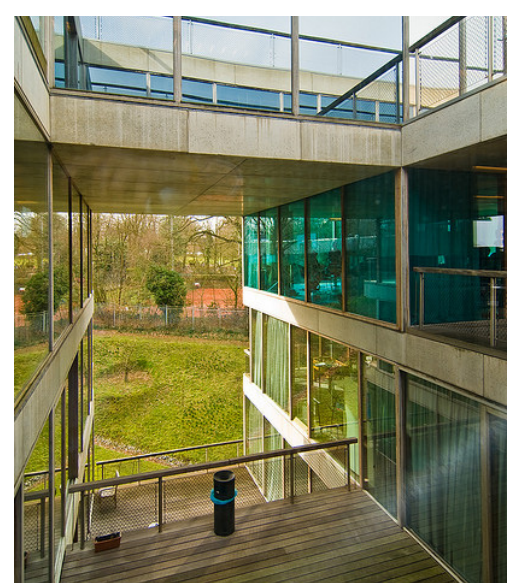

Figure 3.36. The Villa VPRO internal void space

Leng, J. (Photographer). (2008). Retrieved January 26, 2012, from http://www.flickr.com/photos/ ettubrute/2358017442/sizes/z/in/ photostream/

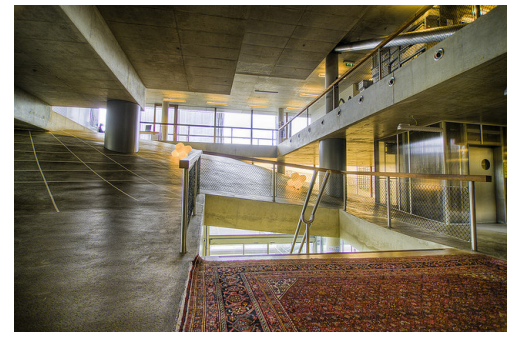

Figure 3.37. The Villa VPRO connection between floorplates

Leng, J. (Photographer). (2008). Retrieved January 26, 2012, fromhttp://www.flickr.com/photos/ ettubrute/2358004198/ 


\section{OMA | Practice Study}

\section{Practice Ideology}

The sudden rise in the importance of pragmatism in architectural practice during the 1990's is credited in a large part to Rem Koolhaas and his Office for Metropolitan Architecture (OMA) (Mallgrave \& Goodman, 2011). The office's attitude to design centres around research, which they use to develop new readings on contemporary conditions and strive to formulate new architectural solutions (Deen \& Garritzmann, 2010). Areas for their research are not restricted to the realm of architecture, “...the implicit hypothesis seems to be that any piece of information can potentially generate an architectural theme or concept" (Deen \& Garritzmann, 2010, p. 228). The office's projects are driven by information and an interest in the modern metropolis rather than an interest in form. In recent years, an important area of research for OMA has been "...accentuating the functional logic of the programme in the creative process, in pursuit of an ideal Diagrammatic Metropolitan Architecture" (Gargiani, 2008, p. 302).

\section{Definition of Diagram}

Although considered one of the most convincing contemporary exemplars of a diagrammatic practice (Vidler, 2004), relatively little is written about the diagrams of OMA. The only published text dedicated to the subject is a 1998 article written by Udo Garritzmann, a former project architect at the practice and Wouter Deen, a student research assistant of Rem Koolhaas. It is clear from the text that OMA uses an eclectic variety of diagrams that range from metaphors (linguistic diagrams) to cartoons to visual representations of data, which allow for an "...optimistic but practical focus on newness" (Deen \& Garritzmann, 2010, p. 228).

\section{Diagram Value}

Diagrams are valued by OMA first of all in a conventional sense for their powers of reduction and simplification. Used in this way the diagram is described as a cartoon and is utilised in a process of 'amplification through simplification'. This process focuses attention on the essential information such as building 
type without requiring detailed architectural elaboration, and is valued for its rhetorical and evocative powers (Deen \& Garritzmann, 2010). These powers are identified in the diagram's ability to connect visual perception with rational thought; the diagram is likened to 'thinking in images' (Deen \& Garritzmann, 2010).

Diagrams are also valued by OMA for their ability to represent graphically the abstract and invisible data which structures contemporary society. When visualised, this data can reveal the essence of a concept or at least provide the practice with a point of departure for a project. (Deen \& Garritzmann, 2010) The visualised data also makes possible a process termed 'romanticising' - a 'systematic idealisation' which blurs the border between data analysis and the conception of the project, whereby "....analysis becomes identical to creation" (Deen \& Garritzmann, 2010, p. 230). Robert Somol (2010) identifies in this approach an attempt to "...supplant design with the diagram, to deliver form without beauty and function without efficiency" (p. 90).

OMA's conception of the diagram is extended to linguistics through the use of metaphors and analogies, which are described as the linguistic equivalent of the diagram (Deen \& Garritzmann, 2010). These linguistic 'diagrams' are used in an instrumentalising manner, describing operating mechanisms or organising principles and conceptually 'charging' the elements which they associate (Deen \& Garritzmann, 2010). This process introduces influences from disciplines outside of architecture and is claimed to lead to the development of innovative organisations, implying a projective and instrumentalising role of the linguistic diagram: "It is this organising potential that makes of the metaphor a diagram..." (Deen \& Garritzmann, 2010, p. 230).

Diagrams are utilised by OMA as both instruments of analysis as well as projective tools in a quest for the new in architecture, addressing simultaneously "...intellect and imagination ... analysis and vision crystallise in the diagram into a pregnantly visualised thought of the new" (Deen \& Garritzmann, 2010, p. 235).

\section{Diagrammatic Design Methodology}

The diagrammatic design methods of the office of OMA generate buildings described as literal transpositions of their diagrams (Mallgrave \& Goodman, 2011), to the extent that they incorporate the qualities of the diagram (Vidler, 2004). Rem Koolhaas is extremely reluctant to speak about his working methods (Attali, 2003), so little is known about the exact diagrammatic methodology of his Office for Metropolitan Architecture.

Research forms an integral part of the OMA design method. The initial research for a project is broad in focus, and includes studies of programme, volume, densities, typologies, building codes and laws. The collected data is mapped in 
an abstract graphic visualisation which allows the outer limits of the project to be identified and explored. This is where the creative moment lies - in the decision of what is charted and how (Deen \& Garritzmann, 2010). Koolhaas (As cited in Lootsma, 1998/1999) describes a process of 'systematic idealisation' - a “... spontaneous overestimation of the existing situation" (p. 16), which is referred to as 'romanticising'. Through this process, the border between analysis and conception of the project is blurred, "....analysis becomes identical to creation" (Deen \& Garritzmann, 2010, p. 230). Deen and Garritzmann (2010) explain that a scheme is developed when analysis, reduction and simplification, and exaggeration of the original situation (romanticising) are brought together where the relationship between separate components (data, phenomenoa, ideas and forms) can be examined. The resulting scheme exists as a synthesis of analysis and a vision of the new which are 'crystallised' in the diagram.

\section{Attitude Towards Ground/Landscape}

Many of the projects by Rem Koolhaas display a preoccupation with exploring the potential of continuous architectural surfaces to create new programmatic combinations (Lootsma, 1998/1999). An exemplary example of this approach is OMA's Jussieu Library project of 1993, which features a spiral of continuously ramped floors. This continuously ascending pathway is termed the 'trajectory', and its variety and scale has been compared to an urban street, introducing urban elements like plazas, parks, cafes, and shops into the building's interior (Gargiani, 2008). Each floor is conceptualised as a 'pliable surface' or 'social magic carpet' (Gargiani, 2008). Aaron Betsky (2002) explains that Koolhaas "...makes buildings as landscapes in which the land becomes a building face and the interior is only a seamless convolution of the exterior's order into labyrinthine caves" (p. 143). Bart Lootsma (1998/1999) identifies the emergence of a series of new architectural concepts and typologies as a product of the working methods of OMA, "...the most important example of which is the large building as a folded and stacked continuation of the landscape" (p. 16). 


\section{OMA | Practice Study}

\section{Project Overview}

The project is for a new central library for the city of Seattle. It seeks to redefine the modern library, balancing the presentation of all forms of media with the increase in social functions and programmatic intricacies typical of modern libraries.

\section{Project Design Methodology}

The project begins with research focusing on the expansion of media types and social functions of modern libraries. The flexibility of generic floors common in library design is observed as a shortcoming of the building type, as the expanding collection encroaches on the public space of the library. To counter this, a strategy of spatial and functional compartmentalisation is proposed, eliminating the threat of one function encroaching on others. This organising principle is expressed using conceptual diagrams.
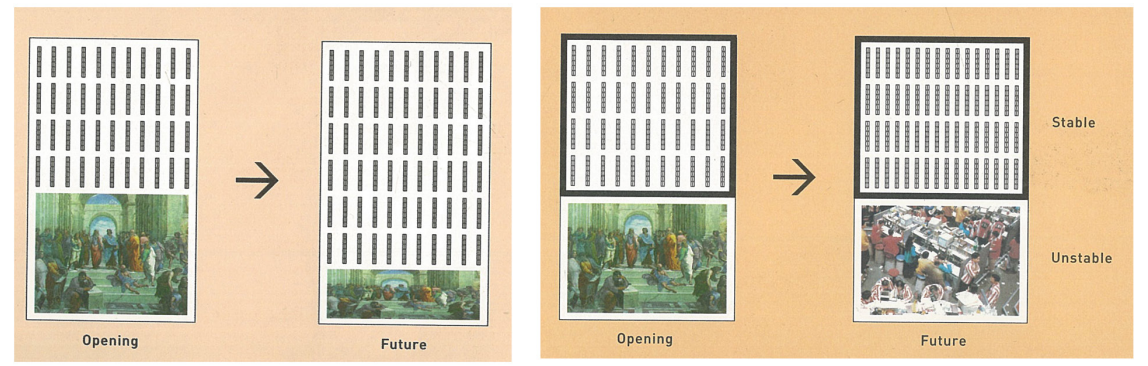

Figure 3.39. Conceptual diagrams explaining the organising principles of uniform flexibility (left) and compartmentalised flexibility (right)

From Seattle Public Library: OMA / LMN (p. 16, 17), by Kubo, M., \& Prat, R. (Eds.), 2005, Barcelona: bActar.

I. The proposed library programme was visualised and consolidated into various functional groupings, illustrating the proportions of floor area occupied by each function [Figure 3.40]. This visualisation communicates essentially the same information as a pie chart, however its vertical stratified organisation creates associations with the form and organisation of office high rises, providing the notion of a formal correlation for the diagram.

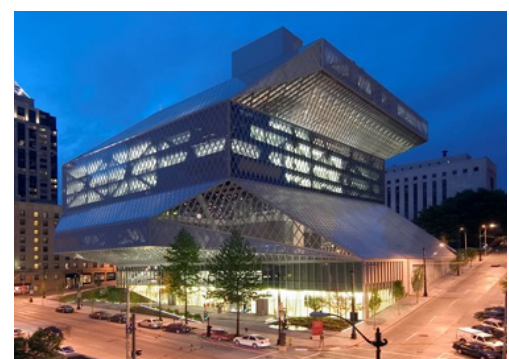

Figure 3.38. Seattle Public Library

(n.d.). Retrieved January 26, 2012, from http://plusmood.com/2008/09/ seattle-public-library-rem-koolhaasoma/

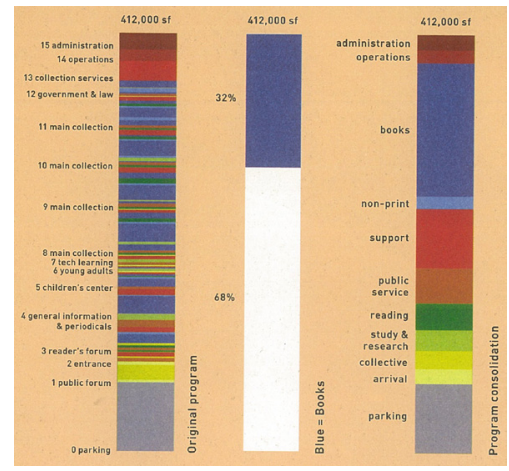

Figure 3.40. Floor area proportions of proposed library programme. The central column illustrates the proportion of the total floor area dedicated to books (shown in blue)

From Seattle Public Library: OMA / LMN (p. 18), by Kubo, M., \& Prat, R. (Eds.), 2005, Barcelona: bActar. 


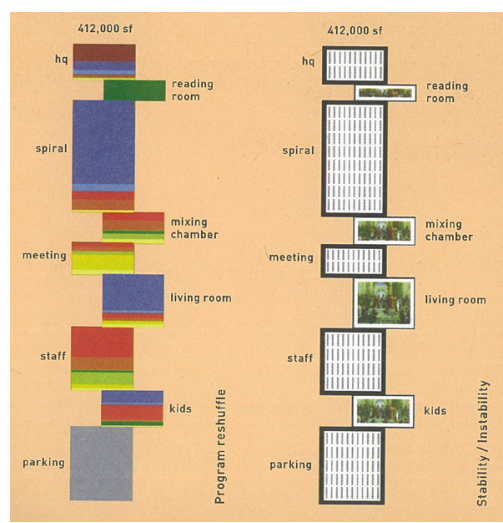

Figure 3.41. 'Unstable' functional clusters are 'pushed out' in the diagram

From Seattle Public Library: OMA / LMN (p. 18), by Kubo, M., \& Prat, R. (Eds.), 2005, Barcelona: bActar.

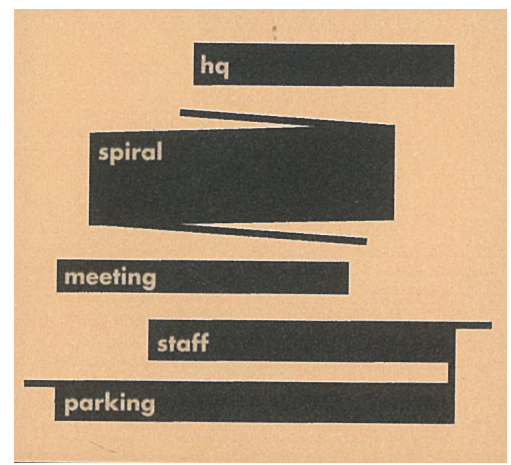

Figure 3.42. Offset stacking of programmatic compartments

From Seattle Public Library: OMA / LMN (p. 22), by Kubo, M., \& Prat, R. (Eds.), 2005, Barcelona: bActar.

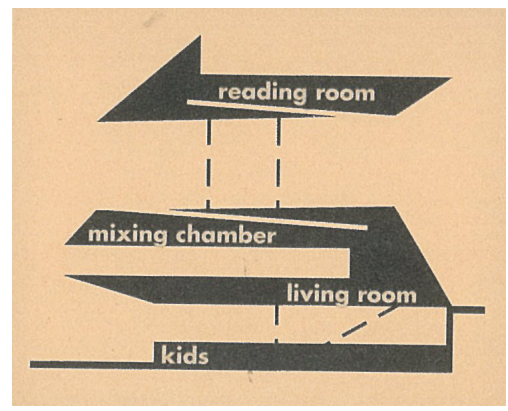

Figure 3.43. Flexible residual spaces between 'stable' programmatic compartments

From Seattle Public Library: OMA / LMN (p. 26), by Kubo, M., \& Prat, R. (Eds.), 2005, Barcelona: bActar.
II. Nine different functional clusters are determined and visualised; five are classified as 'stable,' four 'unstable.' A black outline encloses and compartmentalises the stable clusters, while the unstable clusters are offset or 'pushed out' in the diagram [Figure 3.41].

III. The next diagrams show the mechanistic translation of the programmatic diagram. Each of the 'stable' compartments is scaled according to programmatic requirements and site constraints and stacked on top of one another [Figure 3.42]. The previous abstract diagrammatic operation of offsetting the compartments has been adapted in this diagram, whose seemingly arbitrary offsets of the programmatic compartments are justified by the logic of the programme (Gargiani, 2008). Figure 3.43 shows the residual spaces between the stacked 'stable' compartments which are used to organise the interface between the compartments and house the more informal, social functions of the library. An abstract indication of circulation appears in this diagram.

IV. The specific offsets of the different compartments are influenced by shade and sunlight requirements and the desire to maximise specific views from the library, as well as the urban requirements of the streets surrounding the building. Diagrams illustrate some of the forces influencing the offsets of the compartments [Figure 3.44, Figure 3.45].

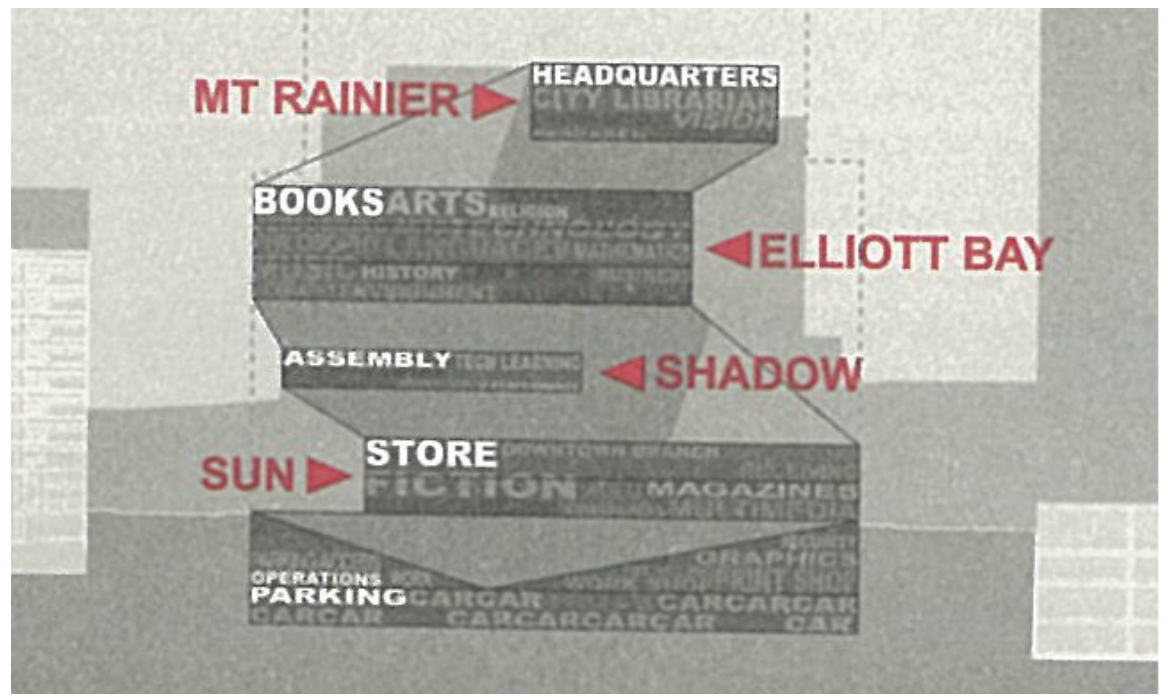

Figure 3.44. Diagram illustrating the influences of view and sun requirements

From Seattle Public Library: OMA / LMN (p. 30), by Kubo, M., \& Prat, R. (Eds.), 2005, Barcelona: bActar.

This series of diagrams illustrates the project's initial process of development, which provides the basic organising principles and form for the building, which emerges out of a relatively literal translation of diagram into built form.

\section{Diagram Methodology}

Undertake research aimed at understanding the situation of the project. Identify 
problems, aims and possible organising strategies for the project and visualise these strategies through diagrams

I. Visualise the programme of the project

II. Identify functional groupings of the programme according to the project's organising strategies - differentiate between the functional groupings using an abstract diagrammatic operation

III. Scale the functional groupings and transpose them to site, relating them according to the previous diagrammatic operation

IV. Organise the specific locations of the functional groupings according to pragmatic requirements and outside influences of the project

This process generates the basic organising principles and form for the building which is subject to further development as other design parameters influence the project

\section{Relationship to Urban Design Principles}

Although clearly distinct from its urban surroundings, the Seattle public library features an unconventional level of integration with its public urban surroundings, beginning with a pedestrian thoroughfare through the building and generous public lobby which work together to create a more permeable building edge. The interior of the building, whose programmatic compartments are stacked up and offset as though pushed by some geological force, feature qualities of landscapes. The compartmental offsets create continuous interiors which spiral up through the building, allowing physical and especially visual connections between the layers of the building [Figure 3.46]. This continuous interior acts as a continuation of the building's urban surroundings, which are stacked and spiralled up into 'labyrinthine caves' (Betsky, 2002, p. 143). Although this strategy does not strive to generate ambiguity between the building's inside and outside, it does encourage ambiguity between what is typically read as public (external space), and private (internal space). The city's urban order is seemingly continued into the building's interior and up through its levels, generating a prolonged sense of urbanity [Figure 3.47].

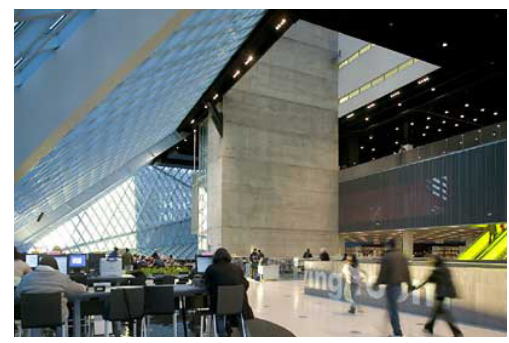

Figure 3.46. Seattle Public Library continutous interior

(n.d.). Retrieved January 26, 2012, from http://pcj.typepad.com/planning_commissioners_jo/2008/05/ downtown-librar.html

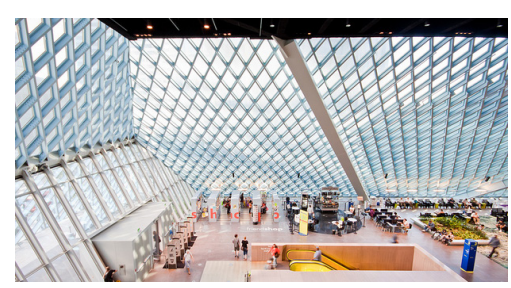

Figure 3.47. Seattle Public Library 'urban' interior

Norsworthy, S. (Photographer). (2011). Retrieved January 26, 2012, from http://www.flickr.com/photos/ scottnorsworthy/6490546513/. 


\section{Case Studies | Discussion}

\section{Diagram Type Summary}

Following the practice and case studies it is clear that the four key practices each utilise diagrams in a variety of ways as part of their design methodologies. By examining the ways diagrams are used by these practices, it is possible to identify a range of diagram types, which are classified based on the information they contain relevant to specific aspects of the design development. Many of the diagram types are common amongst several of the practices. The following is a summary of diagram types which can be identified in the studies.

\section{Analysis Diagram:}

This type of diagram is a relatively conventional tool used to visualise the quantifiable programmatic information of a project. Analytical in nature, these diagrams do not generate the form of the building, but often make visible the architectural problem and can help to construct parameters for the project.
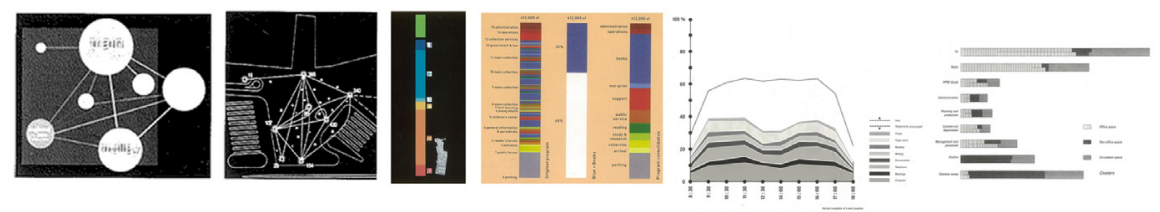

Figure 3.48. Examples of analysis diagrams identified in case studies

Adapted from previously referenced images

Datascape Diagram:

This type of diagram makes visible the quantifiable forces that influence the project, particularly the massing of the building, illustrating simultaneously the constraints and outer limits of the project. It can also illustrate the effects of the forces on the building rather than the forces themselves. This type of diagram is sometimes very literally translated into built form as the diagram is loaded with programme. 

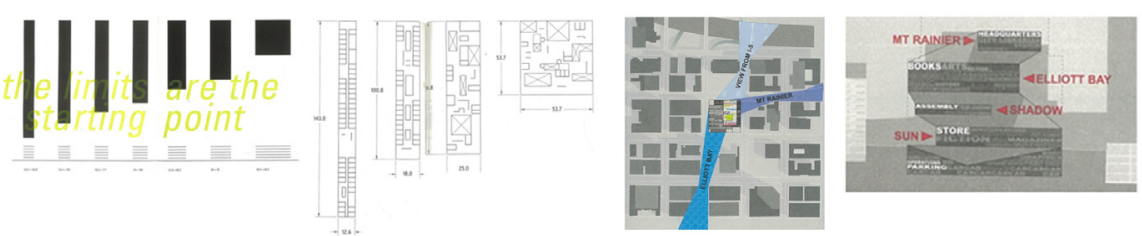

Figure 3.49. Examples of datascape diagrams identified in case studies

Adapted from previously referenced images

Organisational Diagram:

This type of diagram is widely used in conventional practice to visualise the organising principles of a project. It is not typically concerned with the generation of form but rather communicates the strategies for programmatic organisation and circulation in a project.
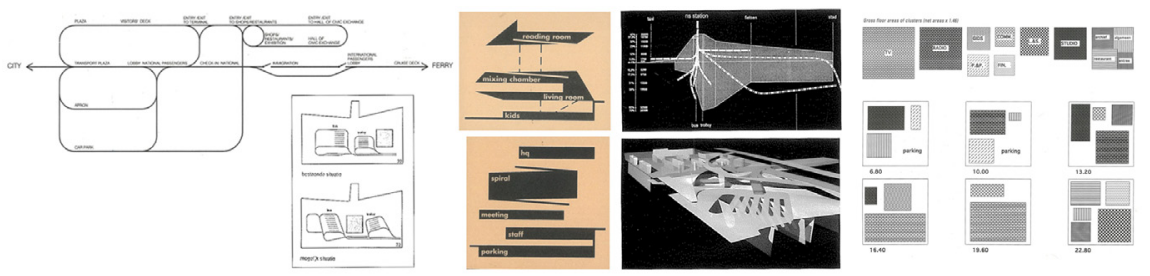

Figure 3.50. Examples of organisational diagrams identified in case studies

Adapted from previously referenced images

Operational Diagram:

This type of diagram communicates the operational strategies of the project - the strategies for materialising the project's organisation, translating it into physical terms which begin to influence the form of the building. This type of diagram often closely relates to an organisational diagram.
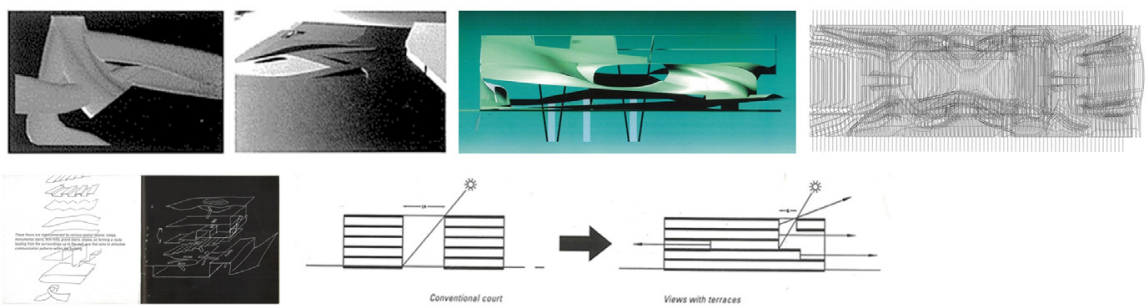

Figure 3.51. Examples of operational diagrams identified in case studies

Adapted from previously referenced images

Conceptual Diagram:

This type of diagram is used to visually condense the information of a project into one central concept and track developments throughout the design process. This type of diagram is widely used in conventional practice and is focused towards communicating a concept which will influence formal and organisation principles for a project but does not directly generate them. 

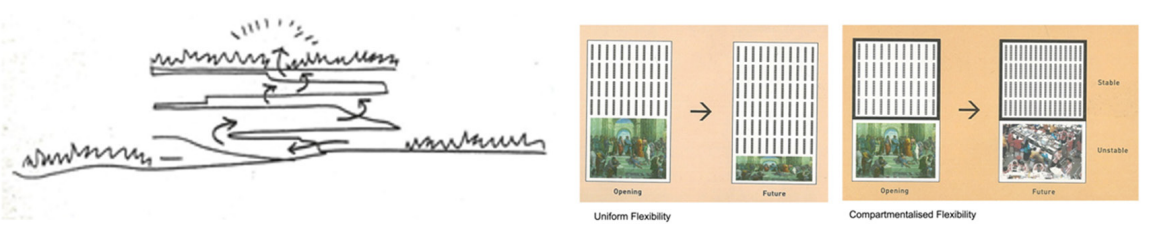

Figure 3.52. Examples of conceptual diagrams identified in case studies

Adapted from previously referenced images

\section{Abstract Diagram:}

This type of diagram is highly abstract and is instrumentalised to generate new ideas for possible organisations for a project. It can be translated to architecture in many different ways for example as construction, landscape, routing, or spatiality. The diagram itself is less important than the manner in which it is instrumentalised.

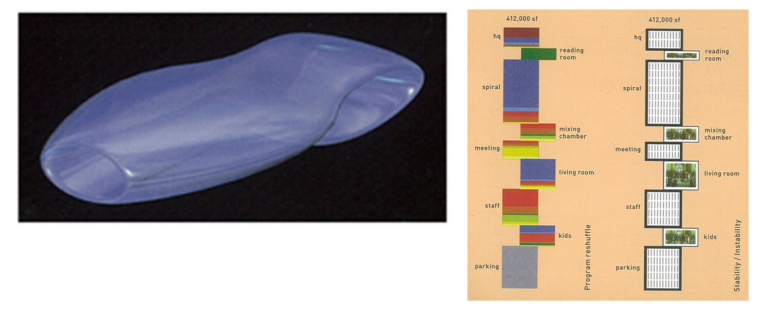

Figure 3.53. Examples of abstract diagrams identified in case studies

Adapted from previously referenced images

\section{Diagram Use Summary}

The previous section proposed a system of classifying the diagrams featured in the case studies based on the information they contain and the way they are utilised in the design process. Further examination of the ways in which the different types of diagrams are used is necessary to determine the areas of different or unconventional diagram use in the design process, especially as many of the case studies feature diagrams which are commonplace in conventional practice, such as organisational and conceptual diagrams.

Figure 3.54 identifies the types of diagrams used to generate various aspects of each project, which are identified in the UTILISATION column. These aspects are arranged from those of the broadest to scope to those of the narrowest. Visualising Problem provides an understanding of the project's situation and challenges and identifies the architectural problem; Visualising Concept communicates at a conceptual level a response to the project's problem; Building Massing/Form is the determination of the project's massing on site; Programmatic Organisation is the determination of how the project's programmatic elements are organised and related to one another; Spatialisation is the making physical of the project's organisation into three-demensional space and the architectural strategies used to accomplish this. 


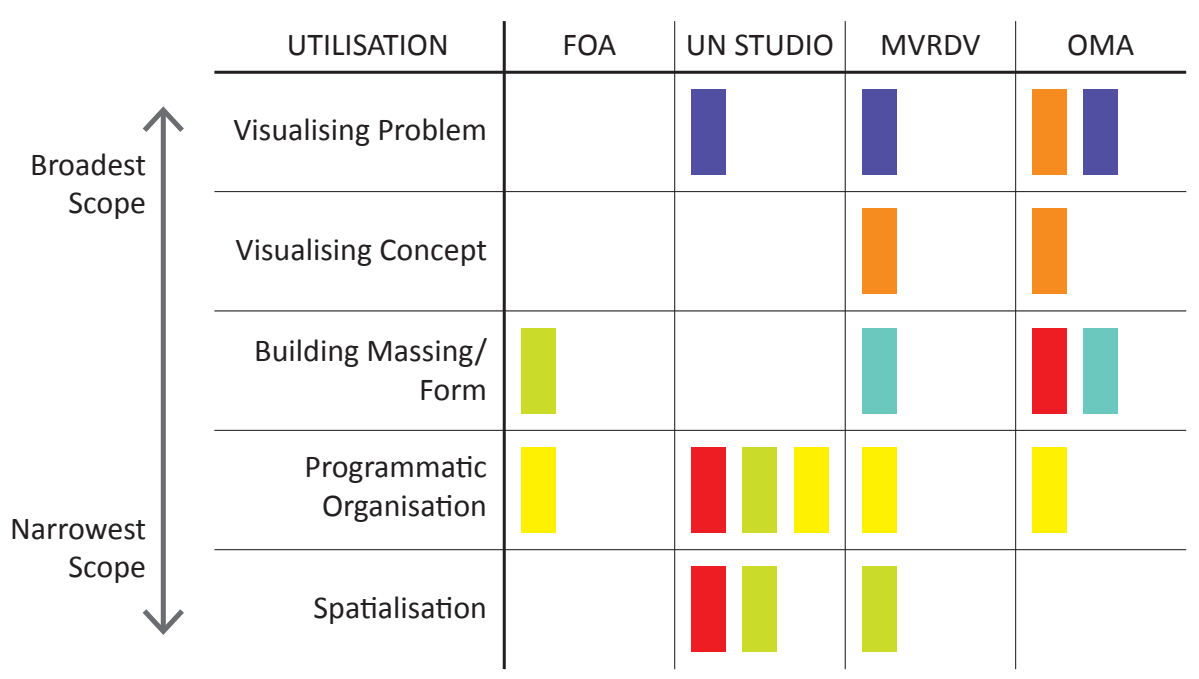

Figure 3.54. Diagram use comparison between the different practices

\section{Unconventional Diagram Use}

Figure 3.55 identifies the areas of unconventional diagram use in the four case studies, each of which will be further examined below.

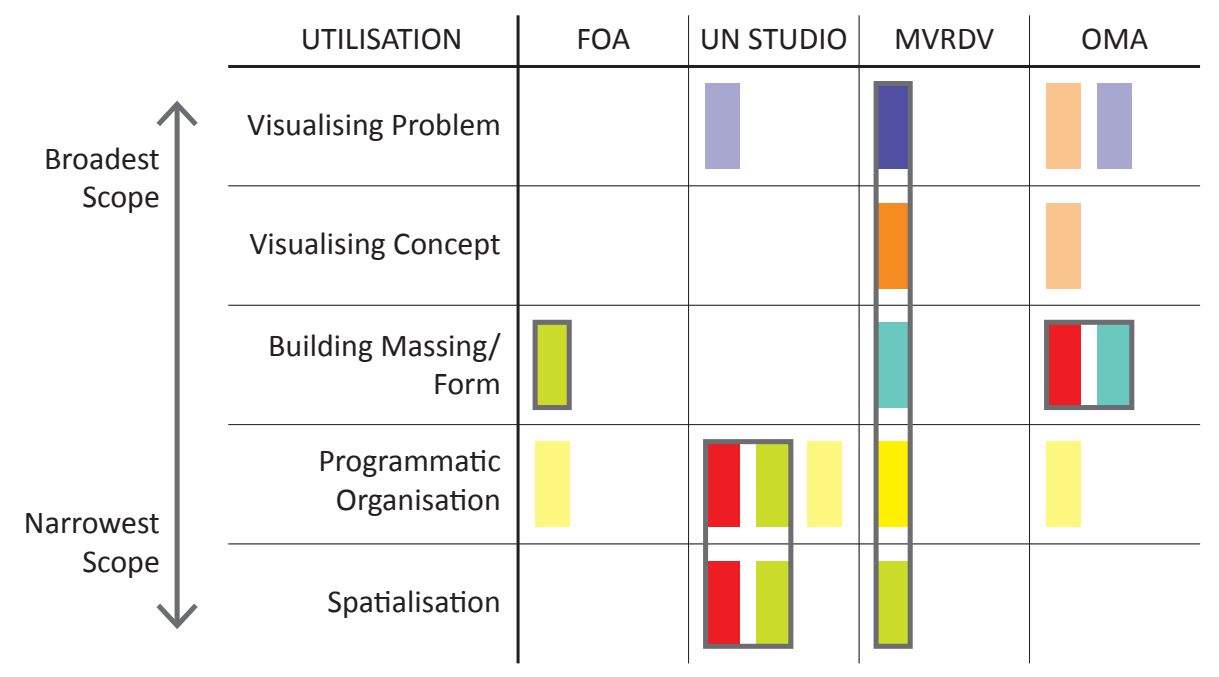

Figure 3.55. Areas of unconventional diagram use

\section{Foreign Office Architects:}

The unconventional diagram use in this case study is based on the development of the organisational diagram into an operational diagram, which is used to generate the form of the building. The project begins with a circulation diagram which is a common tool in architectural practice. By applying surfaces to the circulation diagram and manipulating it in three dimensions, the diagram becomes operational and begins to encompass architectural strategies for materialising the building's organisation. This results in a building whose final form and organisation features an unusually close relationship to the circulation diagram which helped to generate it - the circulation diagram seems to be developed into architecture with minimal design input from the architects.

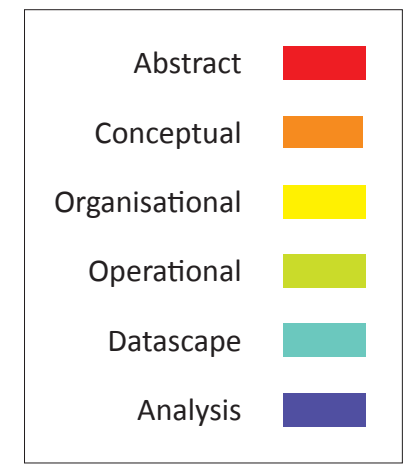

\begin{tabular}{|r|}
\hline Abstract \\
Conceptual \\
Organisational \\
Operational \\
Datascape \\
Analysis \\
Unconventional Use \\
\hline
\end{tabular}




\section{UN Studio:}

The unconventional diagram use in this case study is the development of the organisational diagram into an operational diagram using two diagrammatic languages (cones, single surface), each of which influence the architecture in different ways. The project's operational diagrams are related using an abstract diagram, which further influences the organisation and spatialisation of the project. Unusually, the abstract diagram is sourced from outside the project and is used to trigger new possibilities on many levels: structurally, spatially, organisationally and conceptually. The project seems to emerge from an accumulative process of diagramming; first visualising the problem, then generating organisation in two and then three dimensions, next exploring various operational strategies, and lastly relating these strategies with an abstract diagram.

\section{MVRDV:}

In this case study, many of the wide range of diagrams used to visualise the various aspects of the project are utilised in relatively conventional ways. Individually, the most unconventional diagram use was determining the building's massing using a datascape, but what is more interesting is the unconventional ways the various diagrams relate to one another as they come together to generate the project. No one diagram describes the building's form; instead the building emerges as a negotiation of the different diagrams, which are often transposed quite literally and with seemingly minimal designer input into built form. The integrity of the project's diagrams are maintained and carried through into built form.

\section{OMA:}

The unconventional diagram use in this case study was using an abstract diagram in combination with a datascape diagram to generate the form of the building. The use of this abstract diagram illustrates the importance of how this diagram type is instrumentalised, rather than what it looks like. The abstract and seemingly arbitrary diagrammatic operation of 'pushing out' programmatic compartments is instrumentalised to generate the building's massing. The specific offsets are determined by requirements for sunlight, shade and views, and are justified by the logic of the building's internal programme and its relationship to the site. This project features an unusually literal transposition from diagram into built form, with the building retaining many of the qualities of the diagrams used to generate it.

\section{Common Unconventional Diagram Use}

Through closer examination of the four case studies, areas of common unconventional diagram use can be identified between the practices. These 
common areas are identified in the following table.

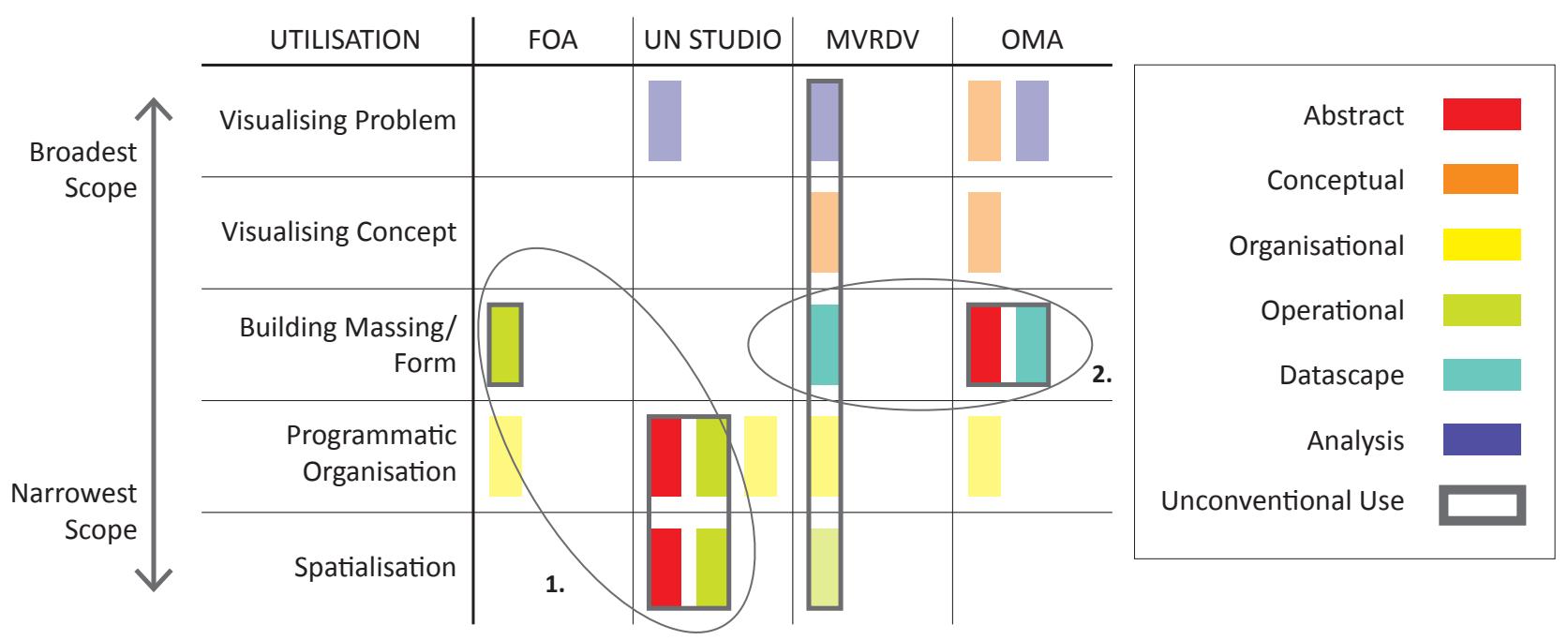

Figure 3.56. Areas of common unconventional diagram use

\section{Foreign Office Architects and UN Studio:}

Common between the case studies of these two practices is an unconventional relationship between the projects' organisational and operational diagrams. Organisational diagrams are not typically concerned with the generation of form; rather, they are abstract representations of the organising principles of a project, used to better understand the relationships between the different actors. They are typically visualised in terms of lines (one dimension) or blocks (two dimensions), and possess no spatial correlation.

In these two case studies, the final buildings share unusually close relationships to their organisational diagrams. Rather than retaining the virtual and abstract qualities typical of this diagram type, these practices instrumentalise the diagrams by applying surfaces to the usually abstract lines, thereby spatialising the diagrams into three dimensional entities and making them operational. As the diagrams are made operational they develop architectural qualities which help to generate the form and spatial qualities of the building.

The close relationship between the organisational diagram which is developed into an operational diagram which generates formal and spatial outcomes is what makes this type of practice unconventional. The role of the designer appears limited or designer input is at least delayed for as long as possible in the design process, which is instead governed by the seemingly pure logic of the materialised organisational diagram.

This type of diagrammatic practice can be summarised as:

- Prioritising organisation

- Translation and materialisation of an abstract ideal

- Instrumentalising, proliferating, projective 
For the purposes of this research, this type of diagrammatic practice is termed Abstract/Instrumentalising, based on its abstract organisational foundation which is instrumentalised to generate the building's form.

\section{MVRDV and OMA:}

Common between the case studies of these two practices is the use of quantified data which is visualised into a datascape diagram to help generate the form of the building. Datascapes are visual representations of the quantifiable forces that influence a project. These forces provide the limits of the project in more conventional architectural practice, however in the case studies the built form shares an unusually close relationship to its datascape, as if directly shaped by its forces. The built form could be considered as a diagram of the forces which helped to shape it.

The design emerges as a negotiation between the different constraints and opportunities of the project as they interact with other conceptual and diagrammatic influences. The diagrams driving the project are translated quite literally into built form - the buildings resemble the diagrams which generated them and begin to take on some of their qualities. The generation of the building's massing and form appears to be given over to the logic of the diagrams and the data they embody, reducing the role of the designer in the project's initial design stages.

This type of diagrammatic practice can be summarised as:

- Focused on the invisible forces which influence form and massing

- Literal translation of diagram into built form- focused on the invisible forces which influence form and massing

- Research, data, and analytically focused

For the purposes of this research, this type of diagrammatic practice is termed Analytic/Literal, based on the analytic and data focused nature of its diagrams and the literal translation of these into built form.

The identification of the two different types of diagrammatic design practice Abstract/Instrumentalising and Analytic/Literal - has implications for the design phase of the research. Because of their different methodologies it is likely that each type of practice has different implications for the project's urban design outcomes and the relationships generated between built form and open space. A closer examination of each type of practice is required to draw conclusions for the research, which will be undertaken as part of a speculative design project in the Design Execution chapter. 


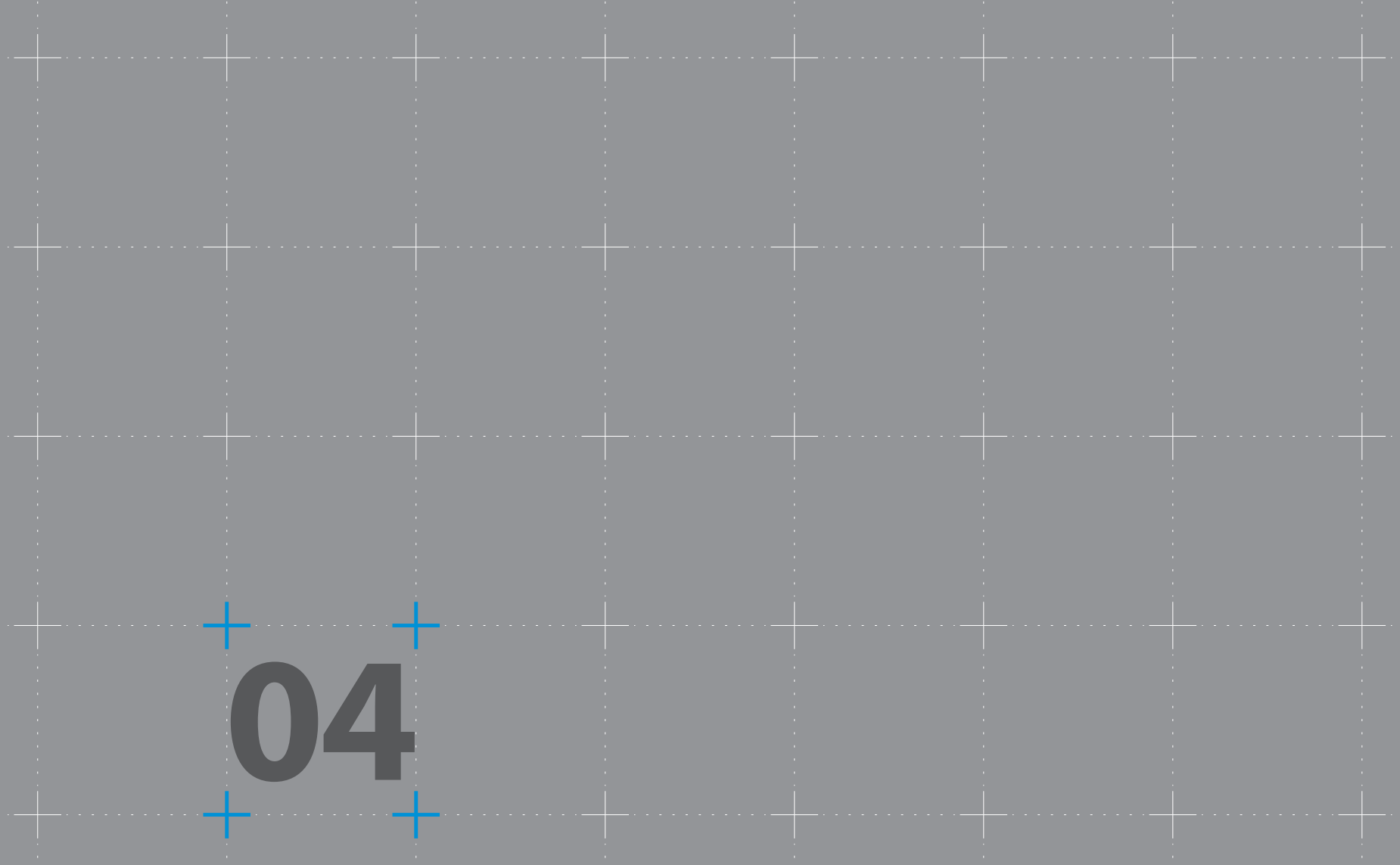
Pre-Design
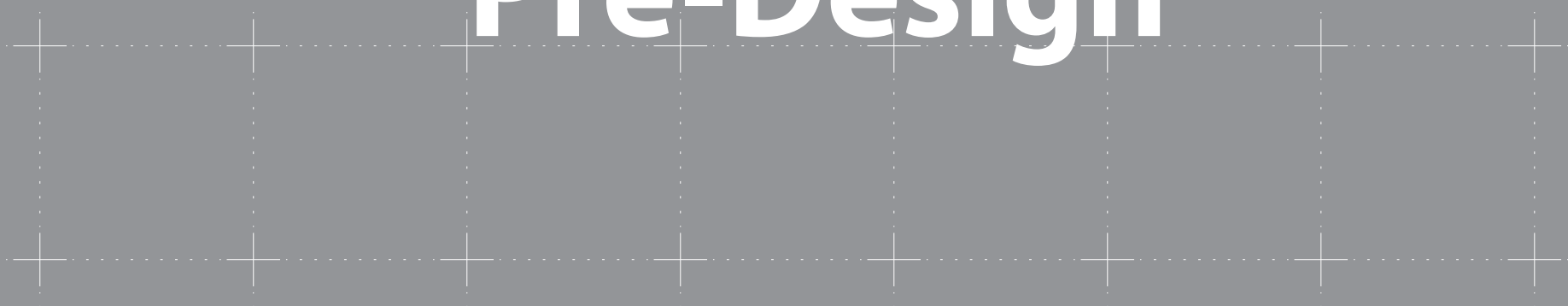

$+$
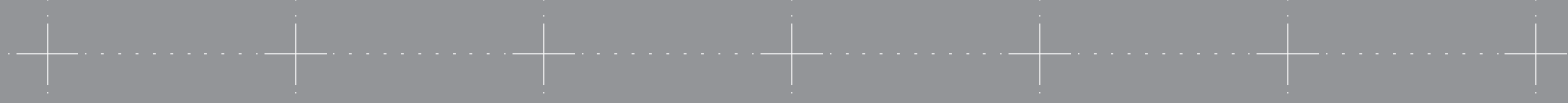

$+$
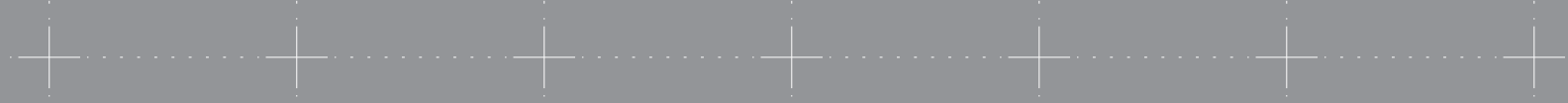

$+$
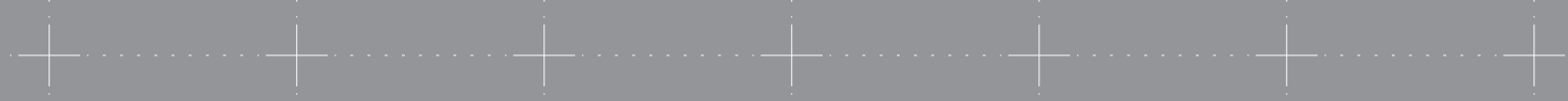

$+$
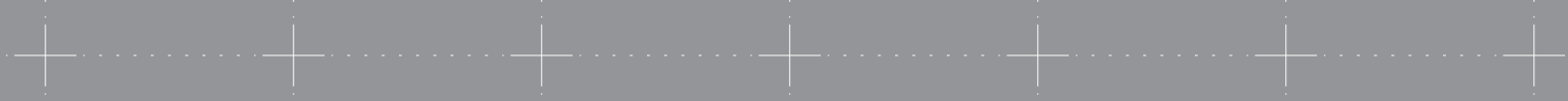


\section{Pre-Design | Introduction}

\section{Design Testing}

The previous chapter described the two different types of diagrammatic practice identified in the case studies section. A design methodology based on each of the two types of diagrammatic practice will be executed in the design phase. This will test each of the two types of diagrammatic practice and will provide a better understanding of each of the design processes, allowing conclusions for the research to be drawn based on both research and design experience.

Each type of diagrammatic design methodology will be executed to generate two proposals for the basic organisation and massing for the project, as it is at these larger scales of organisation and massing (rather than small scale detailed design) that unconventional building/open space relationships are generated. Each of the proposals will be developed to a stage where they can be roughly visualised and analysed in context, allowing areas of unconventional building/ open space relationships to be identified. With a focus on organisation and massing, this research does not seek to develop each proposal into a fully resolved design.

\section{Design Background}

The brief for the design phase is for a mixed-use development in Te Aro, Wellington. The site is located in the wedge shape created between Manners Street, Dixon Street and Cuba Mall. The Oaks, a low quality two-storey retail complex currently occupies the Western end of the site, and the poorly used Te Aro Park currently exists on the Eastern end. The original design for the retail complex featured a two storey atrium space down the centre of the building, connecting Cuba Mall with Te Aro park. The atrium has since failed as a retail space and has been enclosed by shops, isolating the retail areas in the upper floor of the building. The existing Te Aro Park is of poor urban quality and is bounded by roads along its two longest sides, isolating it from adjacent pedestrian movement. The park also suffers from isolation from the leisure node of Cuba Mall.

In their current condition and configuration, neither the Oaks retail complex nor Te Aro park are highly successful in terms of their urban design value. 
Wellington 2040, Wellington City Council's recent urban design framework proposes the demolition of the Oaks retail complex and the creation of a large public park covering the entire site including Cuba Mall. Existing on Wellington's 'Golden Mile,' the site possesses the potential for more intensive development than what is proposed, and so the design project will present an alternative to the Wellington 2040 proposal, whilst still including the provision of quality public space.

\section{Design Brief}

The programme for the building is varied to reflect the mix of uses in the area surrounding the site, and consists of retail, office space and residential apartments. A covered market is also included in the programme which will benefit from proximity to the high pedestrian flows of the Golden Mile and will feed off of as well as contribute to the leisure and culture node of Wellington's Cuba Mall. The covered market will also provide a trade-off for any lost public open space at ground level, and will provide low-cost start-up opportunities for small retailers which will feed into the surrounding retail areas as businesses grow. The site is clearly identified as a suitable location for public space, so the project will explore the possibilities of combining public space with commercial developments. The project also seeks to enhance the cross-site pedestrian connection between Eva Street and Opera House Lane.

The hypothetical nature of the project affords the building a relatively flexible brief in terms of floor area requirements, allowing each design to develop with a high degree of freedom independent of strict design constraints typical in urban developments. This allows a more accurate analysis of the relationship between the project's methods of production and architectural output. The required programmed floor areas are outlined as follows:

Residential: $\quad 4000-5000 \mathrm{~m} 2$

Office: $\quad 3000-3500 \mathrm{~m} 2$

Commercial: $\quad 3000-3500 \mathrm{~m} 2$

Public open space: $\quad$ 2500-3000 m2

Covered market: $\quad$ 1000-1500 m2

The brief is designed to create the challenge of accommodating the $6,500+\mathrm{m} 2$ of public functions on the $3,400 \mathrm{~m} 2$ site. This creates the challenge of providing public inhabitation on several levels of the building, thereby encouraging a less conventional architectural outcome typical of the surrounding area. It is assumed the public functions (commercial, public space, covered market) will be located on the lower floors of the building. 


\section{Pre-Design | Site Analysis}

\section{Urban Context}
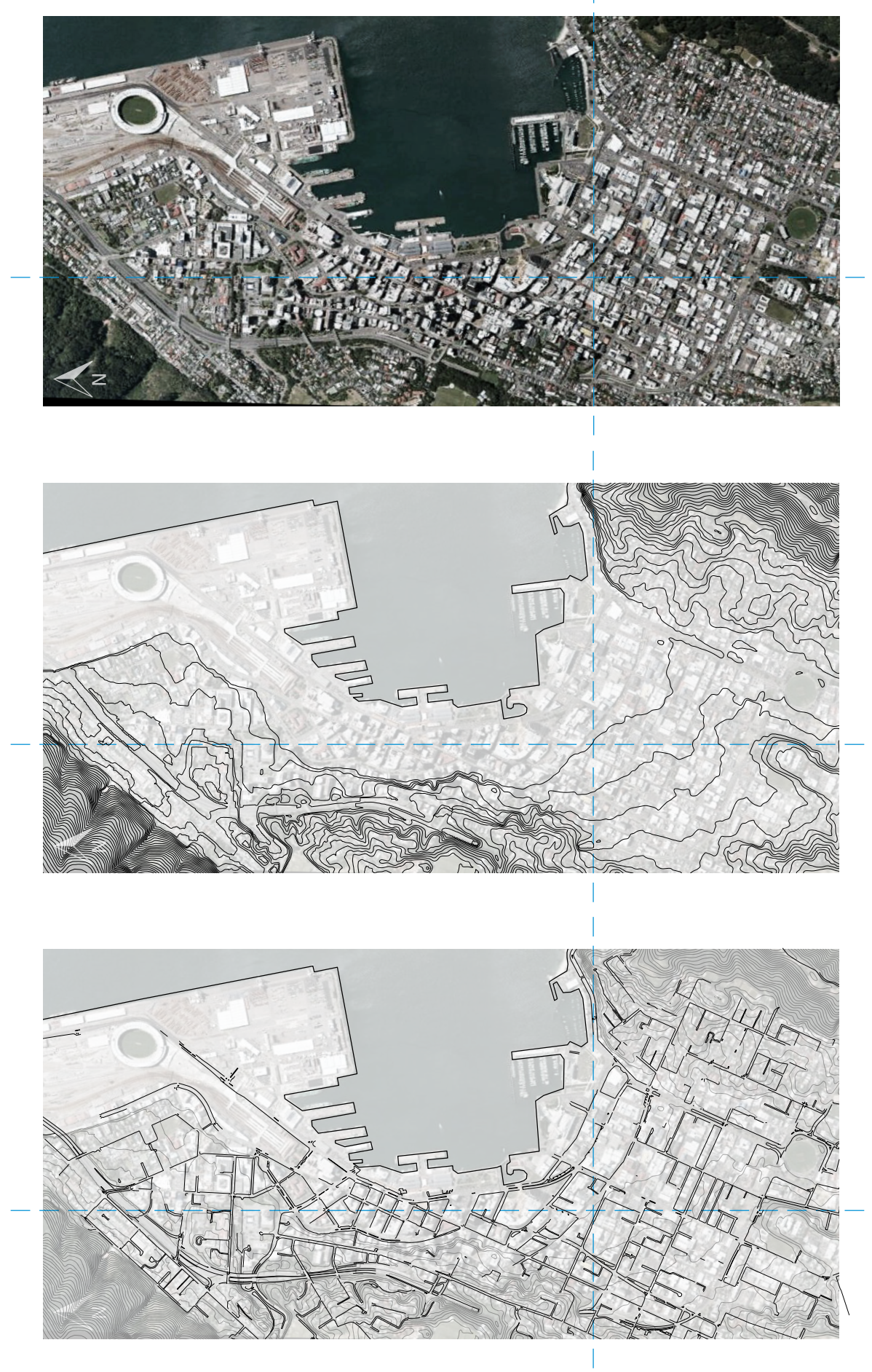
Figure 4.4. Wellington City building footprints

Adapted from Google Earth and \& Koordinates.com

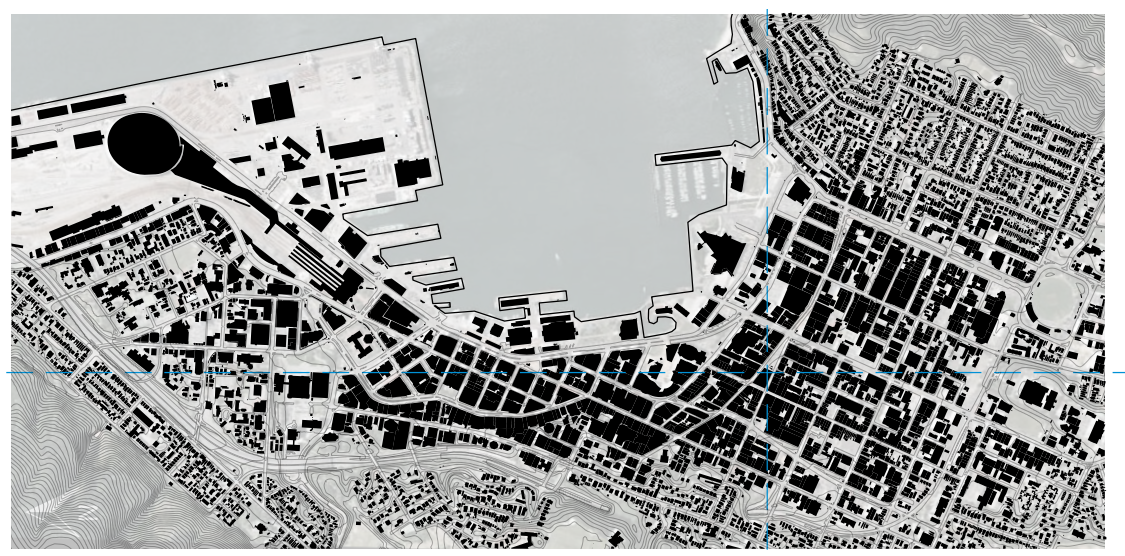

Figure 4.5. Wellington City districts

Adapted from Google Earth and \& Koordinates.com

Civic Centre

Cuba Street

Courtenay Place

Central Business District

Government

Thorndon

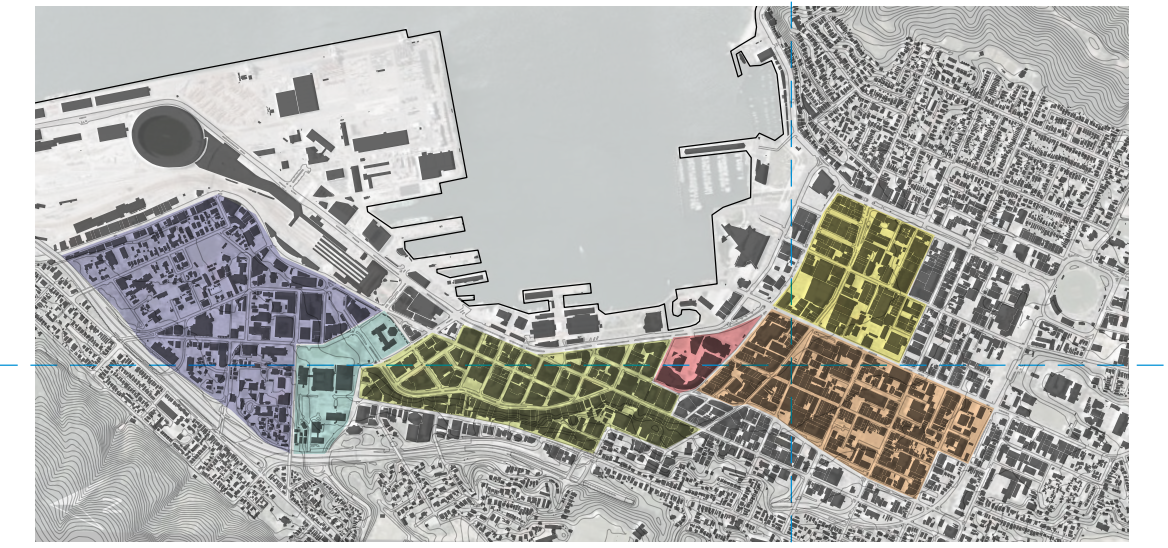

Site Context

Figure 4.6. Arial photograph of site and immediate surroundings

Adapted from Google Earth

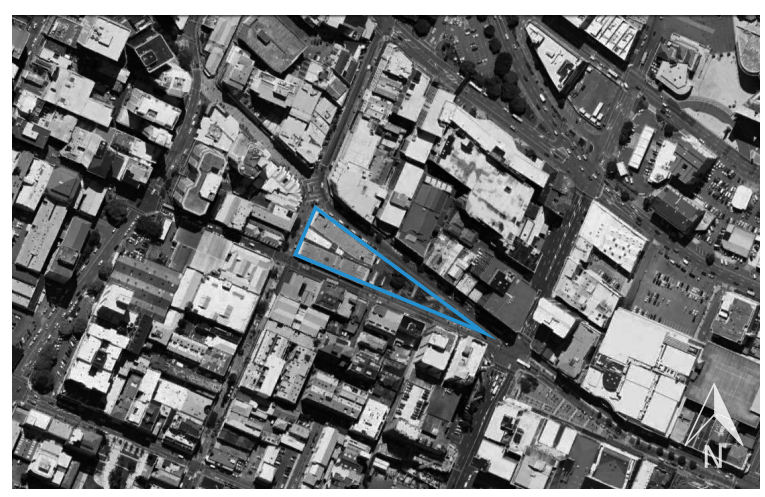

Figure 4.7. Figure-ground diagram showing surrounding building footprints and open space

Adapted from Koordinates.com

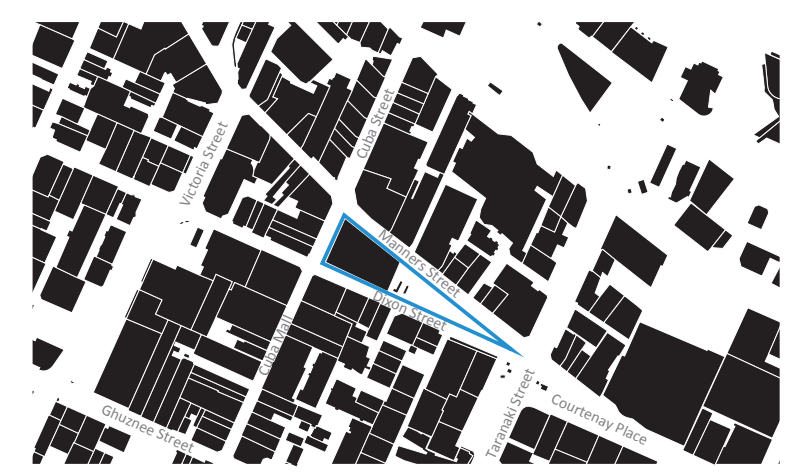



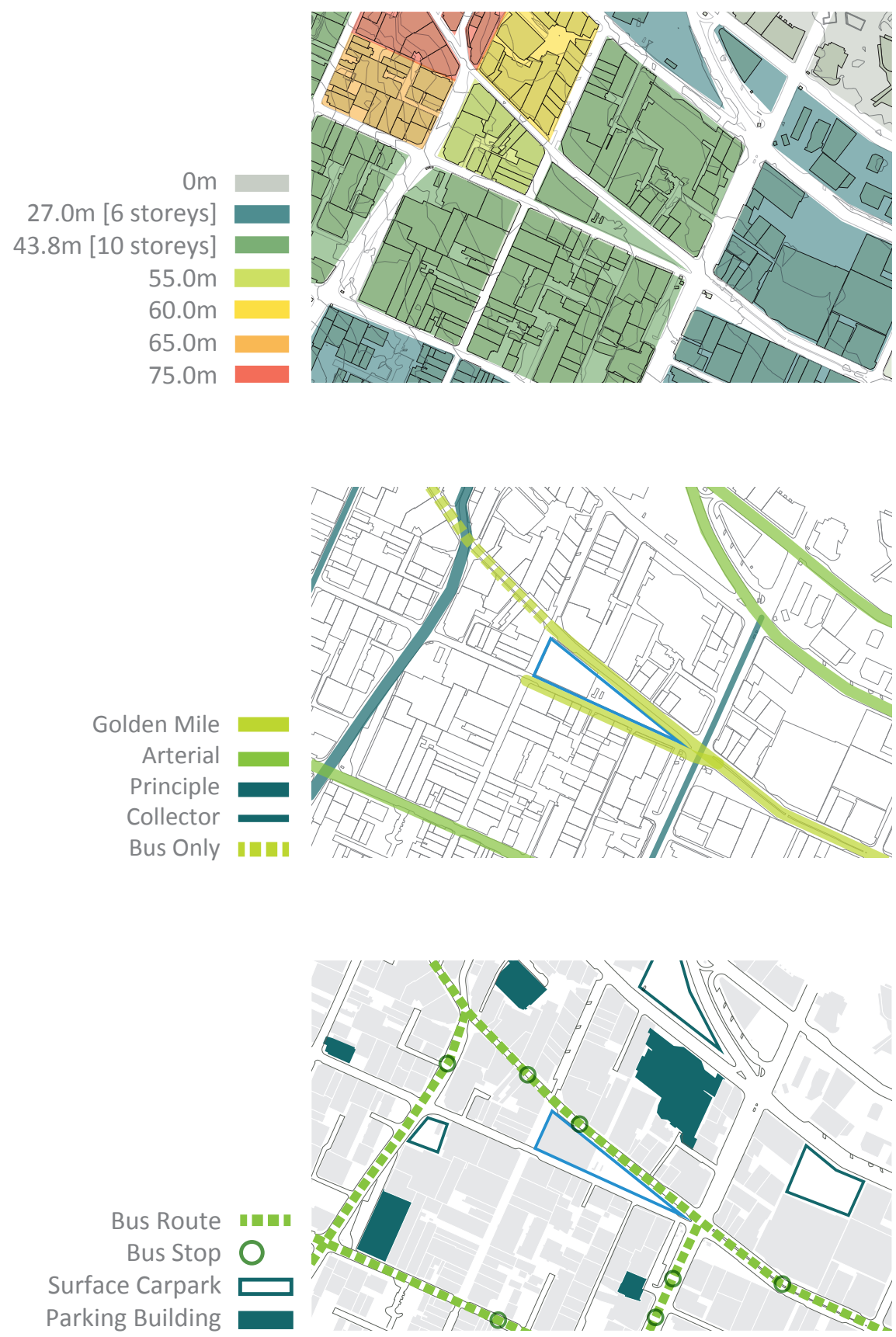

Golden Mile

Pedestrian Mall \#س Primary Pedestrian

Route

Pedestrian

Thoroughfare

Public Open Space

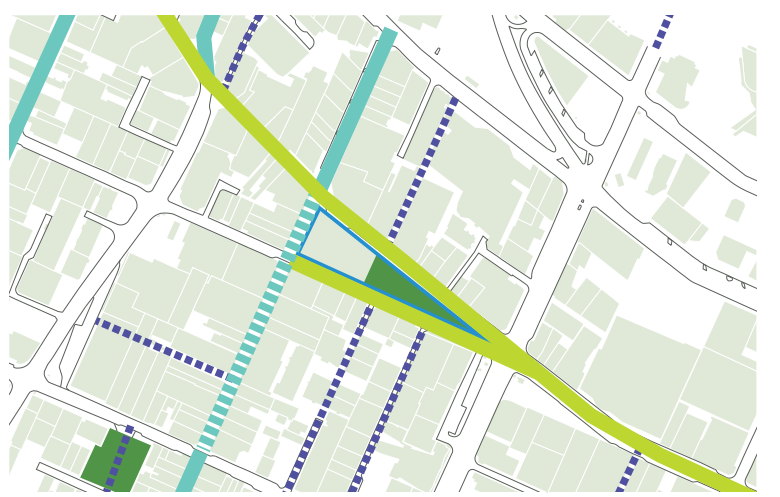

Figure 4.11. Pedestrian network. The site is located on Wellington's 'Golden Mile' - the primary pedestrian connection linking Courtenay Place with Lambton Quay. Adjacent to the site is pedestrian-only Cuba Mall. Pedestrian alleyways are located to the North and South of the site, providing shortcuts through the blocks. The design project has the opportunity to improve the cross-site connection between these pedestrian alleyways

Adapted from Koordinates.com 


\section{Site Photographs}

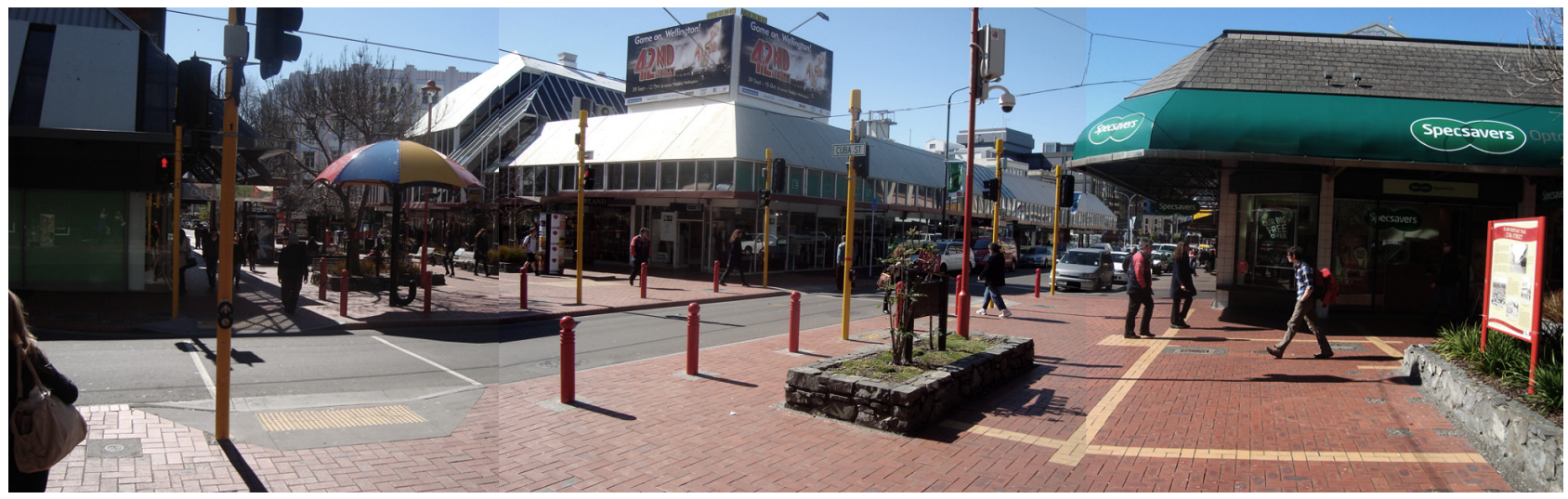

Figure 4.12. Photograph of site taken from corner of Dixon Street and Cuba Mall

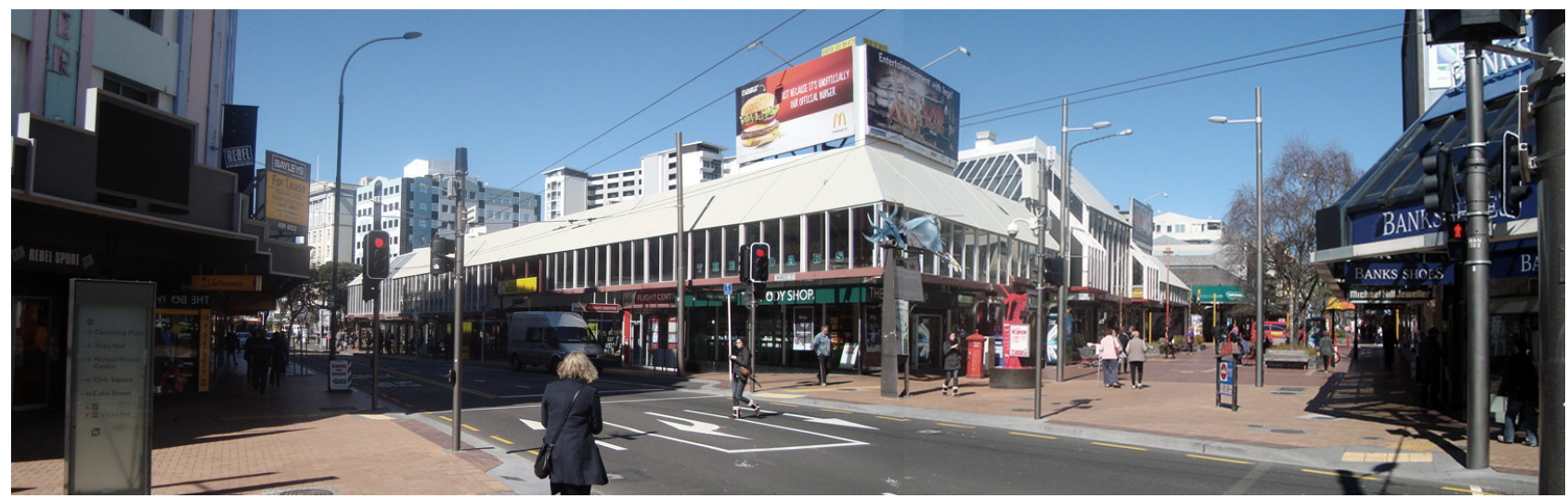

Figure 4.13. Photograph of site taken from corner of Manners Street and Cuba Mall

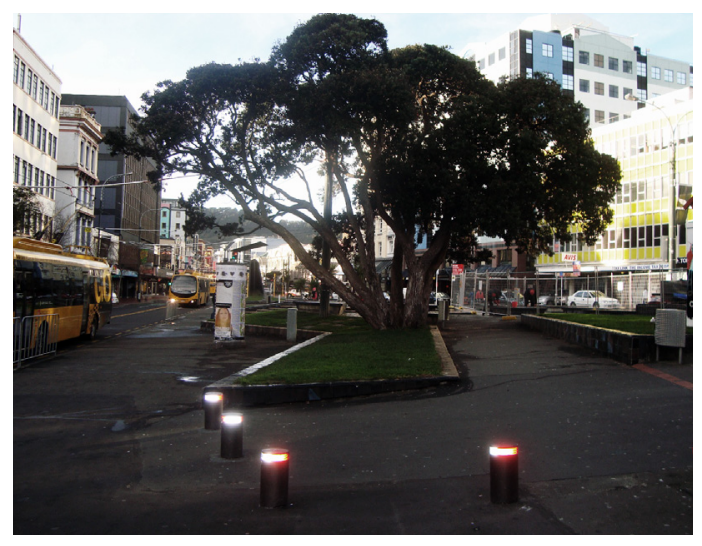

Figure 4.14. Photograph of Te Aro Park taken from Manners Street

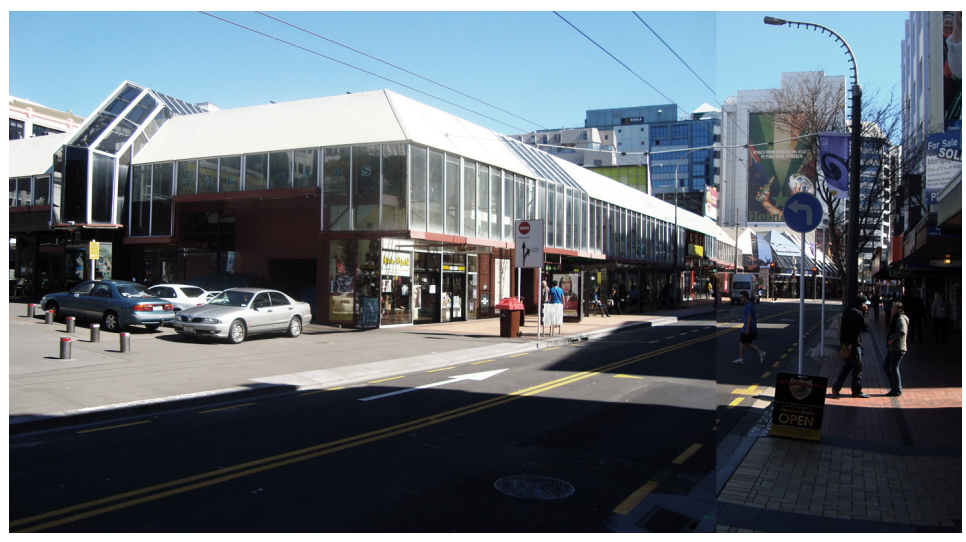

Figure 4.15. Photograph of The Oaks retail complex taken from Manners Street 


\section{Existing Building - The Oaks Retail Complex}

The site is currently occupied by The Oaks retail complex, designed by Warren and Mahoney in 1980. Originally constructed with a central atrium space allowing access to the building's upper level, this space proved unsuccessful and has since been enclosed by shops. The upper floors are now accessible via a narrow staircase from Cuba Mall. The building currently houses a mix of retail and hospitality functions, with the prime retail frontages existing towards the Cuba Mall end of the building. The remainder of the building houses typically lower tier retailers, with the exception of a popular second hand bookshop, a trendy cafe, a nightclub and a restaurant.

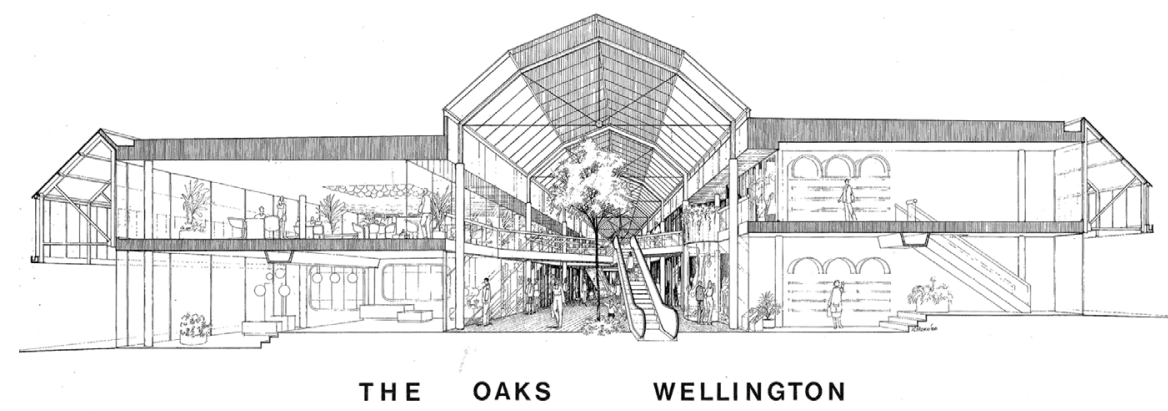

Figure 4.16. Sectional perspective of The Oaks retail complex as it was proposed in 1980. The central atrium space has since been enclosed.

From Wellington City Archives

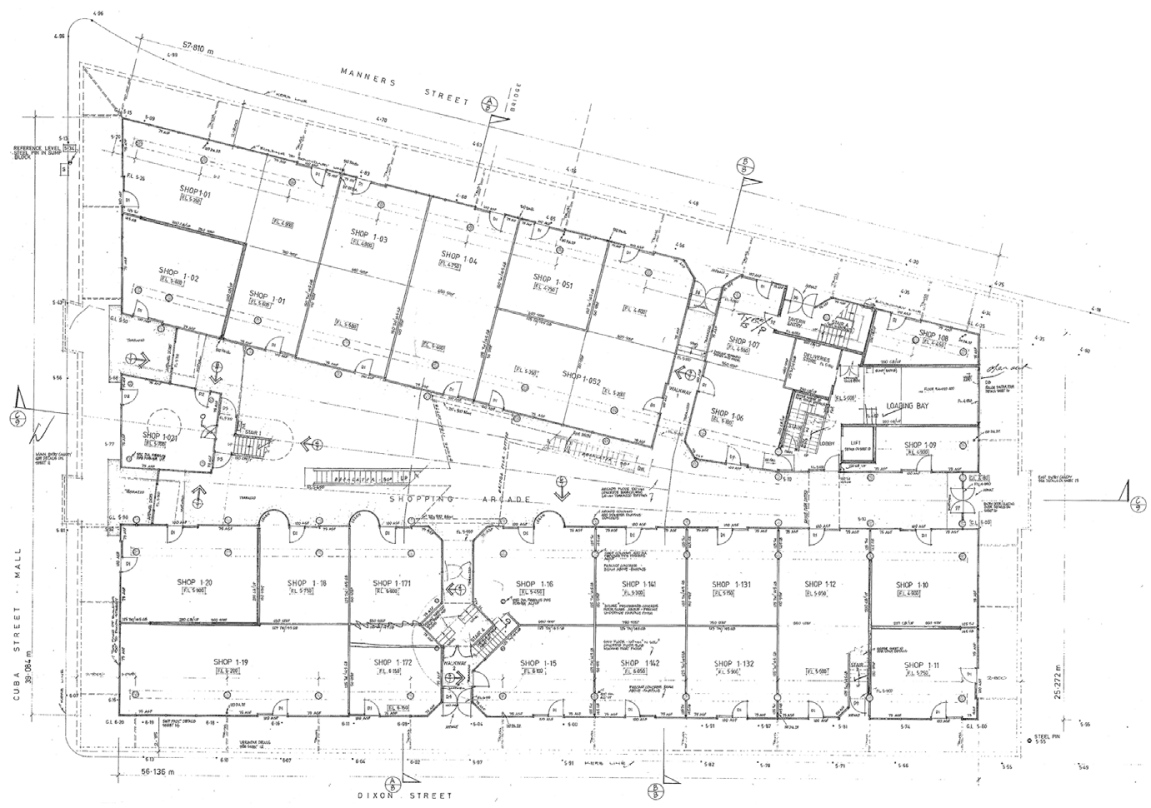

Figure 4.17. Ground floor plan of The Oaks retail complex as it was proposed in 1980.

From Wellington City Archives 


\section{Wellington 2040}

Wellington 2040 is the Wellington City Council's recent urban design framework which provides a vision for the city's future development. Featured in the framework are proposals for urban interventions which specifically impact on the site and its immediate surroundings. These proposals include the development of Wellington's existing laneways [Figure 4.18], and the demolition of the existing Oaks retail complex [Figure 4.20].

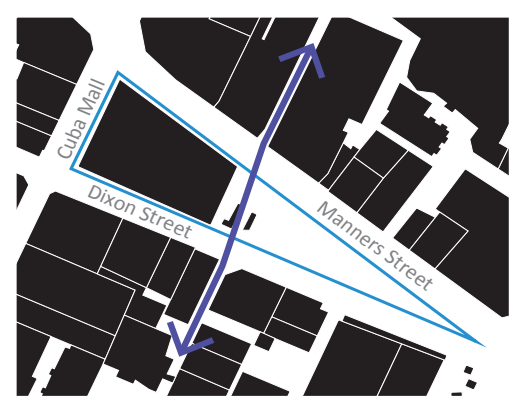

Figure 4.19. Diagram showing the opportunity to improve the cross-site connection between the two existing laneways of Eva Street (South) and Opera House Lane (North).

Adapted from Koordinates.com

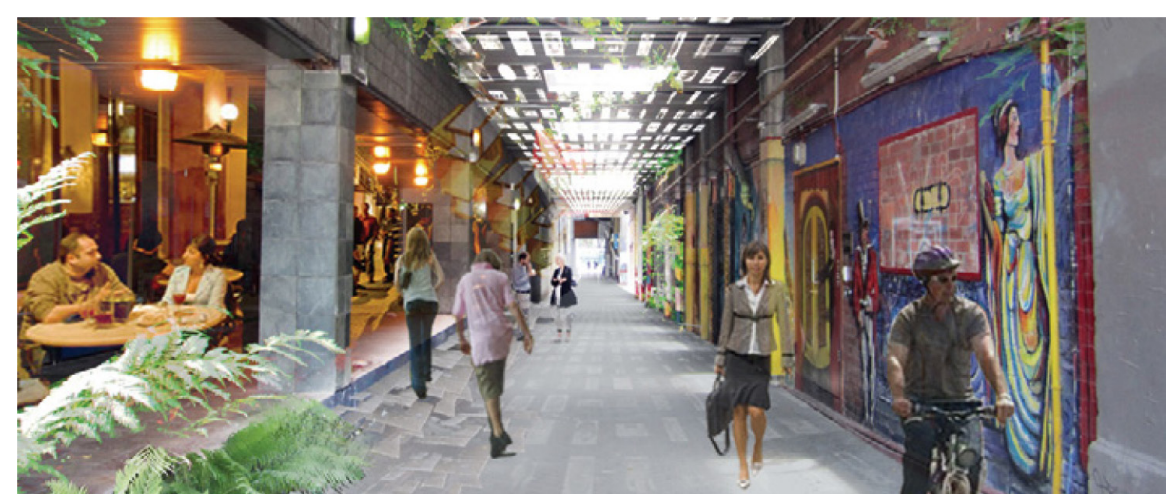

Figure 4.18. Wellington 2040 proposal for development of existing laneways into more attractive, destinctive and pedestrian-friendly environments. This image shows the proposed development of Opera House Lane, opposite the site

From WGTN2040: Reshaping Wellington's Future, Wellington City Council, 2011, Retrieved from http://www.wellington2040.co.nz/sites/default/files/attachments/WCC9663_ WN2040\%20Project\%20Single\%20Cards.pdf

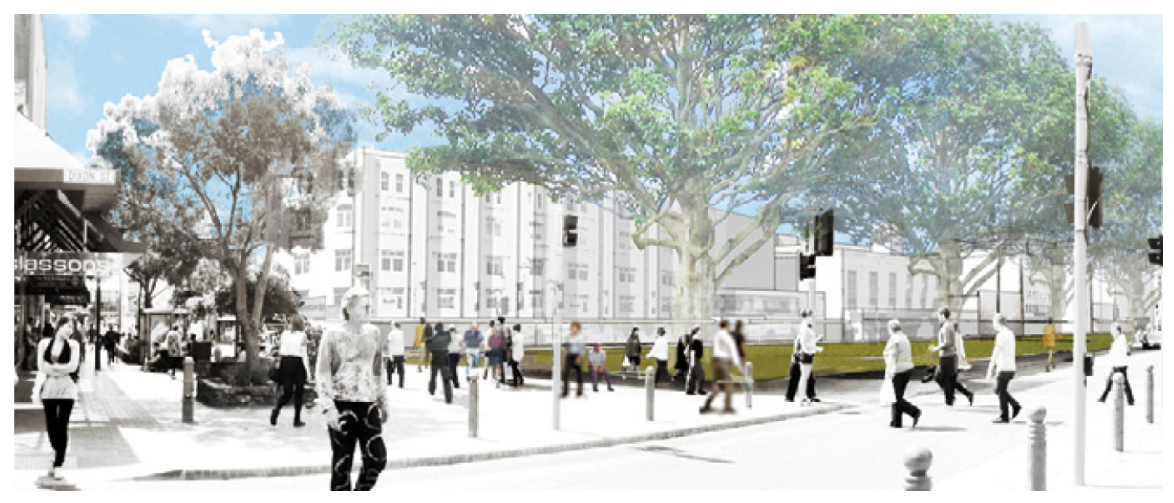

Figure 4.20. Wellington 2040 proposal for the demolition of the existing Oaks retail complex to be replaced by an urban park. This image shows the perspective from the corner of Dixon Street and Cuba Mall

From WGTN2040: Reshaping Wellington's Future, Wellington City Council, 2011, Retrieved from http://www.wellington2040.co.nz/sites/default/files/attachments/WCC9663_ WN2040\%20Project\%20Single\%20Cards.pdf 


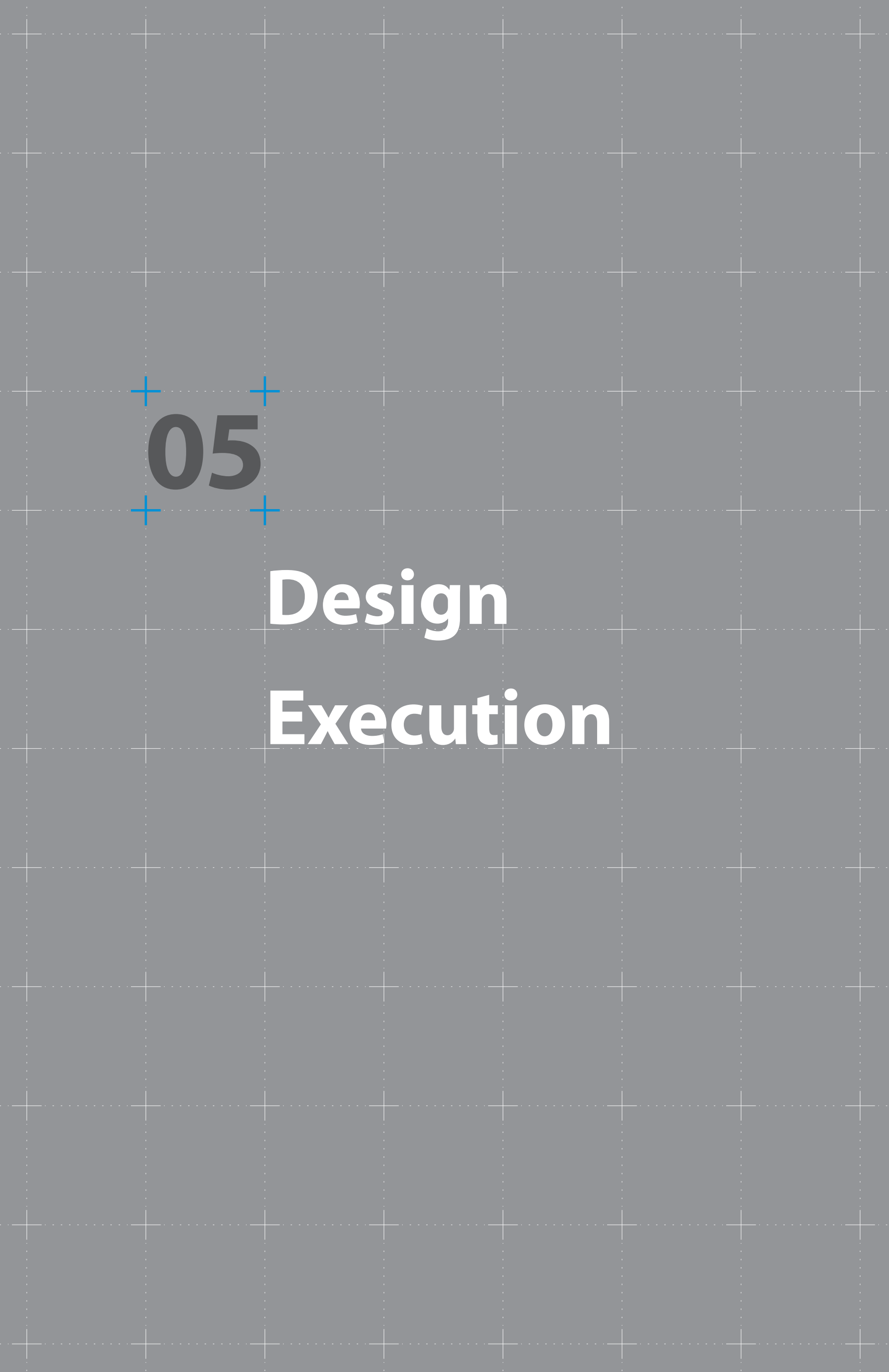




\section{Abstract/Instrumentalising | Design Execution}

\section{Introduction}

The first design methodology is based on the Abstract/Instrumentalising type of diagrammatic practice. The specific design methodology is modelled on Foreign Office Architects' design methodology which was identified in the case study of their Yokohama International Port Terminal project, and is paraphrased below:

I. Identify goals for circulation

II. Develop circulation diagram

III. Associate scaled surfaces with circulation diagram

IV. Manipulate the diagram in three dimensions, relating different surfaces to one another

This process generates a flexible form and organisation which is subject to further development.

The Yokohama project sought to generate form from an organisational diagram based on circulation which is of central importance to a transport infrastructural project, so forms a suitable basis for the project's development. The importance of circulation in a mixed-use urban development is less obvious, however due to the density of programme proposed for the site the necessity for public access beyond the ground floor becomes evident. The existing Oaks retail complex is constructed as a two-storey publically accessible building however the upper storey of this complex suffers from isolation from the street and has largely failed commercially. By developing a design proposal on the basis of circulation, a more successful connection between the elevated public levels and the street could be realised, resulting in a more successful elevated public realm. The pedestrian connection between Eva Street and Opera House Lane could also form a significant aspect of the design proposal by allowing more effective circulation across the site. 


\section{Design Execution}

\section{Identify goals for circulation:}

The goal for the project's circulation is to create the sense that the building is an extension to the public space of the street. It seeks to provide continuity, connection and orientation with the surrounding streetscape by promoting permeability and opposing the discrete stacking of volumes.

\section{Develop circulation diagram:}

A circulation diagram for the project is developed. This diagram uses pedestrian movement to relate the different programmatic elements with one another and with the adjacent streets. The diagram exists as an abstract organisation; the location of most programmatic elements are not defined apart from retail and the market entrance which are located adjacent to Manners and Dixon Streets.

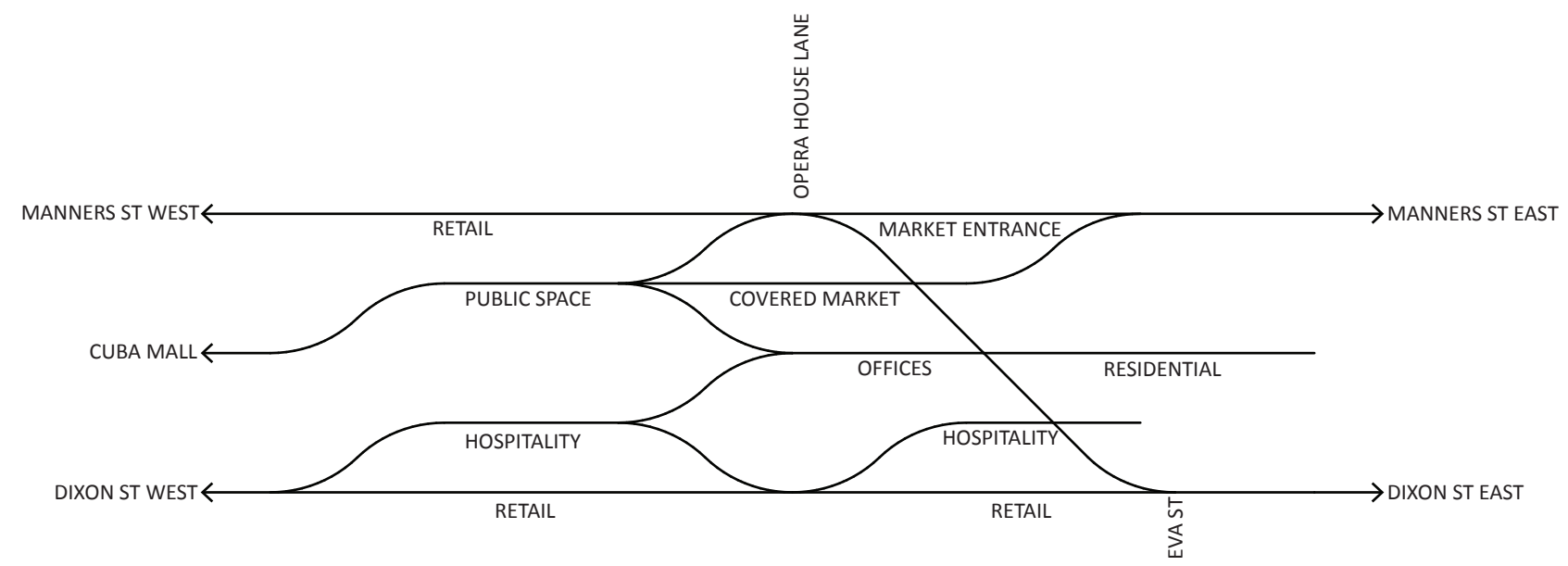

Figure 5.1. Circulation Diagram

For the design of the Yokohama project, Foreign Office Architects developed a circulation diagram based on a diagrammatic language of loops, which they titled the no-return diagram. The looped diagrammatic language related to their circulation goal to oppose the linearity typical of pier structures and create a building with multiple return paths, and also produced a relatively closed system suited to the geometry of a pier which is isolated and discrete. Early attempts to develop a circulation diagram for this project used a similar diagrammatic language of loops, however it soon became evident that this type of language did not lend itself well to an urban setting with multiple points of access. A more open diagrammatic language of waves was instead developed which was more conceptually consistent with the circulation goal of connection and continuity with the adjacent streets. The waved language of curves branching smoothly from the streets visually expresses the circulation goals. The relationship of the building's programmatic elements within the diagram is determined by desired programmatic adjacencies (e.g. access to public space from Cuba Mall) as well as other urban considerations. 
III. Associate scaled surfaces with circulation diagram:

Surfaces are associated with the circulation diagram. Each surface is a scaled representation of a the floor area required for a particular programme, and its width is based on the average width of the site.

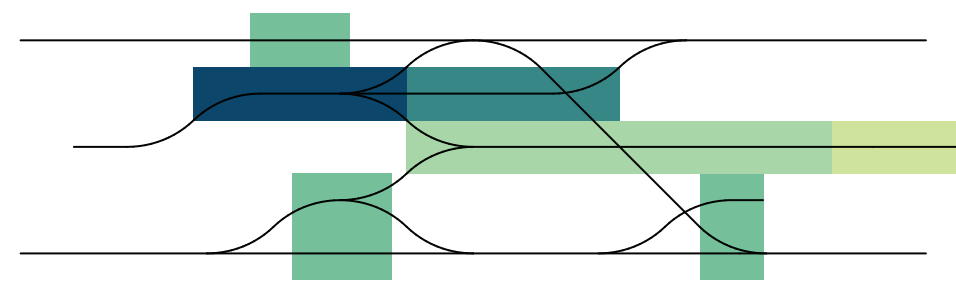

Figure 5.2. Scaled Surfaces Diagram

RESIDENTIAL

OFFICES

COMMERCIAL

[RETAIL + HOSPITALITY]

COVERED MARKET

PUBLIC SPACE

IV. Manipulate the diagram in three dimensions, relating different surfaces to one another:

The scaled surfaces diagram is manipulated in three dimensions, elevating certain programmes above the level of others. The abstract diagrammatic language of waves influences the development of the three dimensional formal language of the project. The project now exists as a three-dimensional organisation of layered programmatic elements whose associated surfaces begin to inform the operation of the project, as a series of ramps branching from street level.

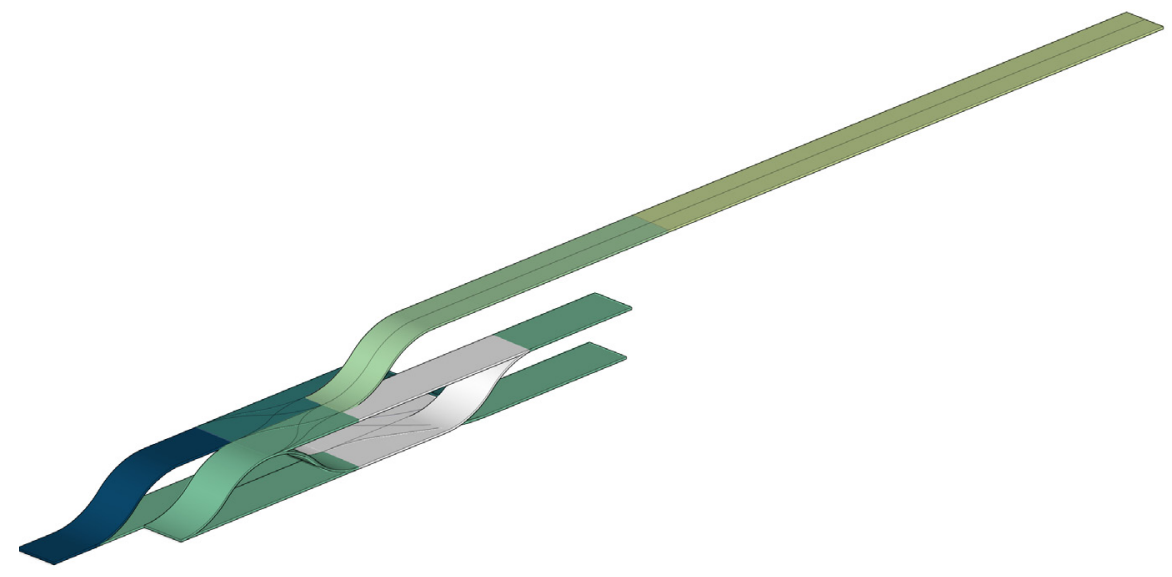

Figure 5.3. Three-dimensionally manipulated diagram

The previous diagram exists in abstract space outside the limits of the site. The following diagram represents the next phase of development where site constraints are introduced. The introduction of the physical boundary constraints results in the programmatic surfaces being squashed and stretched to fit within the limits of the site. Considerations concerning inhabitation are also introduced, which results in a reduced area of ramped surfaces. Urban considerations are also introduced to the organisation which influences the location of programmatic elements and circulation ramps. At this stage in the development the three-dimensional diagrammatic manipulations have little 
influence on the building's upper office and residential floors.

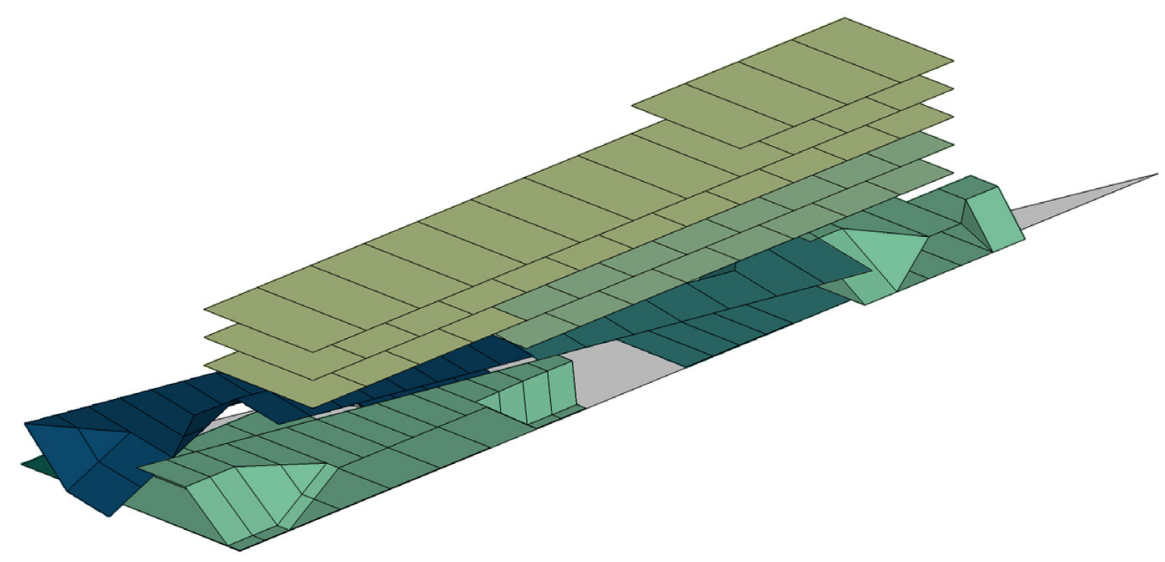

Figure 5.4. Three-dimensional diagram manipulated within site constraints

This process generates the basic form and organisation of the project, which is then developed by introducing architectural considerations such as construction, building regulations, and the relationship between the different programmatic elements. The desire to maximise sunlight exposure to the public space and Cuba Mall also influences the massing of the project.

\section{Resulting Form}
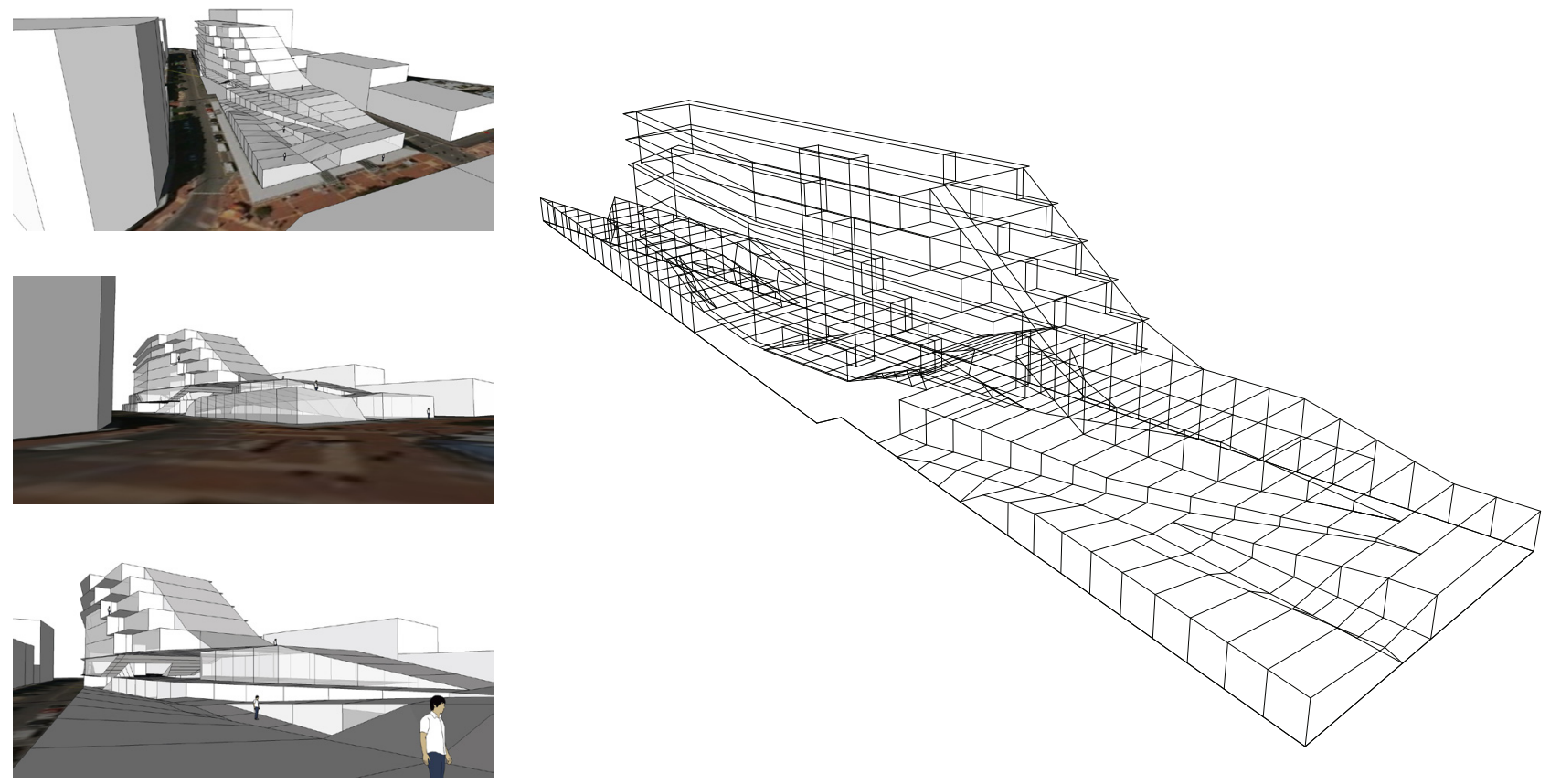

Figure 5.6. Resulting form visualised in context of surrounding building masses

Figure 5.5. Resulting form after first stage of development

The resulting form is taken through a relatively conventional process of design development requiring rapid design decisions to present the building in an architectural language encompassing construction and materials. This allows the design to be considered in its urban context and allows areas of unconventional building/open space relationships to be identified. 
Five | Design Execution 

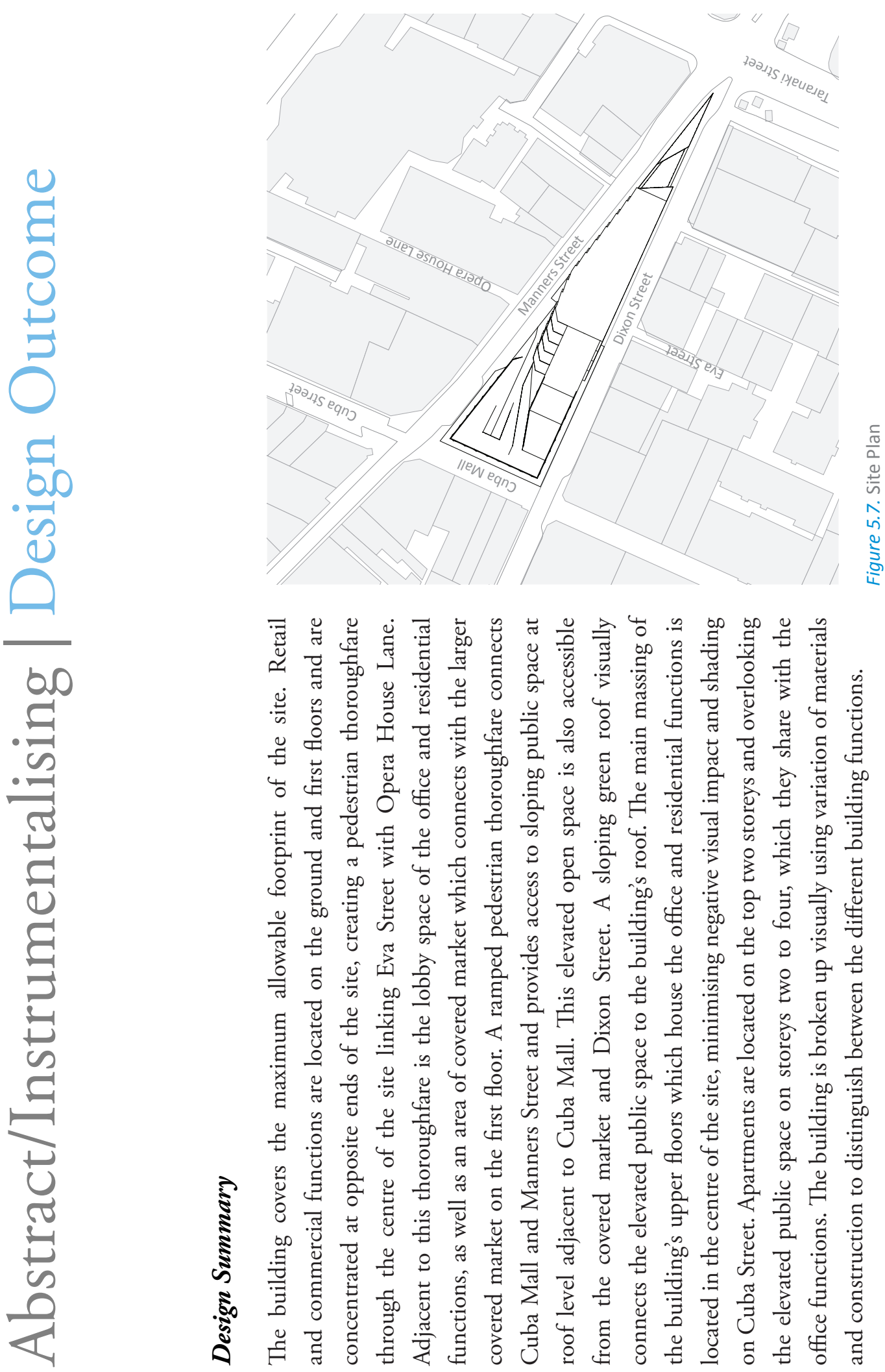

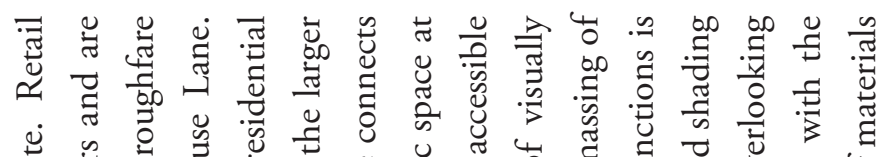
嵌

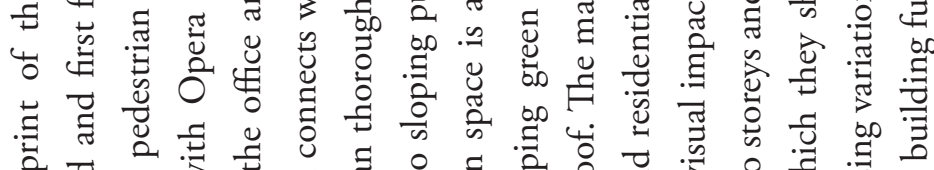

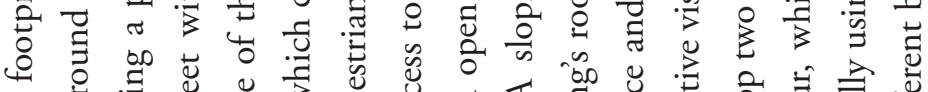

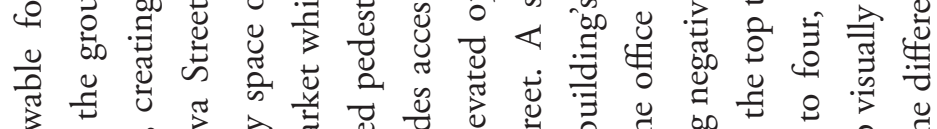

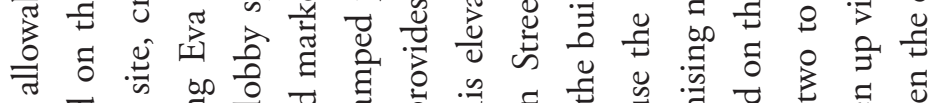

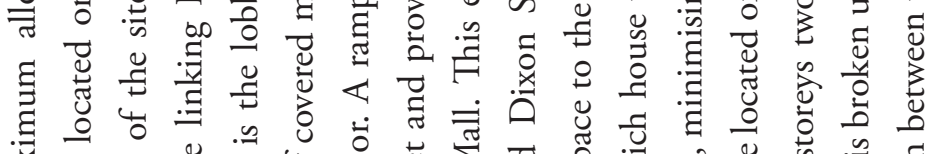
获 章

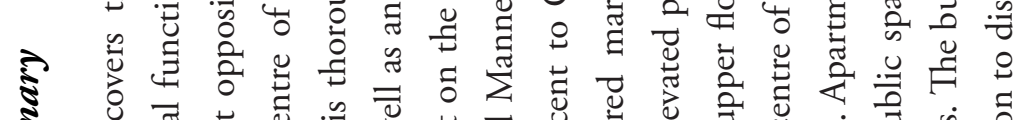

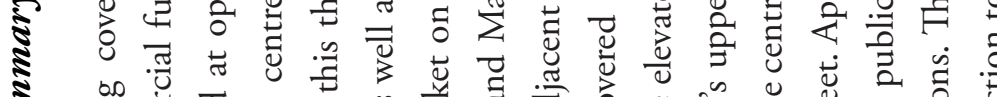

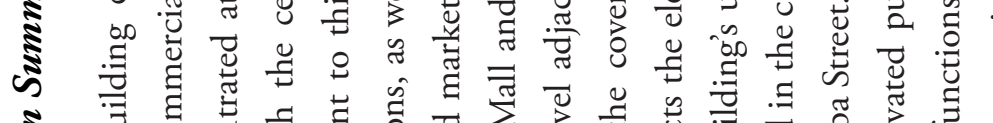

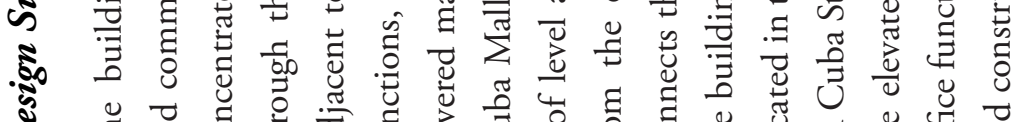

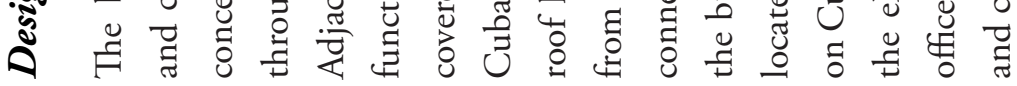




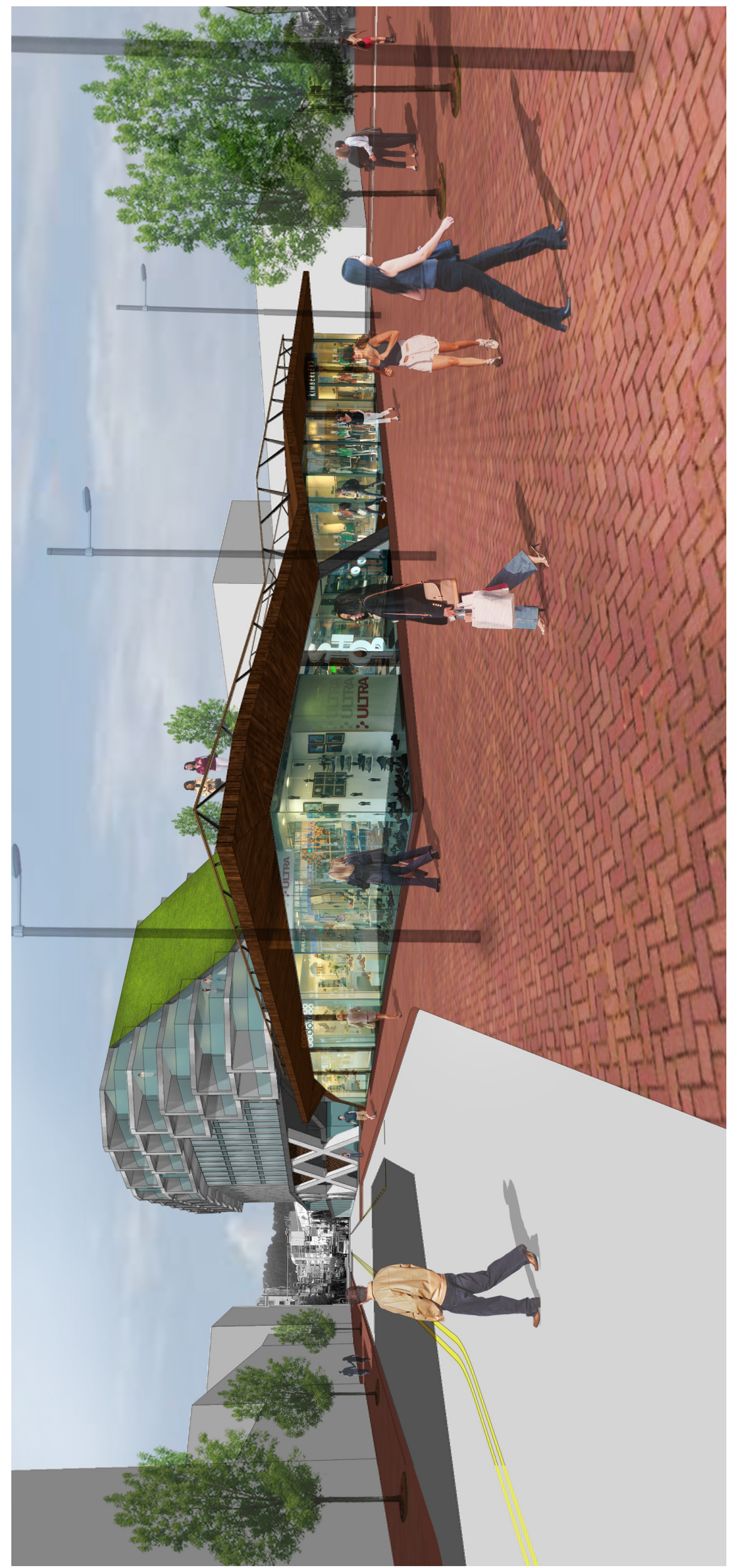

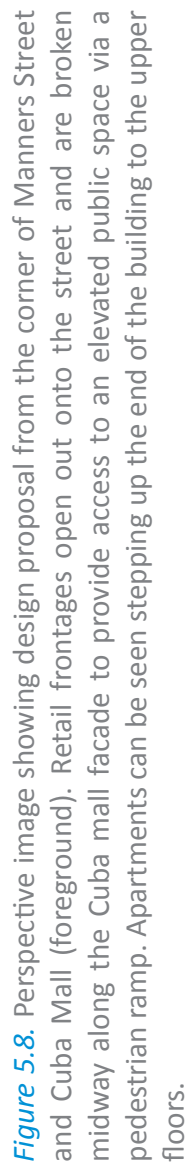



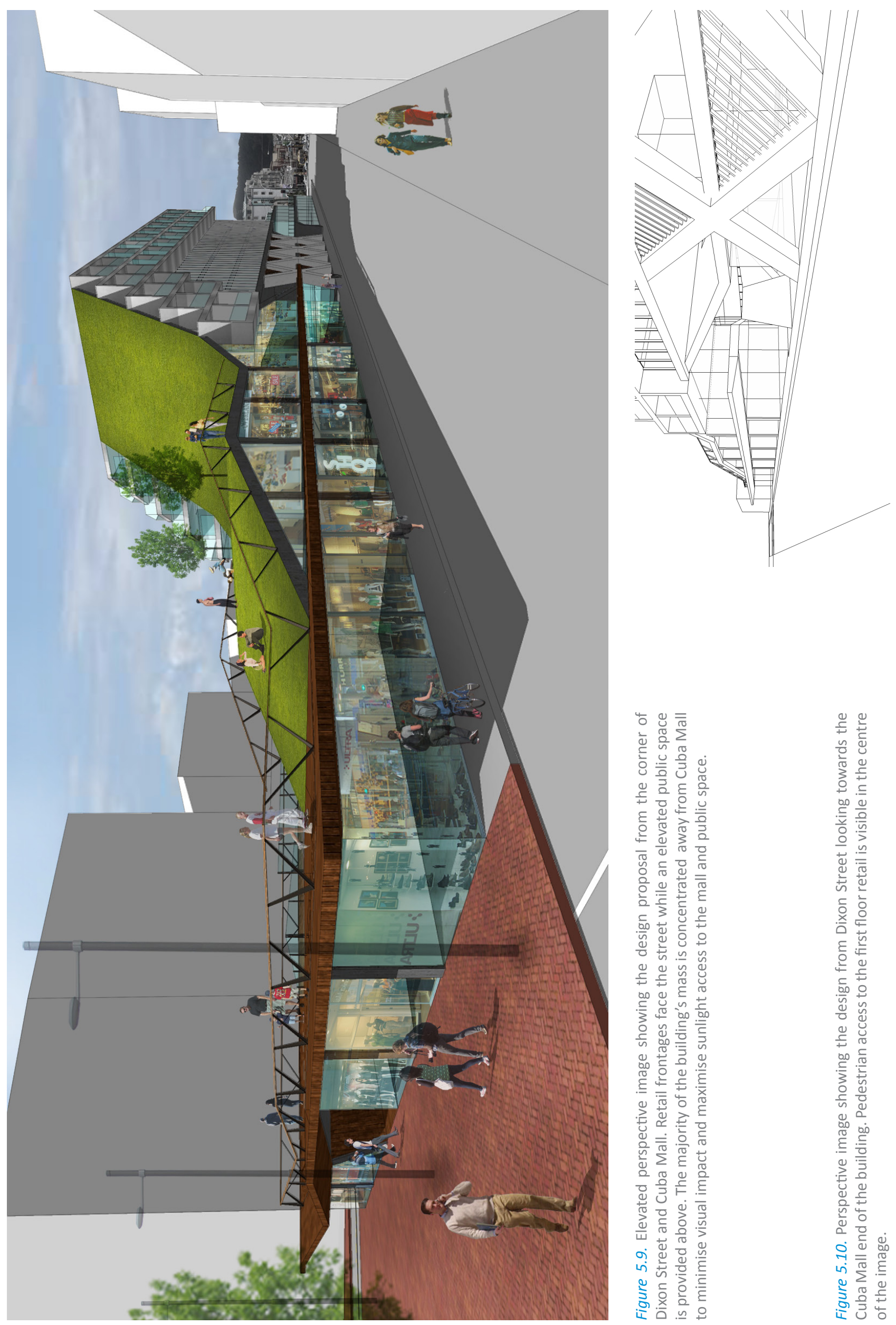

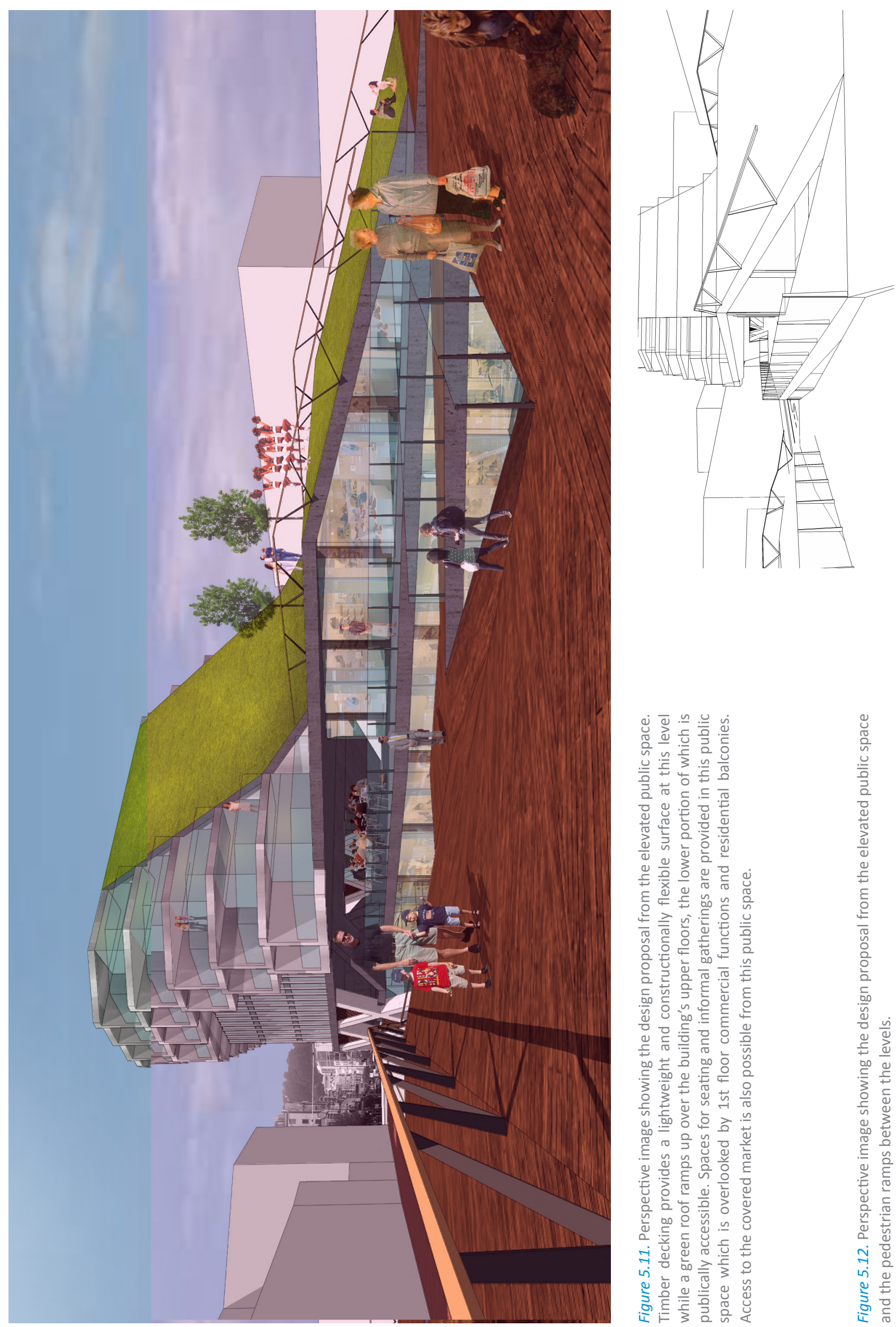

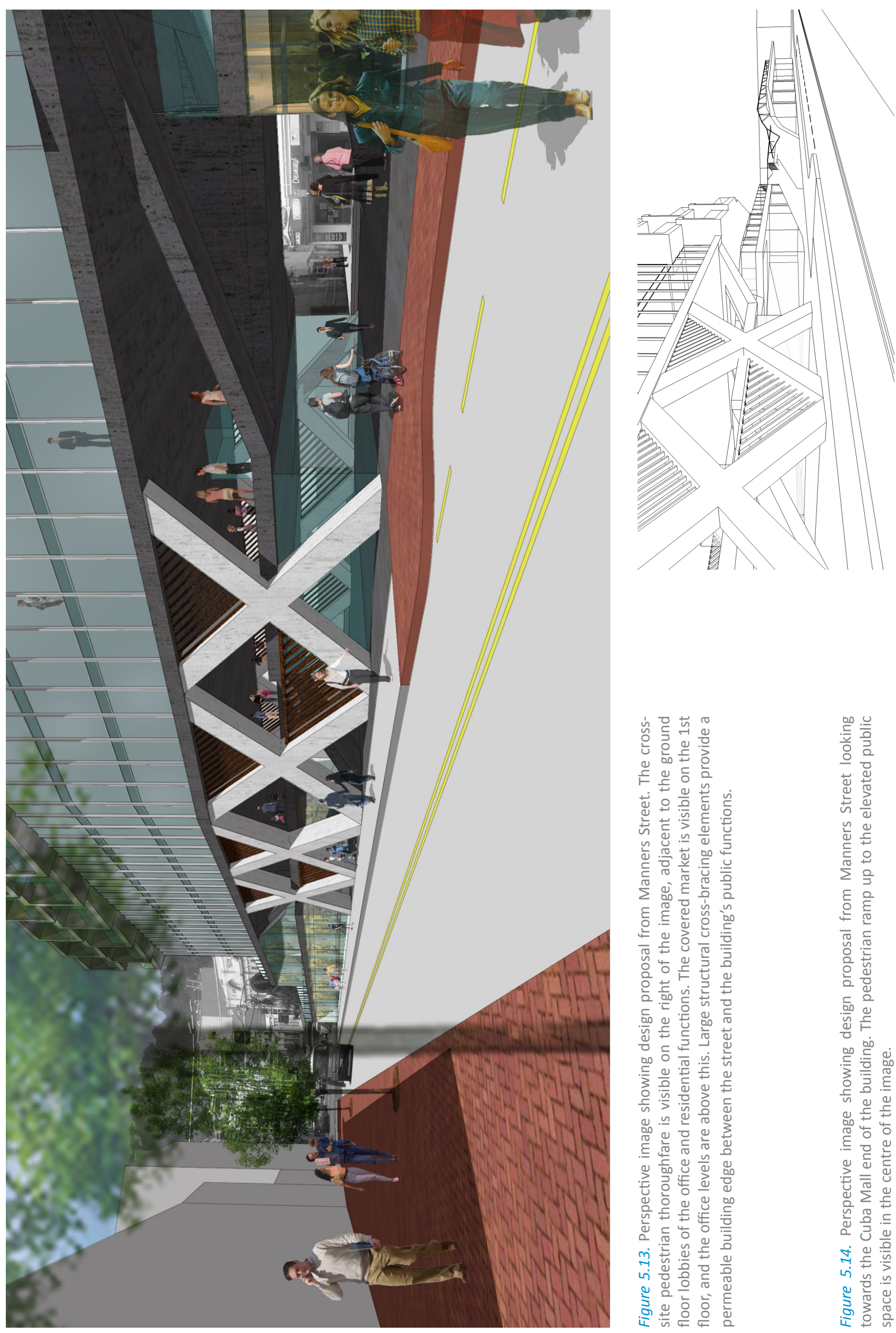

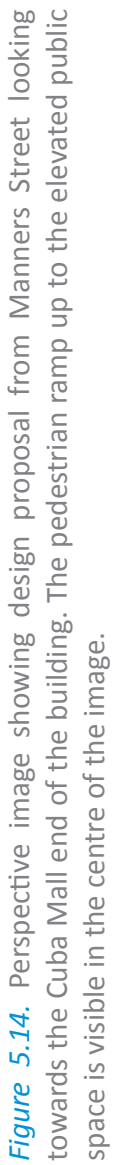




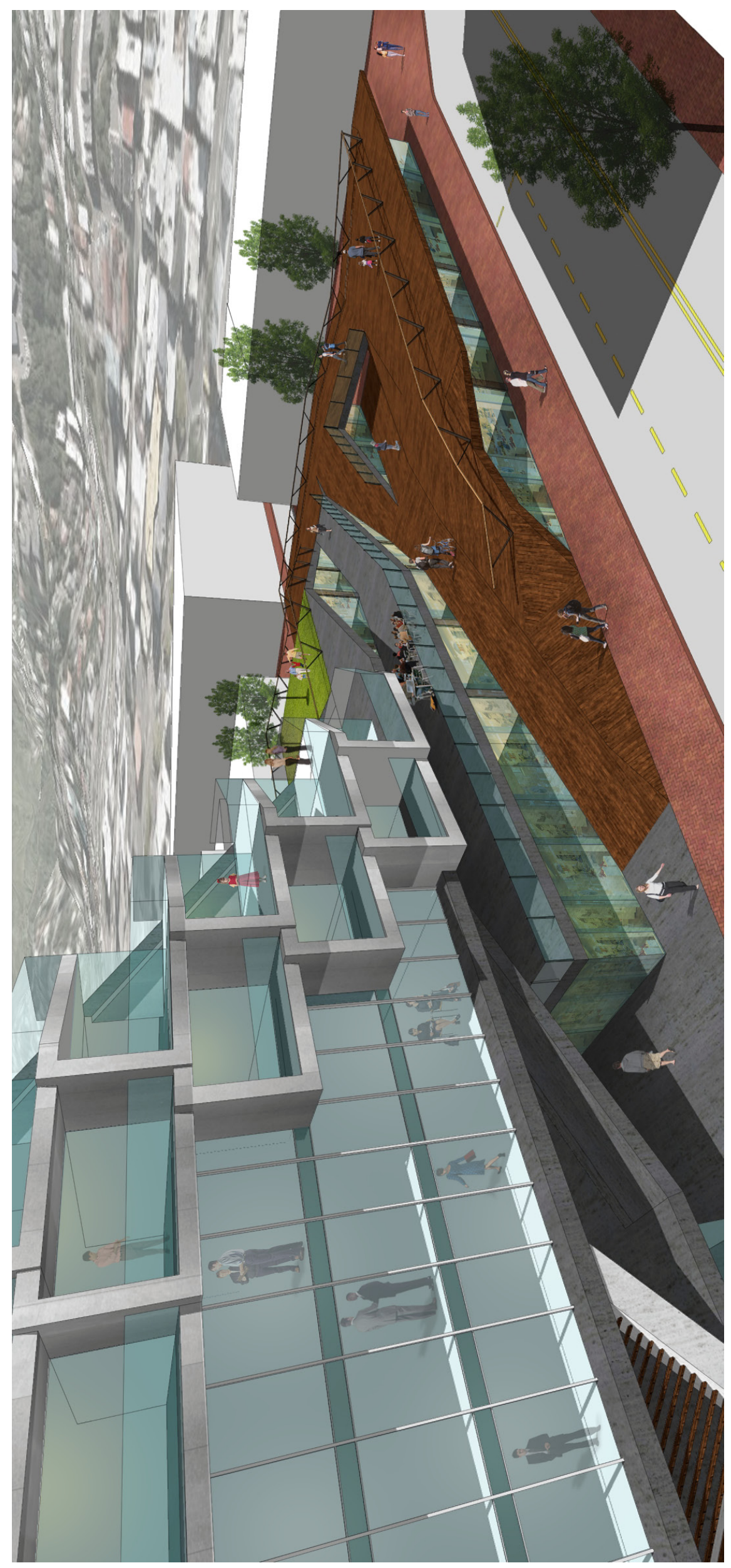

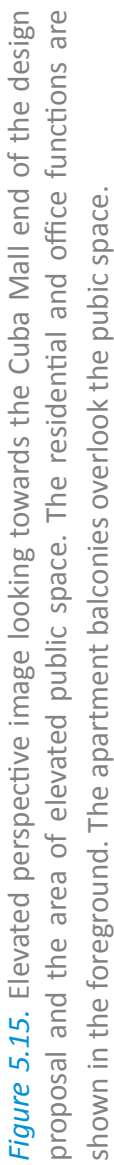




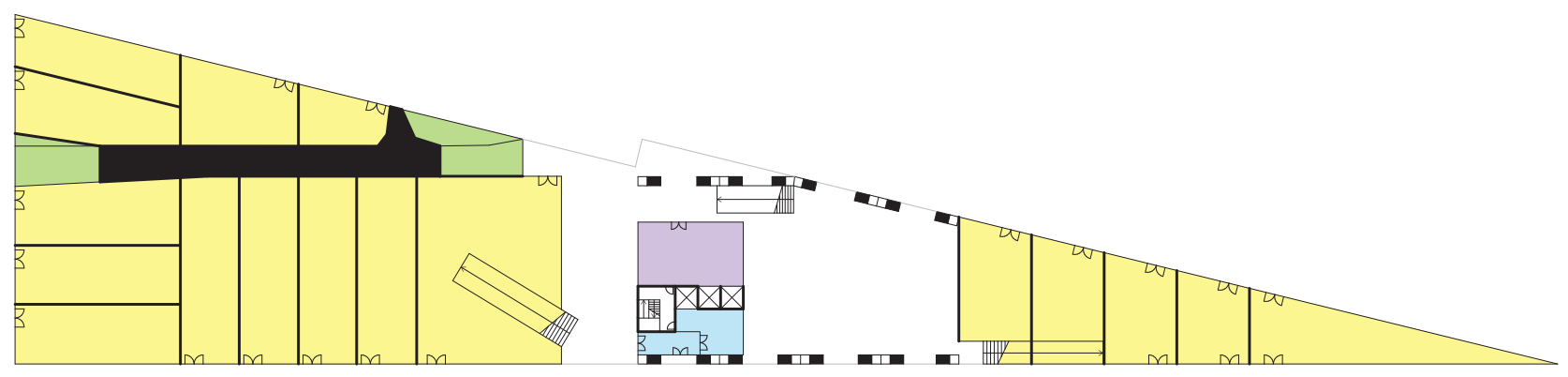

Figure 5.16. Ground floor plan

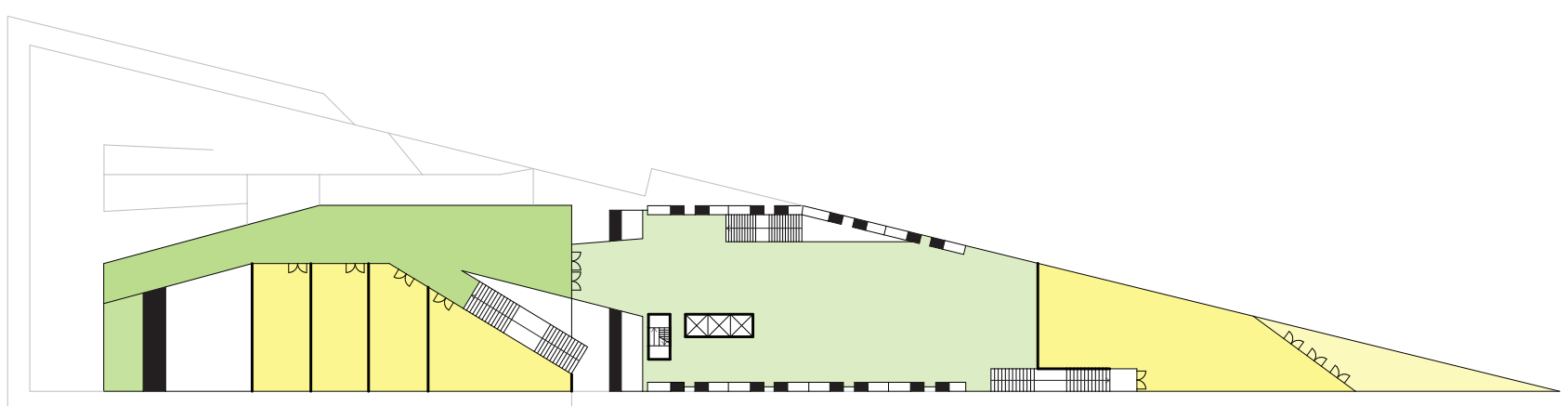

Figure 5.17. 1st floor plan

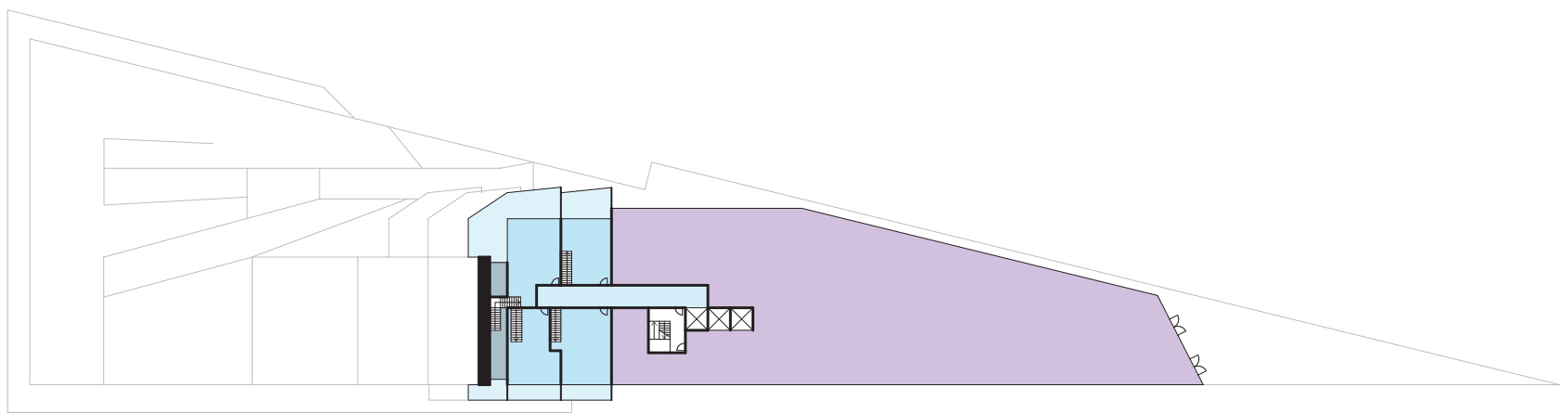

Figure 5.18. 4th floor plan - typical office plan

$\stackrel{5 \quad 10 \quad 20}{\square}$ 


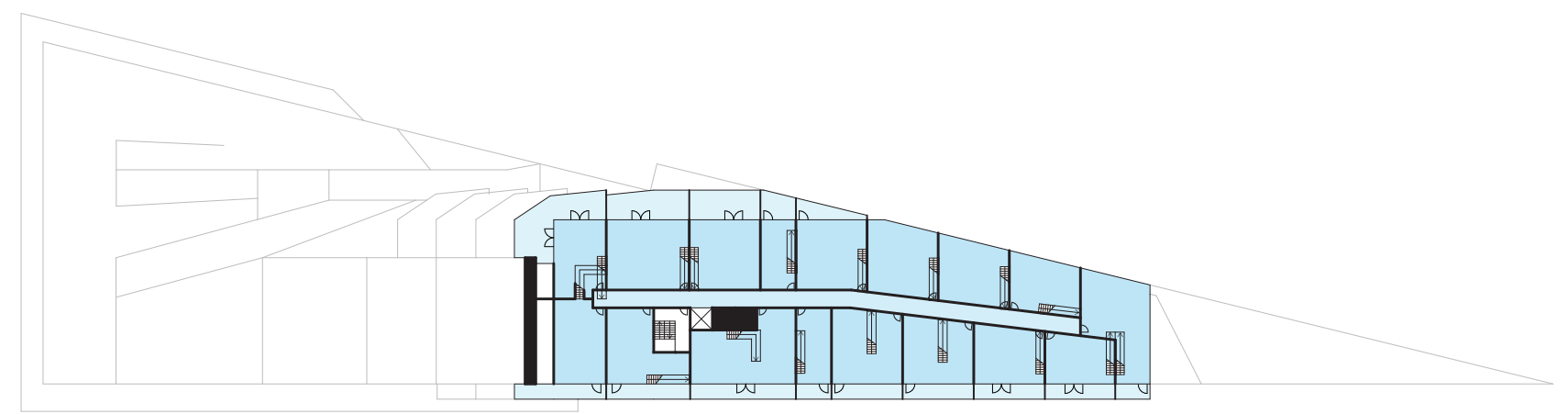

Figure 5.19. 5th floor plan. The apartments on the upper floors of the building are two storeys. This level provides access to the lower floors of these apartments.

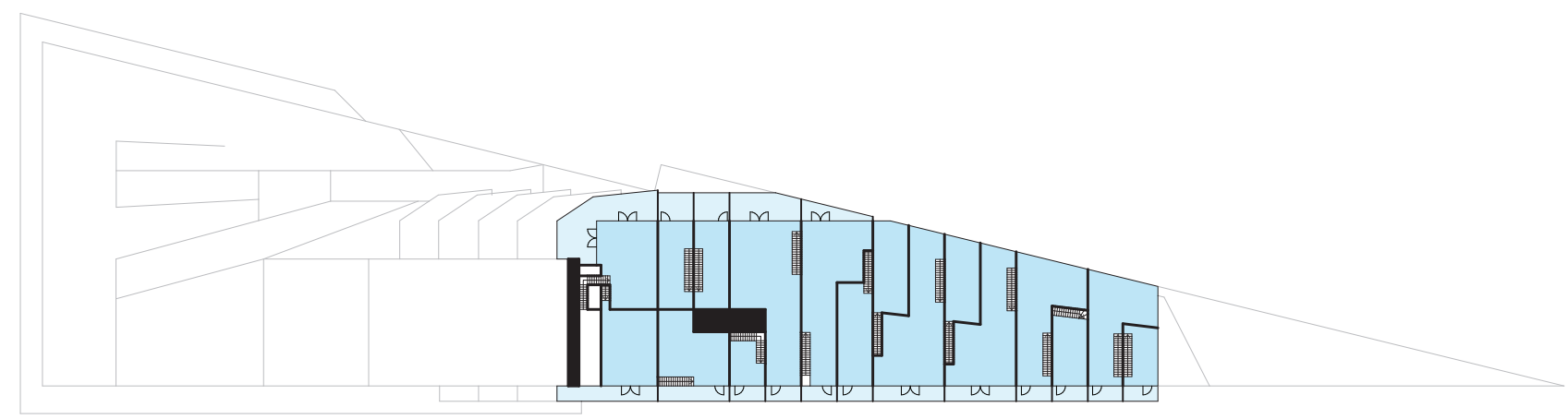

Figure 5.20. 6th floor plan. The upper floors of the apartments are accessed via internal staircases. The apartments are configured to provide each apartment with views from both sides of the building, e.g. an apartment whose lower level is on the building's Southern side will have an upper level on the Northern side. 


\section{Analytic/Literal | Design Execution}

\section{Introduction}

The second design methodology is based on the Analytic/Literal type of diagrammatic practice. This type of diagrammatic practice, identified in the case studies of MVRDV and OMA is based less on a well defined design process than a negotiation of the different constraints and influences of a project. The design development will seek influence from the diagrammatic techniques of both practices and will seek to apply a similarly rigorous logic to the project's development as is evident in the practices' case studies. A predefined design methodology is impossible to formulate for this type of diagrammatic practice, however the process of design development has been ordered as follows for presentation purposes:

- Formulation of massing logic

- Determination of site massing

- Accommodation of programme/configuration of lower floors

- Provision of daylight/configuration of upper floors

These headings provide recognisable markers in the presentation of the design process, although they do not represent discrete, linear 'steps' in the design development.

The logic, rationale, and design instincts and intentions of the designer have a significant influence in the Analytic/Literal design methodology (as will be further discussed following the design execution). Therefore, every effort has been made to distinguish the strictly diagrammatic influences on the project from those due to the logic of the designer.

\section{Design Execution}

Formulation of Massing Logic:

An important aspect of the project, as identified in the Design Background section, is the provision of public space as part of commercial development. 
If the provision of quality public space is to be maximised for the project, it is logical to pack internal programmes within the smallest possible building footprint, thereby maximising public space at ground level where it will be the most easily accessed.

This massing logic [Figure 5.21], a product of the designer's rationale and informed in part by MVRDV's central concern for increased density in order to preserve open space, forms the basis for the project's subsequent site massing exploration.

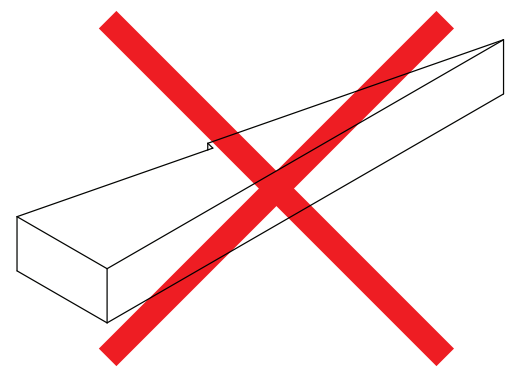

Figure 5.21. Diagram showing the massing logic for the project

\section{Determination of Site Massing:}

The floor area proportions of the project's programme are visualised, as are the floor area proportions of the project's internal (residential, office, commercial) and external (public space, covered market) programmes.

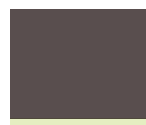

RESIDENTIAL X 1.5

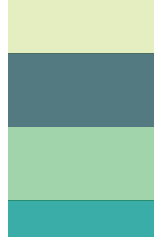

OFFICE X 1

COMMERCIAL X 1

PUBLIC SPACE X 1

COVERED MARKET X 0.5

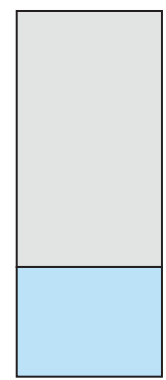

INTERNAL FUNCTIONS X 3.5

EXTERNAL FUNCTIONS X 1.5

Figure 5.22. Diagrams showing the floor area proportions of the different programmes to be accommodated on the site. Each programme's floor area is quantified in terms of the total site area (e.g. residential floor area $=$ site area $\mathrm{X} 1.5$ )

The project's internal programmes are packed within a single volume and the possibilities for locating this on the site are explored. The height of the volume is at the maximum allowed under the district plan $(43.8 \mathrm{~m})$ to fulfil the massing logic of a minimum building footprint.

A sunlight and shading study is completed for various massing options which are located at the extremes and centre of the site. The study examines direct sunlight exposure to the open public space in the different site configurations for the hours between 0800 and 1600 on both the summer and winter solstices. 

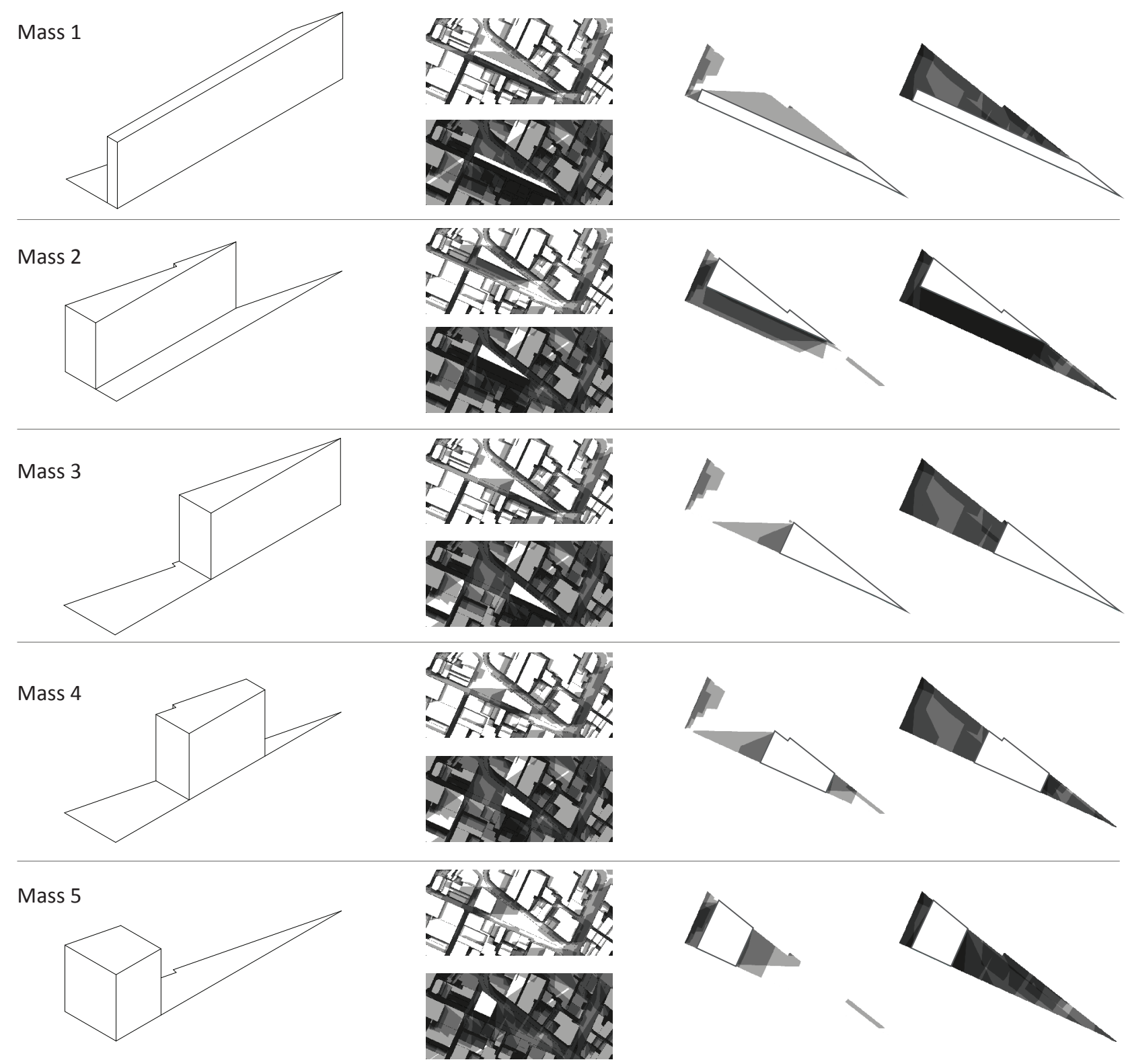

Figure 5.23. Sunlight and shading study

Masses $1 \& 2$ perform relatively poorly for sunlight exposure to the public spaces, so are ruled out of further analysis. Masses 3-5 perform similarly well, with Mass 3 allowing the maximum sunlight exposure. These remaining masses are analysed in terms of promotion of the cross-site connection between Eva Street and Opera House Lane and the compactness of the floor-plate they create [Figure 5.24]. The central concern for compactness in the project's development is informed by MVRDV's development of VPRO, whose footprint was determined by compactness studies [Figure 3.29], and the logic that the most compact form will minimise both internal circulation space and exterior visual impact. 
MOST COMPACT
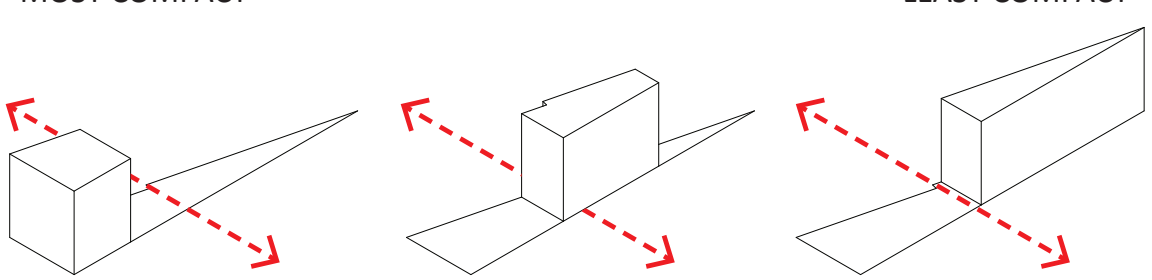

Figure 5.24. Compactness and cross-site connection study

Following an analysis of sunlight penetration, compactness and crosssite connection, mass 5 is selected as the most suitable solution. Urban considerations also feature in the rationale behind this decision, specifically the desire to maintain an active street frontage along the valuable retail location of Cuba Mall.

Diagrams in this stage of development are used as tools of analysis; they are not projective as they are not instrumentalised to generate the form or organisation of the building. Diagrams facilitate the comparative analysis of the massing options identified by the designer, but it is the designer's logic and rationale that decides the most suitable massing.

\section{Accommodation of Programme/Configuration of Lower Floors}

With the project's basic massing for the internal functions determined, the additional space requirement for the external programmes (public space, covered market) is visualised.

INTERNAL FUNCTIONS
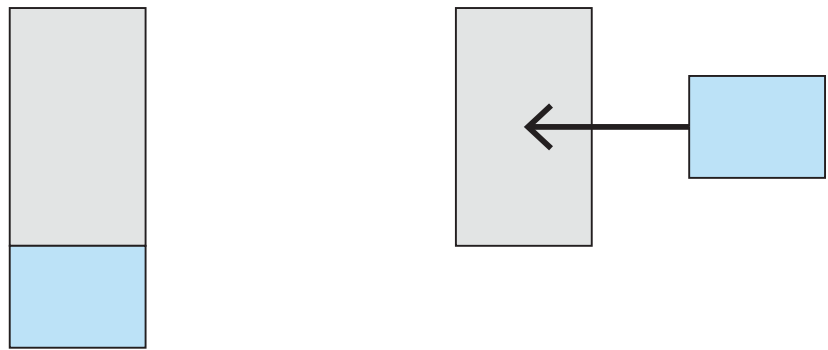

EXTERNAL FUNCTIONS

Figure 5.25. Diagram showing the requirement of additional space to accommodate the project's external functions

To meet the external space requirements the project seeks influence from OMA's Seattle Public Library project. In the Seattle project the abstract diagrammatic operation of 'pushing out' programmatic compartments is used to meet requirements for sunlight, shading and views, and begins to influence the massing of the building [Figure 3.41]. A similar abstract diagrammatic operation is utilised in this project to provide additional horizontal surfaces for the external programmes. 

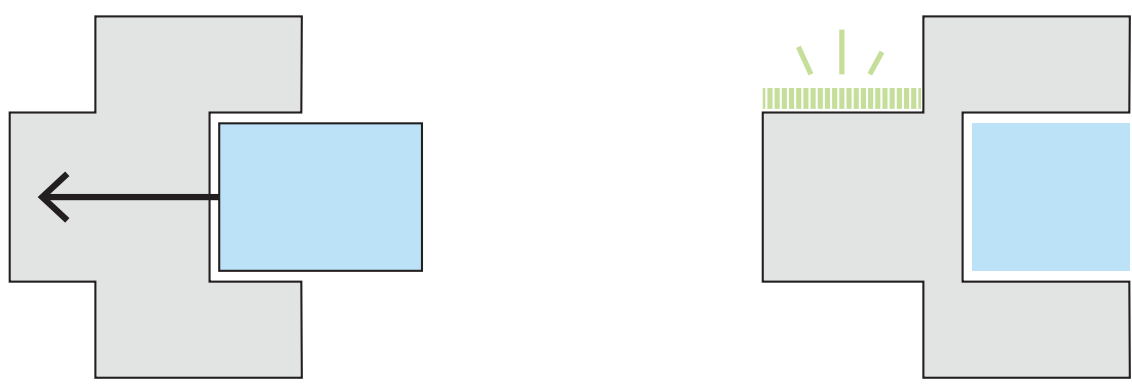

Figure 5.26. Abstract diagrammatic 'pushing' operation

In an abstract diagrammatic operation adapted from the internal compartmental offsets featured in OMA's library project, the possibility of 'pushing' the project's external programmatic compartments into the diagram of internal functions is identified, thereby deforming the diagram's rectangular shape. The formal implication of this compartmental 'pushing' operation is the offsetting of floor plates within the tower, which is justified by the logic of the programmatic requirement for additional floor area.

The abstract diagrammatic 'pushing' operation is refined into a 'precision push,' where the external programmes are fragmented and pushed into the rectangular diagram of internal functions at various levels.
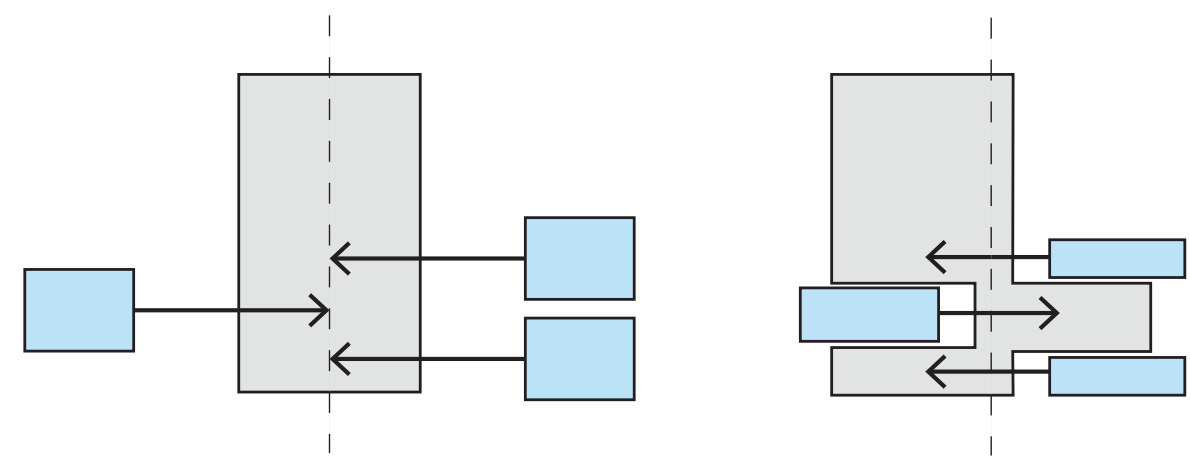

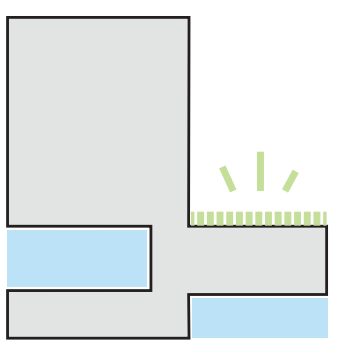

COVERED MARKET PUBLIC SPACE

Figure 5.27. 'Precision push' diagrammatic operation

Through this operation a covered market area is created at ground level and on the first floor, and an elevated public space is created, providing a public terrace for the city.

In this stage of the project's development the abstract diagrammatic 'pushing' operation is instrumentalised to generate formal and organisational possibilities for the project, which will be translated from diagrammatic figure into built form relatively directly. The configuration of the diagram's 'pushing' operation is rationalised by the designer and is influenced by urban and site considerations. 


\section{Provision of Daylight/Configuration of Upper Floors}

The deep plan of the building, a result of its site massing, presents a challenge for providing natural light and ventilation to its upper office and residential floors. The strategy of subtracting 'voids' from the building's volume is adapted from MVRDV's VPRO project. This strategy allows the clarity of the tower's simple geometry to be maintained whilst providing outdoor space, natural light and ventilation for the building's upper floors.
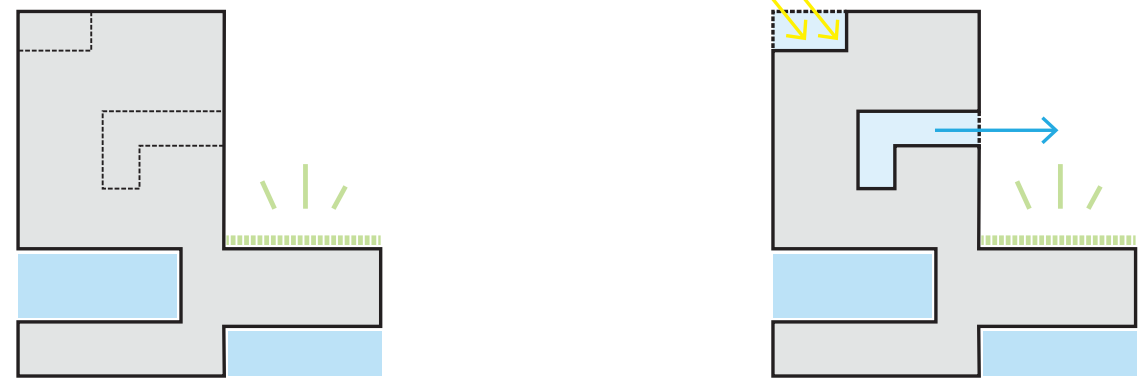

Figure 5.28. Subtracted 'voids' allow sunlight penetration and provide external views

The configuration of the voids will be generated based on a negotiation of the various constraints concerning their operation. These constraints will be concerned with both the building's interior programme requirements (light, shading, views, ventilation, plan shapes, $\mathrm{min} / \mathrm{max}$ floor-plate depths) and requirements for the subtracted outdoor void spaces (spatial proportions, variety of outlooks, direct sunlight access, circulation between voids). The fulfilment of some of these requirements will be achieved based on a data driven process of development (e.g. interior natural daylight levels, $\min / \max$ floor-plate depths), and others will be fulfilled based on the judgement of the designer (e.g. views, circulation), resulting in a built form generated by the complex negotiation and confrontation of a 'datascape' of requirements, a reference to MVRDV's working method.

For the purposes of this research, a full execution of this working method has not been undertaken due to its complex nature and deviation from the identified scope of research. The configuration of the voids for the project's presentation is based on the designer's judgement [Figure 5.29] and provides an indication of how their shape may have been configured had the full method been executed. While the configuration of the voids is essential for the operation of the building's upper floors, their impact on the project's urban design outcomes is relatively insignificant, and does not depend primarily on their precise shape.

Had the full datascape method had been executed for this stage of development, diagrams would have played both a projective and analytical role for the formal and organisational development of the project. Once the strategy of subtracting voids from the building's mass had been selected by the designer (a strategy

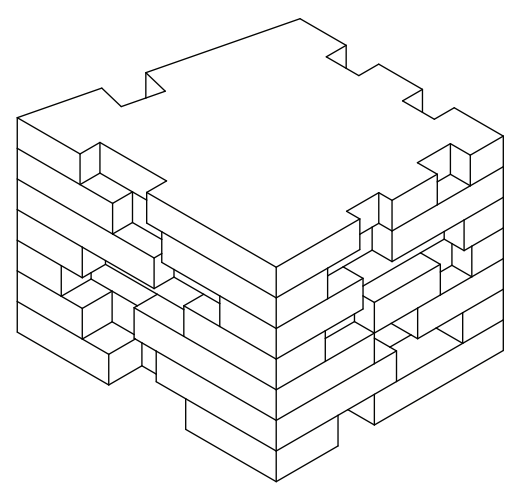

Figure 5.29. Configuration of 'voids' based on designer's judgement. The configuration of the voids are developed further in the project's later stages of design development 
which finds precedent in MVRDV's VPRO project), diagrams would have been used to optimise the various constraints to generate the specific shape of the voids and analyse the impact of any decisions made by the designer.

This process generates the basic form and organisation of the project which is also further developed into an architectural proposition and visualised in context.

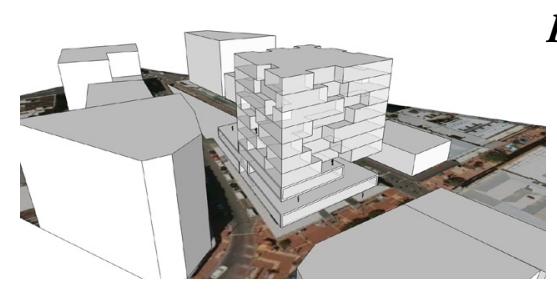

\section{Resulting Form}
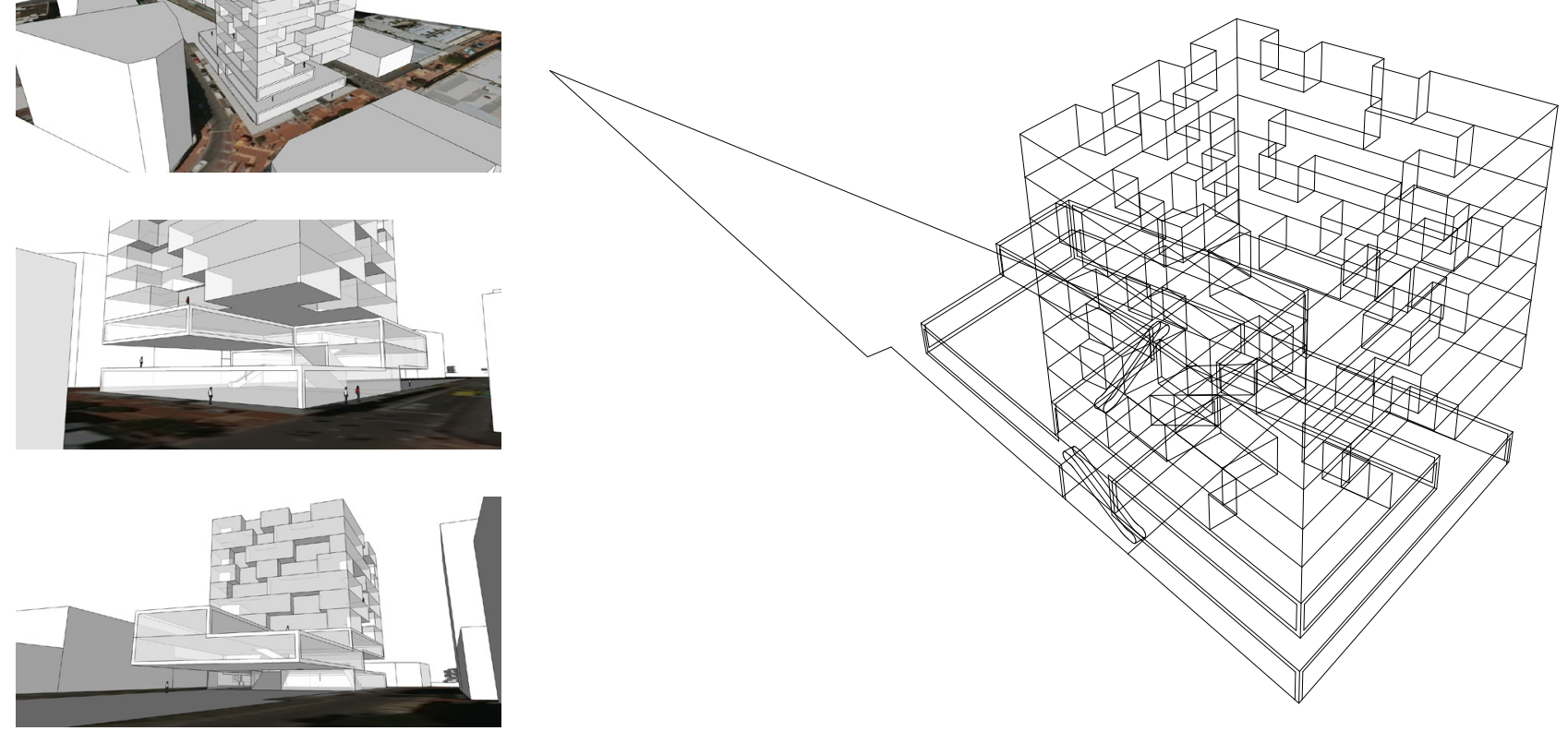

Figure 5.31. Resulting form visualised in context of surrounding building masses

Figure 5.30. Resulting form after first stage of development

As with design one, the resulting form is taken through a relatively conventional process of design development requiring rapid design decisions to present the building in an architectural language encompassing construction and materials. Again this allows the design to be considered in its urban context and allows areas of unconventional building/open space relationships to be identified. 
Five | Design Execution 

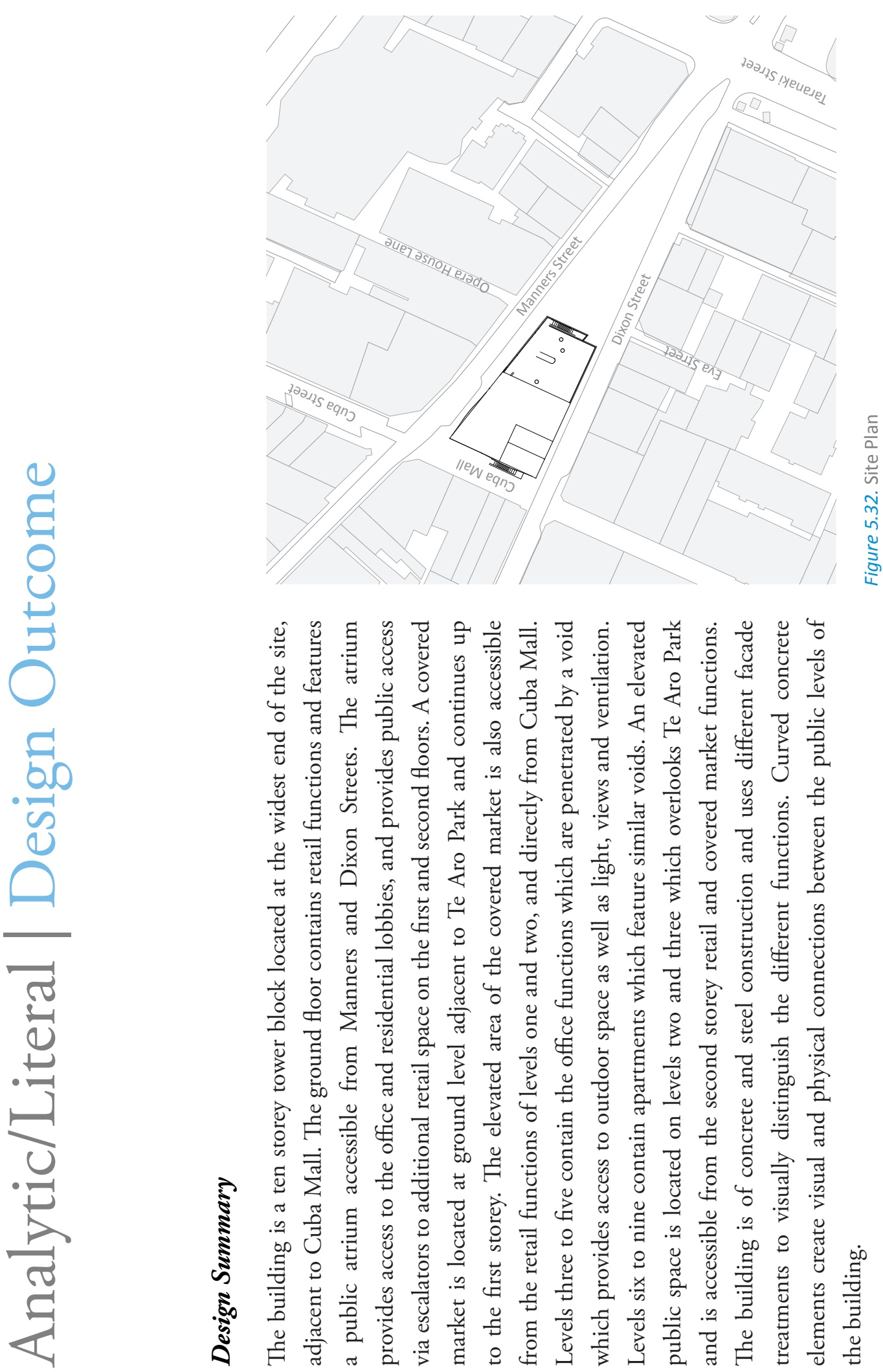

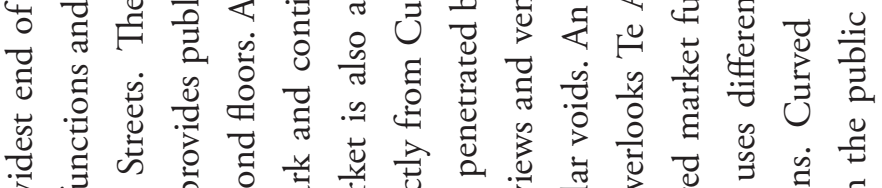

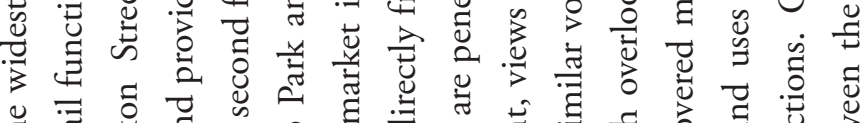

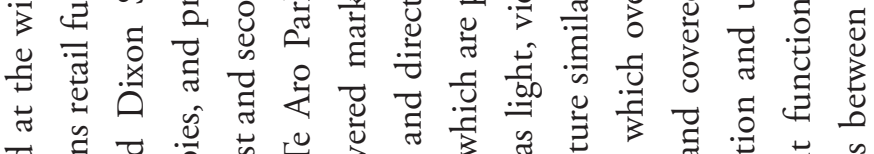

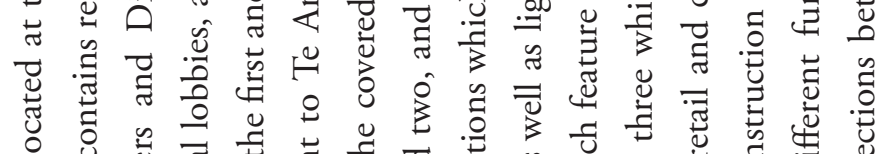

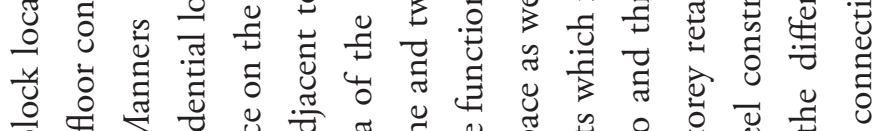

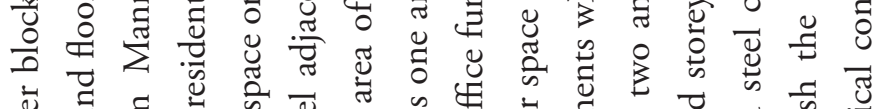

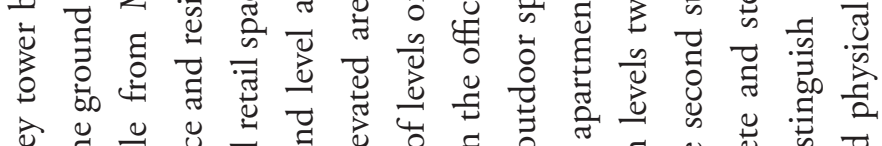

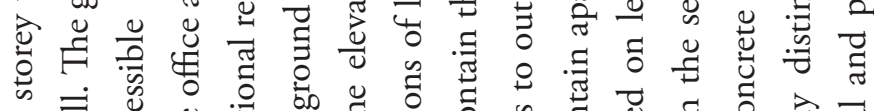

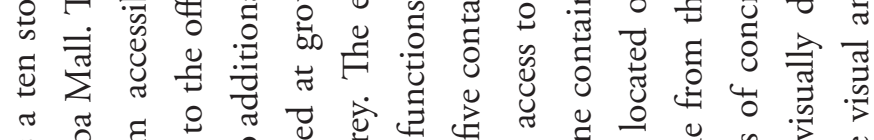

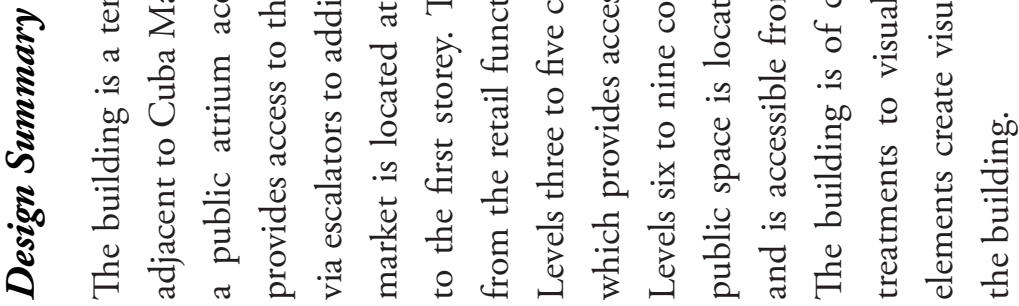




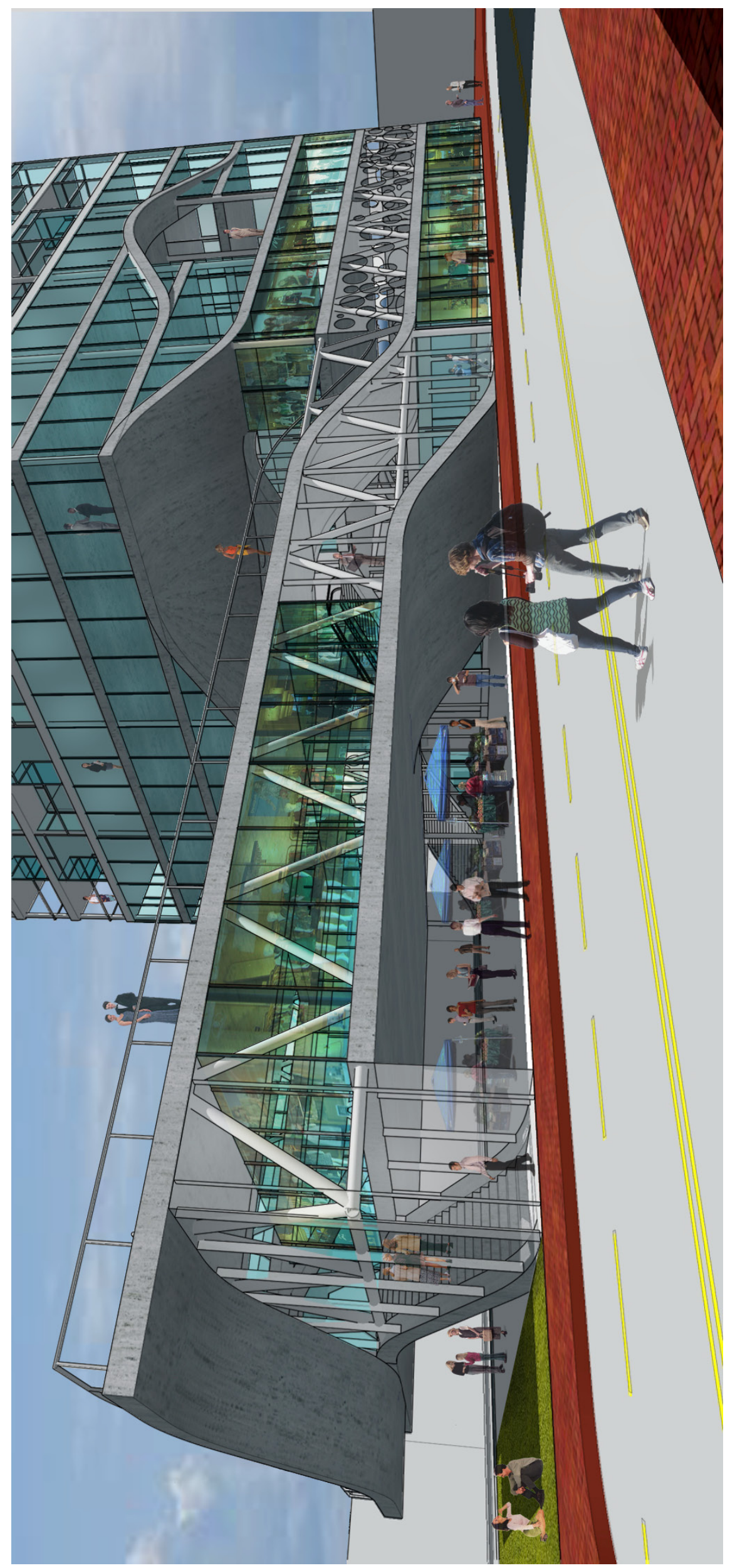

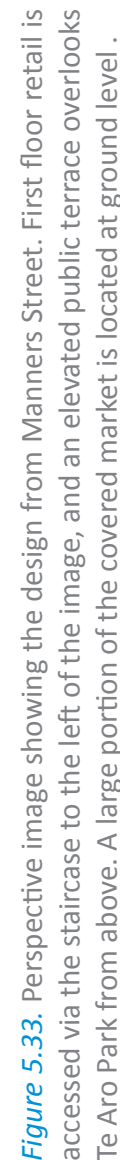



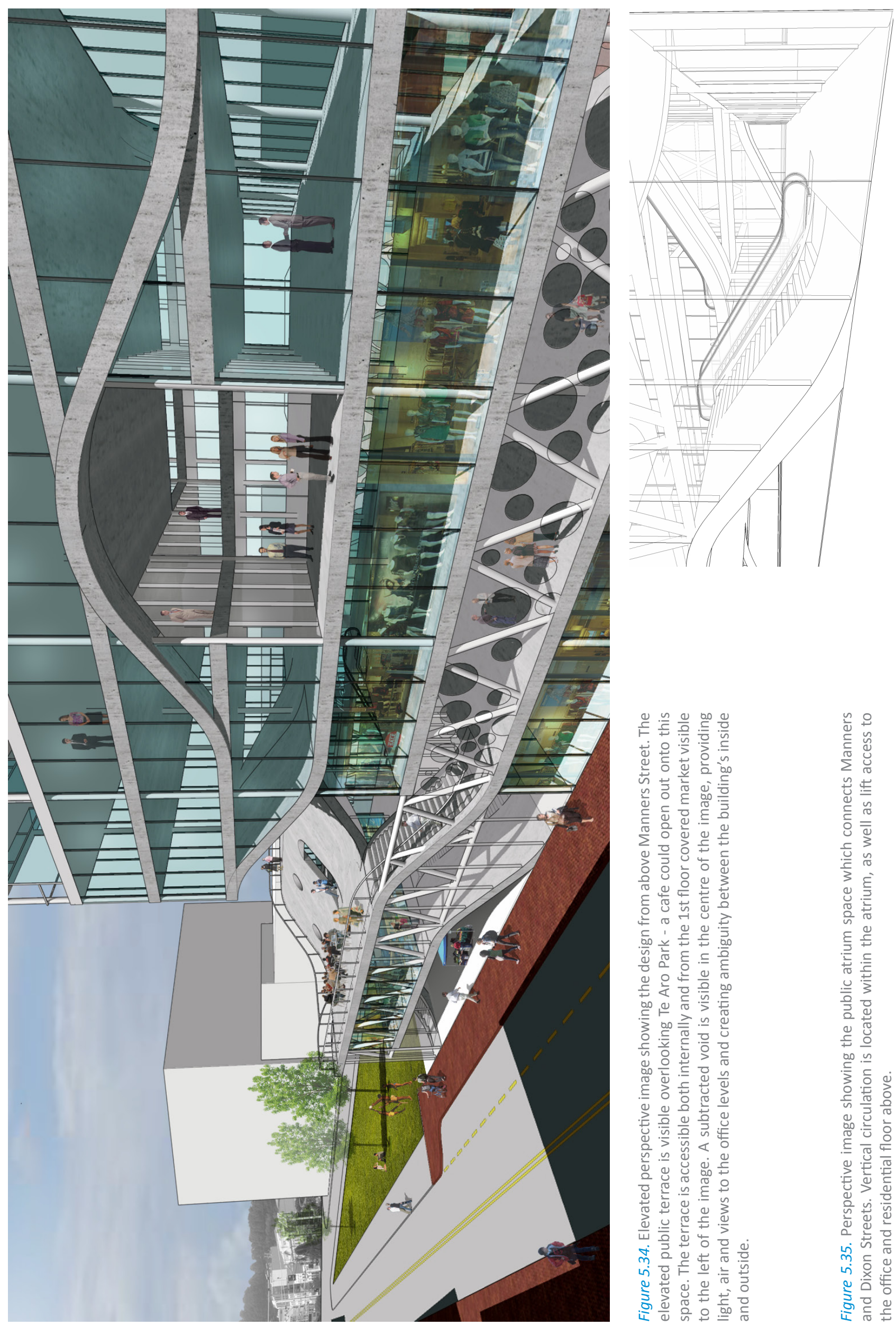

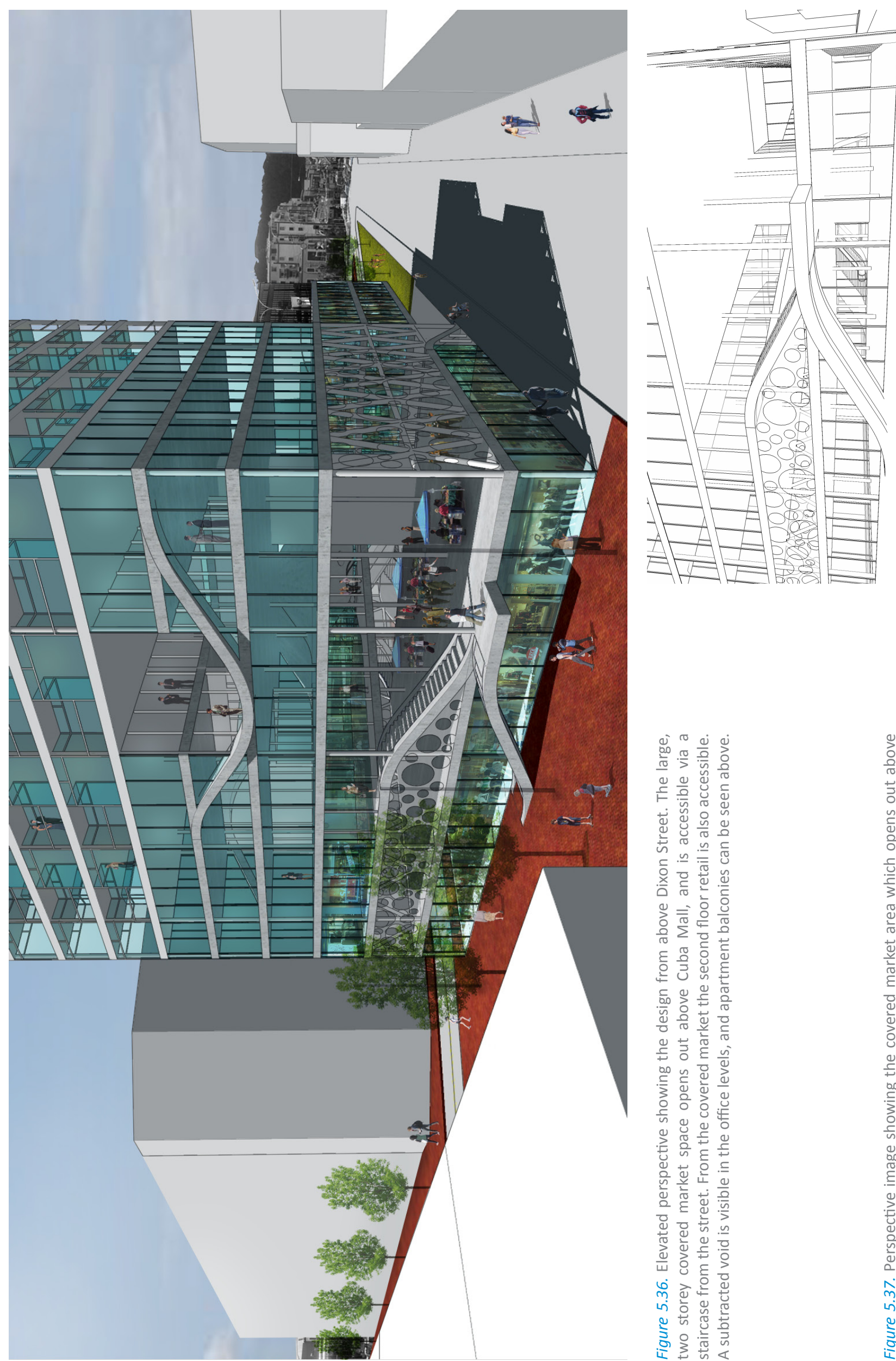

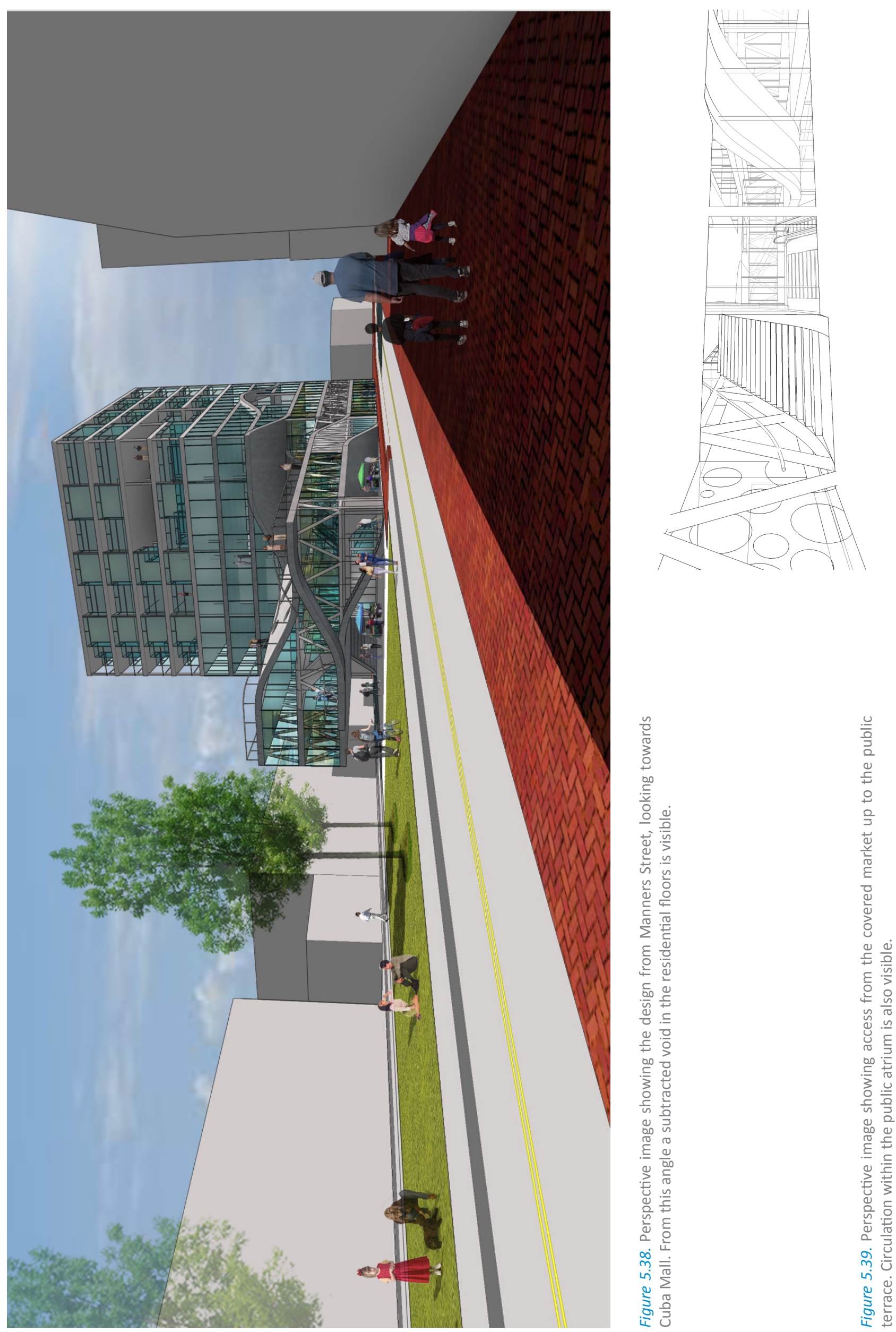

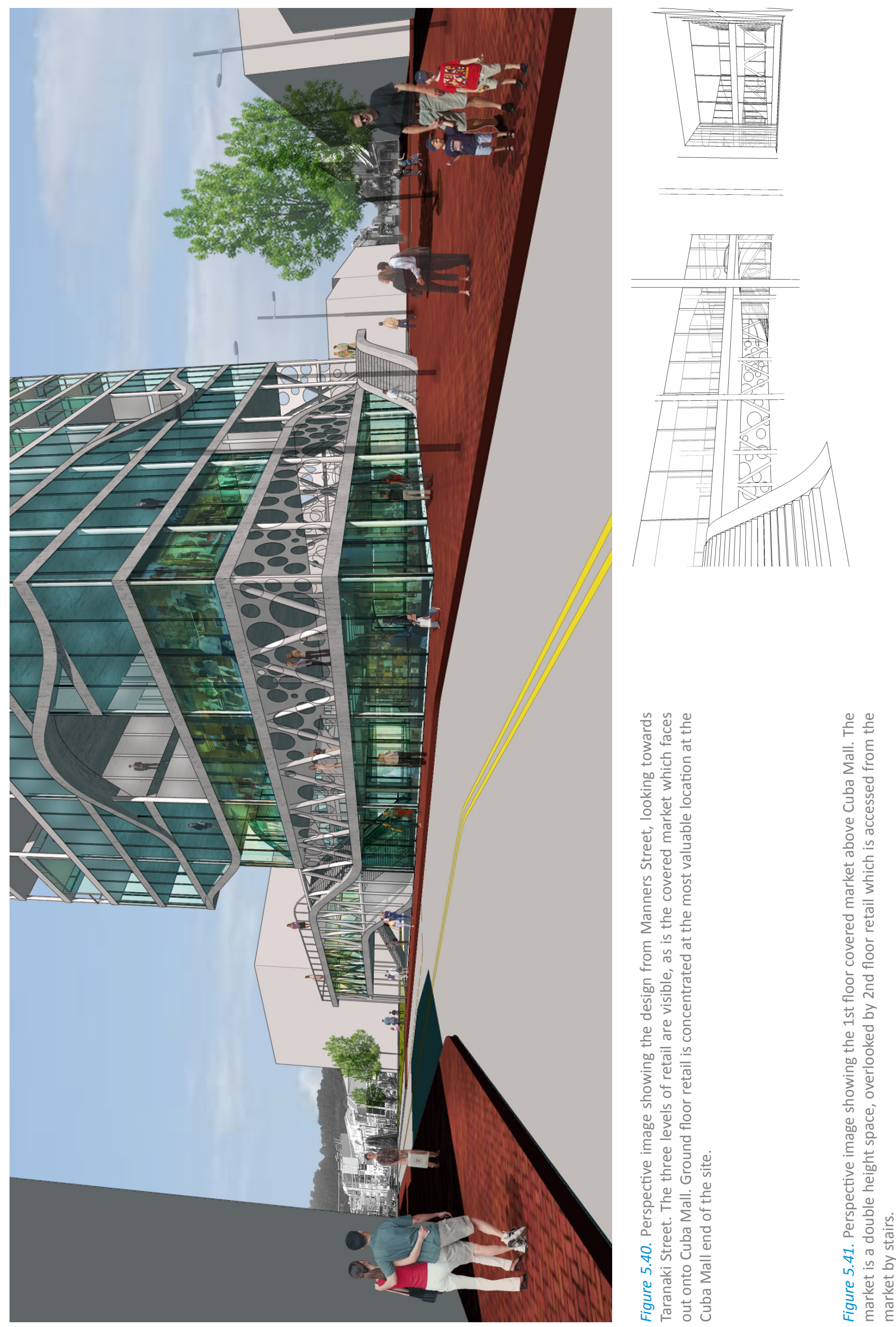
Diagrams in Architecture

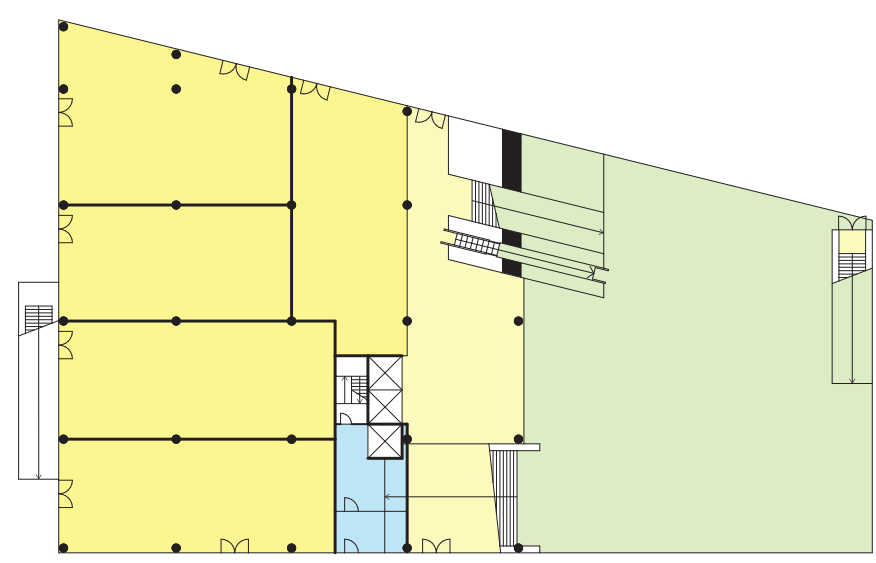

Commercial Space Public Space Covered Market Office Space Residential Space

Figure 5.42. Ground floor plan

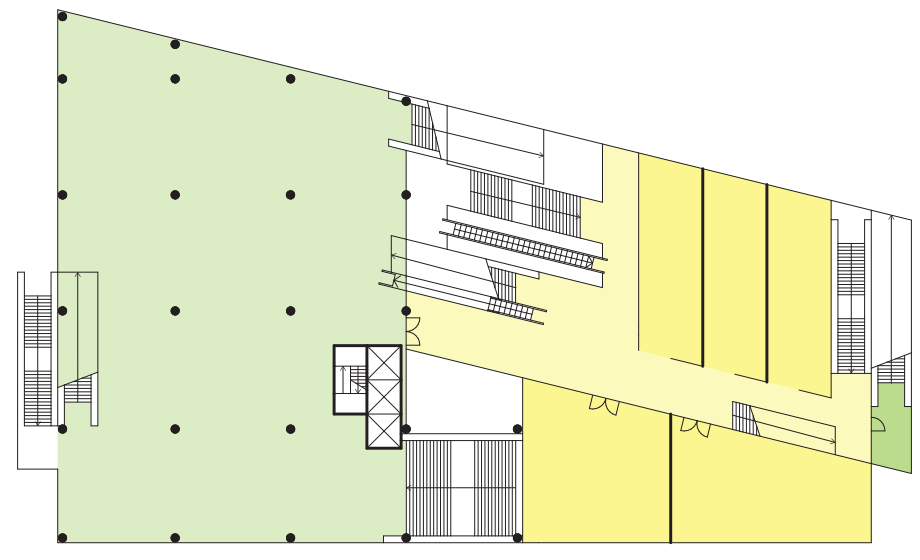

Figure 5.43. 1st floor plan

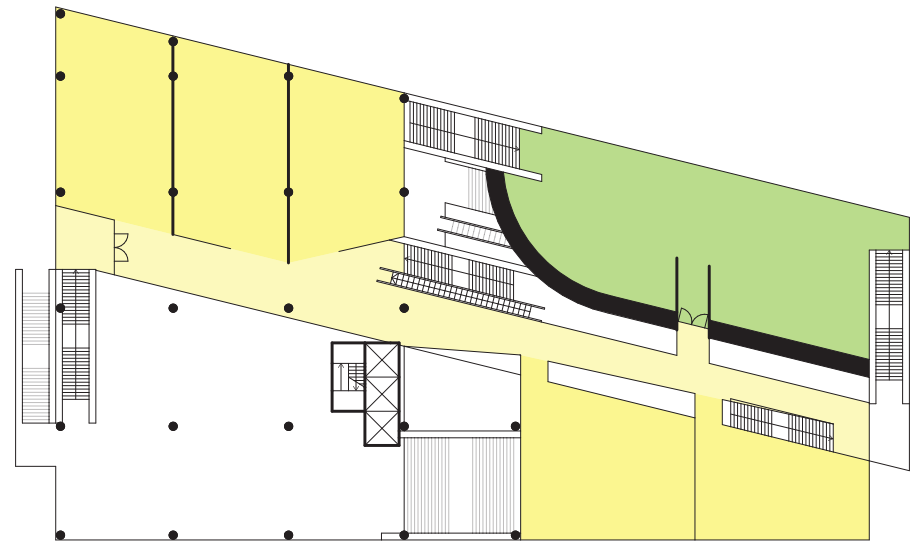

Figure 5.44. 2nd floor plan

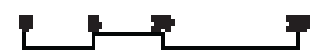




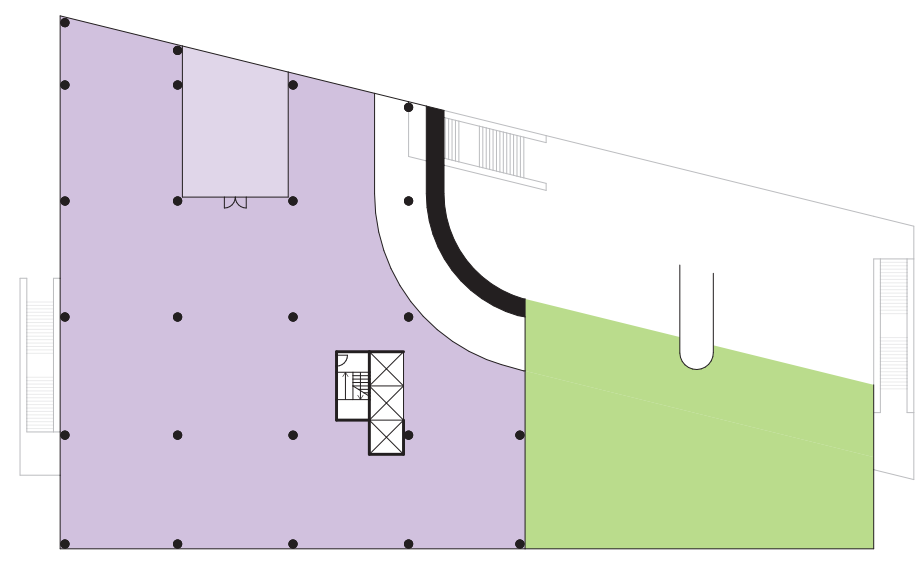

Figure 5.45. 3rd floor plan

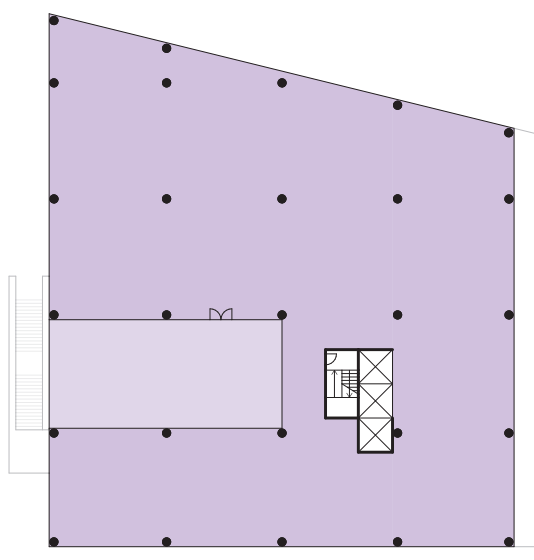

Figure 5.46. 5th floor plan

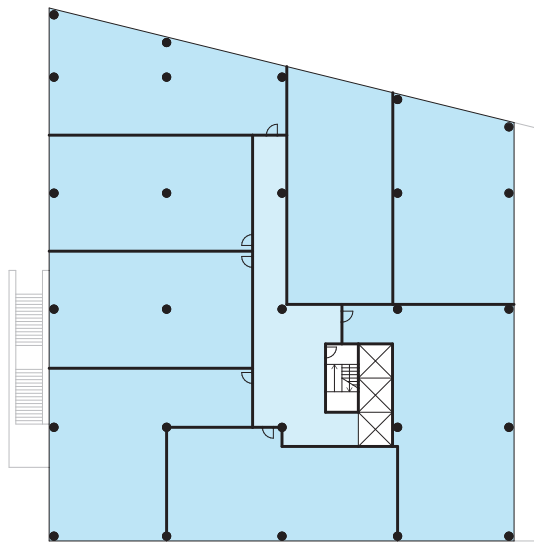

Figure 5.47. 6th floor plan

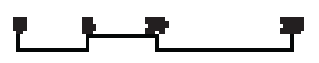




\section{DesignExecution|Discussion}

Two different diagrammatic design methodologies identified by case studies were executed in the previous chapter to generate different design proposals in response to the brief. This chapter discusses the execution and outcomes of the two diagrammatic design methodologies. For each design proposal, aspects of unconventional building/open space relationships are firstly identified, and the role of diagrams in their development are examined. Following this an examination of the role of the designer, and the differences in the architectural outcomes produced by the different methodologies is undertaken. Lastly, the limitations of the different methodologies are addressed.

Following these areas of discussion, the aim of the research is comprehensively addressed in a discussion of the instrumentality of diagrams in generating the unconventional urban design outcomes identified in the two design proposals. This section draws on the previous areas of discussion to produce a conclusive summary of the findings for the design phase of the research, answering the question: "what contribution do diagram-based design methods make towards the realisation of non-conventional urban design outcomes?"
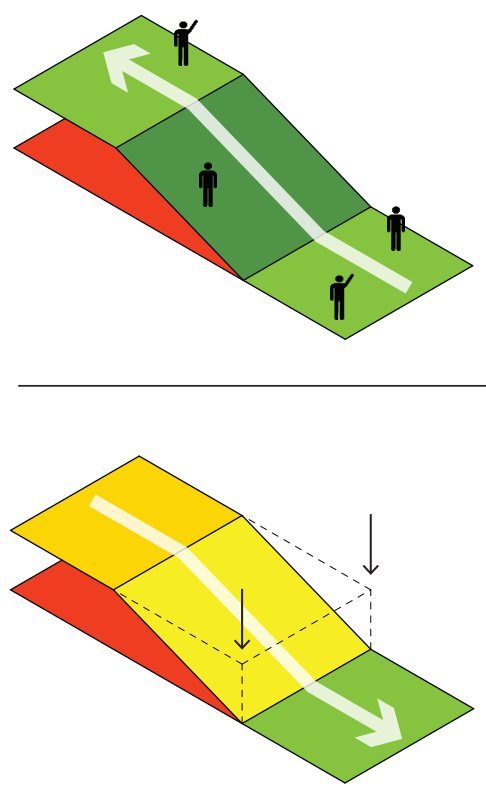

\section{Design One: Areas of Unconventional Building/Open Space Relationships}

Figure 5.48. The typical boundary between public and private occupation, the building's footprint, is transcended as the public open space of Cuba Mall is extended via a ramped surface onto the public roof of the building

Figure 5.49. This same ramped and warped surface reduces the distinction between figure and ground, as it blends the public roof level with the surrounding urban landscape 
Figure 5.50. The extension of public space onto the warped surface of the building's roof creates a public realm rich in topographical variation - public occupation is extended beyond the level of the street and the occupied surface is not horizontal

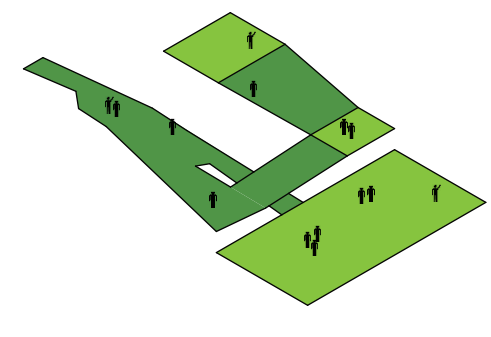

Figure 5.51. The sloping surfaces of the building integrate conventionally horizontal elements (roof, floor) with vertical elements (walls), creating ambiguity between occupied surfaces and enclosure

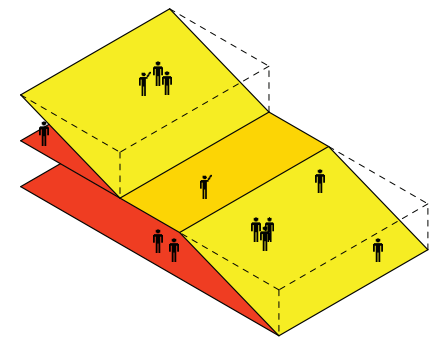

Figure 5.52. The permeable building edges of the covered market area minimise the distinction between the building's inside and outside

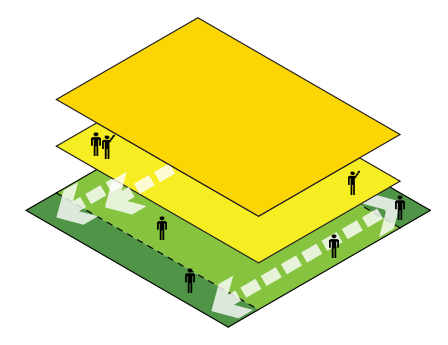

\section{Design One: Role of Diagrams in Design Process}

Many of the unconventional urban design outcomes of this design, such as the minimisation of both the boundary between public and private occupation and the distinction between figure and ground, were directly generated from the Abstract/Instrumentalising diagrammatic design methodology. The circulation goals of the project, formulated prior to any diagrammatic design input, also emphasised the spatial qualities of continuity and connection which contributed to the generation of unconventional building/open space relationships.

The circulation goals of the project influenced the first diagrammatic step of the design methodology - the development of the circulation diagram; specifically the use of the diagrammatic language of waves [Figure 5.53]. In an adaptation of Foreign Office Architect's 'closed loop' diagram, the circulation diagram's language of waves embodies the circulation goals of the project; the curved 'wave' lines branch seamlessly from the diagram's otherwise orthogonal lines, existing as the diagrammatic expression of continuity and connection. The 'waved' diagrammatic language was selected as a more appropriate diagrammatic language for an urban site compared to the 'closed loop' diagram

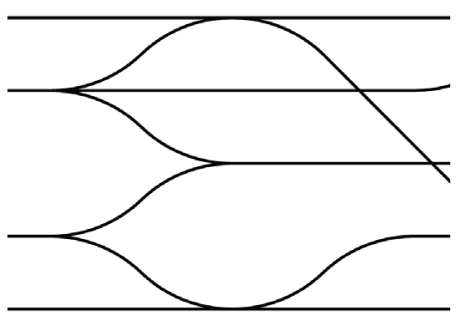

Figure 5.53. Diagrammatic language of waves which is better suited to the linearity of a pier.

The development of the project is based on the optimised, abstract organisation of the circulation diagram rather than on the primary basis of formal 


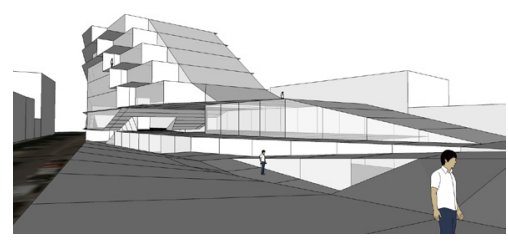

Figure 5.54. Warped surface of public space considerations, as would be the case, for example, when working from an initial concept sketch. Surfaces are applied to the circulation diagram [Figure 5.3], thereby providing the diagram with an operational strategy (interpreted architecturally as continuous ramped surfaces) and forming the basis for the development of the building's form and massing as it is transposed from the abstract space of the diagram onto the site.

By transposing the project's operational diagram onto the site and developing it into an architectural proposition, unconventional solutions emerge; solutions which would have unlikely been generated had the project developed on the basis of form, inhabitation, and a conventional architectural language. The primary example of such an unconventional solution is the warped inhabitable surface of the elevated public space [Figure 5.54], whose unusual geometry is an outcome of the building's close relationship to the circulation diagram which generated it. This surface is an unusual architectural outcome as it minimises the distinction between surface and enclosure and integrates vertical and horizontal elements.

\section{Design Two: Areas of Unconventional Building/Open Space Relationships}

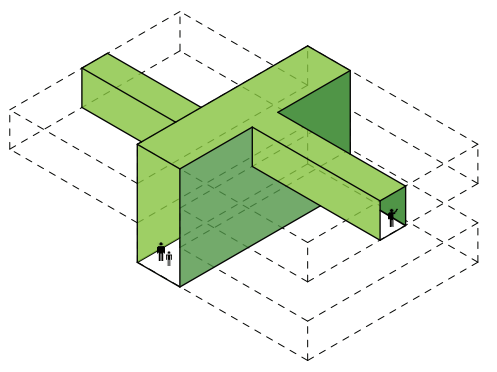

Figure 5.55. The public realm is extended within the building's footprint to allow access to the multiple levels of retail, extending a sense of publicness and urbanity within the building

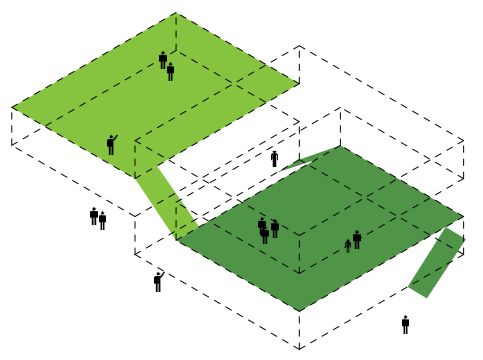

Figure 5.56. The multiple levels of retail, covered market and public space elevated above the level of the street create topographical variation for the public occupation of the building

Figure 5.57. The permeable building edges of the covered market area minimise the distinction between the building's inside and outside, as do the voids which penetrate the upper floors of the building to create ambiguous 'third' spaces which are neither inside nor out 
Figure 5.58. The elevated outdoor public space which features no direct connection to the ground is an unusually public addition to the normally private upper floors of the building, creating an elevated terrace for the city

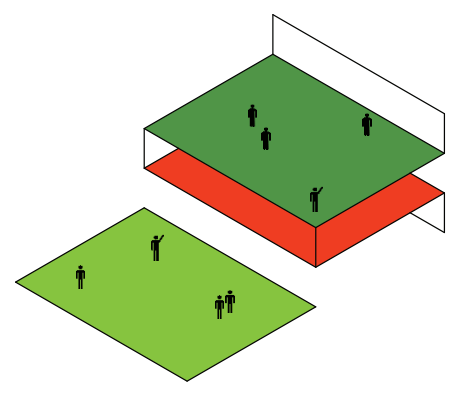

\section{Design Two: Role of Diagrams in Design Process}

The unconventional urban design outcomes of this design were a product of the Analytic/Literal diagrammatic design methodology, however were not always directly generated by diagrams. Input from the designer is an important component of this design method, as will be discussed in the following section.

The building's massing, selected by the designer following a diagrammatic analysis of the various massing options, created the necessity for three levels of public functions. The multiple levels of public functions extend the public realm inside the building and also create topographical variation for the public occupation, however these unconventional urban outcomes were not directly generated by a diagram; rather they are the necessary result of the logic dictating the building's massing.

The high degree of permeability of the building's volume which creates ambiguities between the building's inside and outside is an architectural outcome influenced by diagrams. The permeability of the covered market which creates a strong sense of visual and physical connection with Cuba Mall is the direct architectural outcome of an abstract diagrammatic 'pushing out' operation, which was generated at the abstract level of the building's massing diagram. This operation generated the void space in the building's massing to house the market and also generated the elevated public terrace.

The subtracted void spaces which penetrate the upper levels of the building and create ambiguities between inside and outside were an architectural strategy selected by the designer as an adaptation of MVRDV's VPRO project. The shapes of these spaces were to be directly generated by a diagrammatic negotiation and confrontation of the various constraints and influences effecting their operation - a 'datascape' of requirements.

In the Analytic/Literal methodology, the influence of the designer's logic is equally as important as the influence of diagrams in the development of the project. It is impossible to consider the diagrammatic influences alone, as they are intrinsically linked to the designer's logic which dictates what information the diagrams engage with. 


\section{Role of the Designer in the Different Methodologies}

Just as the role of diagrams varies between each of the methodologies, so too does the role of the designer. In the Abstract/Instrumentalising methodology, the design intentions of the designer have a lesser influence on the project's formal development, which is developed primarily on the basis of the manipulated circulation diagram. The designer's role in this relatively linear design process is predefined as manipulating the diagram in three dimensions. Although this process does require architectural judgement from the designer, the logic dictated by the diagram dominates the project's development rather than the designer rationalising each design move. Materials and construction are selected partly by the designer and are partly dictated by the formal outcome of the diagrammatic design methodology; e.g. the wooden decking of the elevated public space is required to construct the warped surfaces generated by diagrams.

In the Analytic/Literal methodology the intentions of the designer have a more significant impact on the development of the project. This methodology does not feature a predetermined design process, so the designer must decide what information to diagram and how best to present it. For some aspects of the design, diagrams are used to explore and analyse the alternate options, leaving the selection of the most effective solution to the judgement and rationalisation of the designer. An example of this approach is the determination of the building's site massing, which was selected based on a study of sunlight, compactness and cross-site connection. The rationale of the designer dictates which design factors are considered in the process of analysis. In other cases the designer identifies an architectural problem (e.g. daylight penetration to upper floors) and a strategy for solving this problem (e.g. subtracting voids), then deploys a diagram to generate the most effective configuration of the strategy.

Neither methodology has a primary concern for context or the experience of inhabitation, so it is up to the judgement of the designer to ensure these important aspects of the design are effectively addressed. The development of the design is never left solely to the logic of the diagram - the values and intuition of the designer still inevitably influence the design outcome, therefore different designers executing the same methodology would produce entirely different results.

\section{Architectural Outcomes of the Different Methodologies}

Not surprisingly, the different diagrammatic design methodologies produce different architectural outcomes. The Abstract/Instrumentalising methodology produces an architectural outcome realised in a relatively complex architectural and constructional language, as is illustrated by the warped and sloping surface of the elevated public space. These less conventional outcomes are direct products of the diagrammatic design methodology, as the 'stuff' of the diagram 
- it's sloping programmatic surfaces - is transposed to the site and manipulated to become the 'stuff' of the final building, thereby maintaining a close formal relationship between building and diagram.

By contrast, the Analytic/Literal methodology produces an architectural outcome realised in a relatively mainstream architectural and constructional language. This diagrammatic methodology is concerned more with the generation of organisation rather than the direct generation of built form, allowing a relatively conventional architectural language to be deployed on the diagrammatically generated organisation later in the design process.

\section{Limitations of the Different Methodologies}

\section{Design One:}

The Abstract/Instrumentalising design methodology produced a building whose upper office and residential levels are realised in a relatively conventional architectural language and organisation. The circulation diagram which was used to generate the organisation for the project had very little influence on the design of these floors, whereas on the lowest two public floors the diagram's surfaces are materialised to directly generate the building's form. The programme of these floors allowed this less conventional architectural response, however office and residential functions typically require a more standard architectural language. Furthermore, the design driver of circulation doesn't lend itself to the creation of office space (large, flexible floor plates) or the creation of apartments (discrete packets of space), resulting in a relatively conventional response to the brief for the design of these programmes.

This methodology also prioritises the large scale organisation and generation of form at the expense of a more considered response to the constraints of the project. An illustration of this is the ground level of the building which is underutilised in terms of usable floor area as the sloping pedestrian ramps create significant uninhabitable areas at ground level due to low ceiling heights. The design constraints of minimum ceiling height and maximising floor area are not a primary consideration for the building's development.

\section{Design Two:}

The Analytic/Literal design methodology works primarily with the constraints of a project, however the execution of this methodology considered relatively few constraints so the development of the project was somewhat lacking in complexity - especially as managing complexity is one of the most highly valued aspects of this methodology. The lack of constraints is due partly to the hypothetical nature of the project due to the absence of a real client who would have introduced a multitude of new constraints, such as a more complex functional programme. Also, with a greater understanding and level 
of experience with the methodology many other constraints could have been identified and considered by the designer, increasing the complexity of the developed building. Therefore, the designer's limited experience designing in this way is another limitation of the design execution.

Another limitation of the project is the form given to the 'voids' or penetrations in the upper floors of the building. The shape of these voids were intended to be developed diagrammatically, based on an optimisation of the requirements for sunlight, natural light, views and ventilation. For the purposes of this research the shape of the voids were designed by the designer to illustrate their possible urban outcomes as their specific shape was not deemed to be a significant factor for the project's urban design outcomes. The practicalities of time constraints and the need for the rapid development of each design proposal also influenced this part of the project's development. Had the voids been developed in a more diagrammatic manner, a more unexpected architectural outcome could have emerged.

Some of the most significant formal outcomes of the project were design decisions made by the designer rather than the outcome of any diagrammatic generator; for example the curve of the pedestrian ramps. It could be argued that this design move lacks integrity as it is a purely formal gesture and is not informed by any underlying functional logic. The necessity of such a formal gesture is questionable. On the one hand the curve of the ramps allow them to blend seamlessly with the two horizontal levels they connect, promoting continuity between the levels whilst also enhancing the aesthetic interest of the design (the building's construction would be entirely conventional were it not for these curved elements). On the other hand it could be argued that the highly unconventional programmatic organisation of the project would suffice in generating mass appeal for the building without the need for formal design gestures. Furthermore, had the shape of the subtracted voids in the building's upper volume been generated diagrammatically, they might have taken on a less conventional appearance. The architectural identity of the building might have relied on these elements rather than the curved elements which might have become unnecessary.

\section{Findings for the Instrumentality of Diagrams}

The execution of the diagrammatic design methodologies has produced buildings which challenge conventional urban design principles relating to the interface between built form and open space. The architectural outcomes variously reduce the distinction between public and private, built form and open space, and indoors and outdoors, in each case extending and generating new possibilities for the public occupation of the building. Based on the research it would be difficult to argue a causal relationship between the diagrammatic design methods and these unconventional urban design outcomes as the design phase was predisposed to produce such outcomes - it was the focus of the 
design research after all.

What can be argued, however, is that diagrams where instrumentalised in each design process, becoming more than explanatory or analytic devices and actually driving each project forward, generating new possibilities which would have unlikely been conceived had the projects been developed on a more conventional basis. This is not to say that diagrammatic design methods are the only way unconventional outcomes are produced; other methods, for example working primarily with form, could of course produce new, perhaps even similar, outcomes. How the diagrammatic design methods differ however, is the unconventional design outcomes are developed on the basis of an underlying functional rigour, and are presented as a logical, even probable response to the constraints of the brief. Unusual forms and organisations are not created based on the artistic whim of the designer, but are generated based on idealised information, forming a more defensible basis for the project's development. The functional logic which forms the basis for each project's development is present in the architectural outcome, however its translation into built form generates an unconventional architectural response.

The projects are developed not on the basis of form, but as organisations which exist in the abstract space of the diagram, exclusive of architectural or constructional considerations. Problems are posed and solved in this abstract space with little concern for architectural convention. For example in the early development of design one the ground-plane is of little special significance, and is just as open to manipulation as the rest of the project's elements; spatial compartmentalisation is non-existent as the circulation diagram promotes continuity and connection. In the development of design two the building's massing is manipulated as though conceived out of weightless blocks; entire floors are 'pushed' outwards from the building's volume, to be replaced by the building's 'external' functions. It is in this abstract space of the diagram where the project's unconventional urban outcomes are conceived as the by-products of an overriding logic. The architectural outcome's distinction between figure and ground is minimised because in the space of the diagram this distinction is non-existent, as is also the case with public and private, horizontal and vertical, and inside and outside. The buildings' unconventional interface with their surrounding open space is the result of their formulation in the noncontextual, non-physical space of the diagram.

Developing the project through diagrams allows the complexities of the projects to be effectively managed. The inevitably complex unconventional architectural outcomes are achievable thanks to a working method which facilitates the management of these complexities. The diagrammatic design methodologies manage the complexities of the project by allowing multiple paths of development to be explored without physical effect, and by combining both functional and formal influences into a single operational tool. 


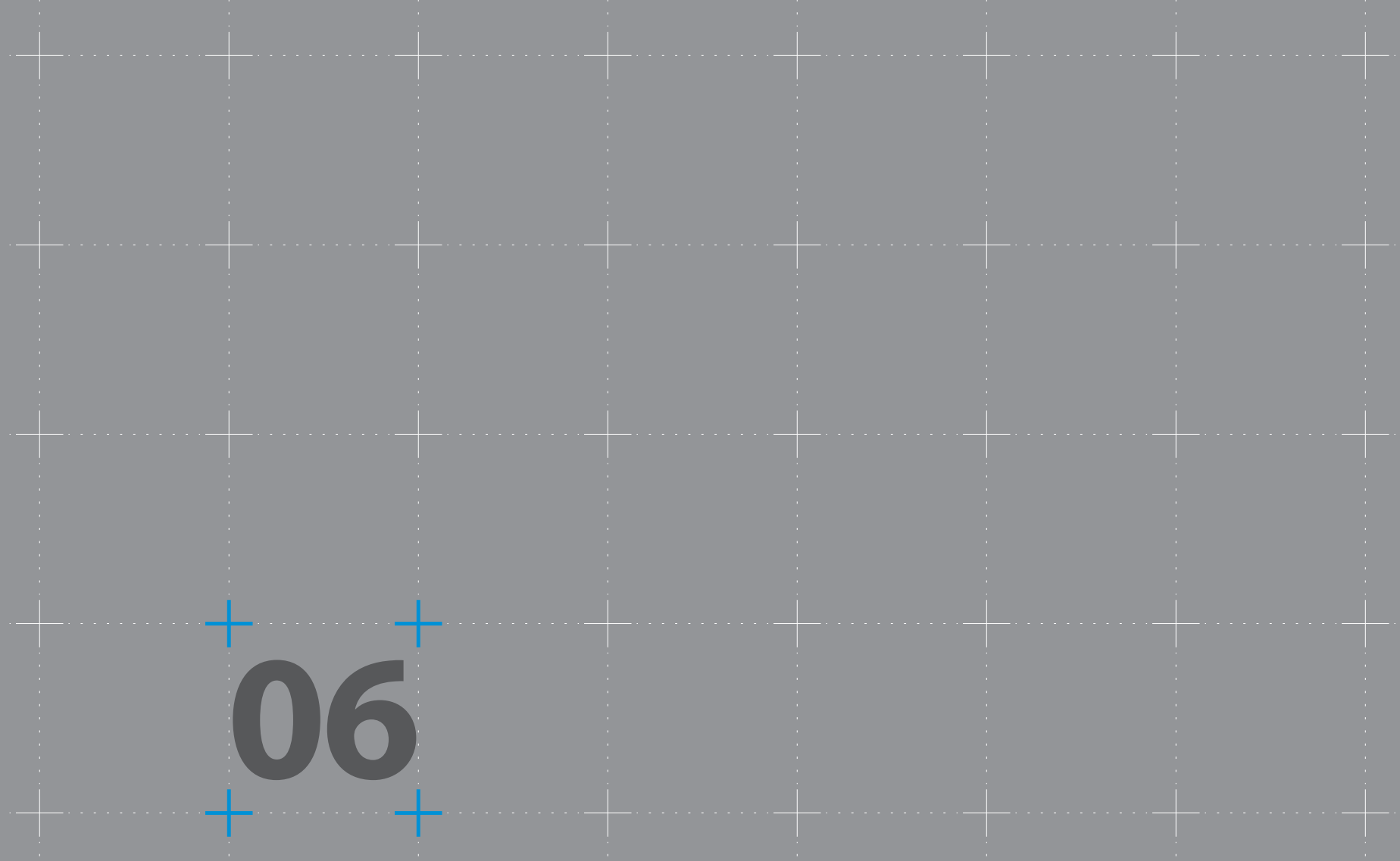

\section{Conclusions}
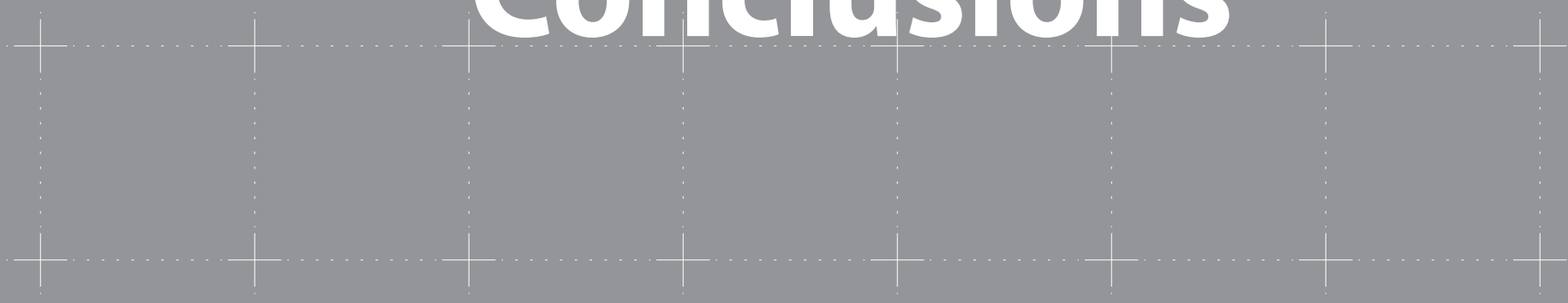

$+$
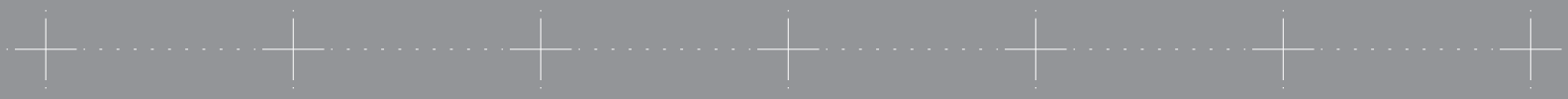

$+$
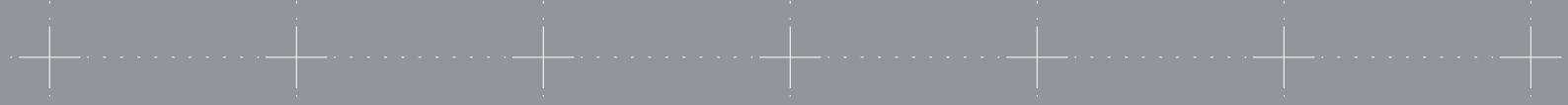

$+$
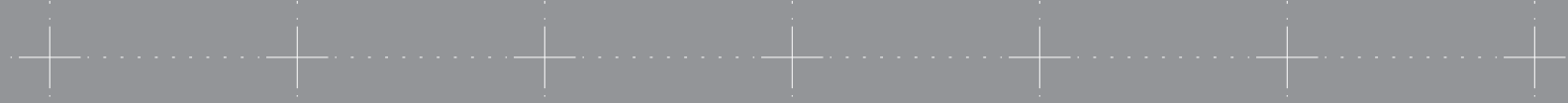

$+$
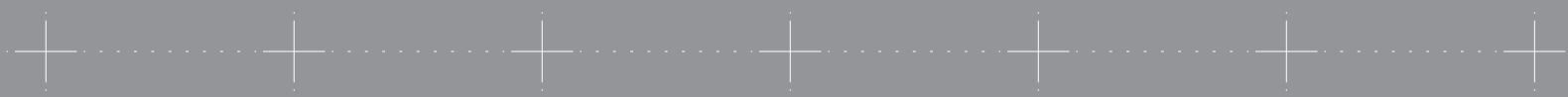


\section{Conclusions}

The main intention of this research was to examine the contribution made by diagrammatic design methods in the design of urban architecture projects. The observation forming the basis for this research was that many practices who utilised diagrams extensively in their design methodologies seem to produce buildings which relate to their surrounding urban space in unconventional ways. These buildings challenge conventional urban design principles relating to the interface between built form and open space, representing part of an emerging trend in urban design. The research therefore examined the instrumentality of diagrams in the production of unconventional urban design outcomes relating to the interface between built form and open space.

Three conclusions have been produced for this topic of research. The first conclusion relates to the different types of diagrammatic design practice. The second relates to the different urban design outcomes produced by the different methodologies. The third conclusion is composed of three subsidiary findings, and addresses the aim of the research by concluding what contribution diagrammatic design methods make in the realisation of unconventional urban design outcomes.

\section{Conclusion One: Different types of diagrammatic practice}

The first conclusion, supported by case studies of four key diagrammatic practitioners, is the prevalence of two different types of diagrammatic design practice: Abstract/Instrumentalising and Analytic/Literal. Case studies identified common aspects of unconventional diagram use between the practices and allowed them to be grouped into the different types of diagrammatic design practice. The Abstract/instrumentalising type is characterised by an instrumentalisation of an organisational diagram into an operative diagram, prioritising the translation of an abstract, optimised organisational diagram into built form. The Analytic/Literal type is characterised by a utilisation of diagrams to prioritise data, analysis and the invisible forces which influence a project's development, often resulting in a relatively literal translation of diagram into built form. A significant difference between the two types of diagrammatic practice, supported by findings from an execution of each methodology, is the role of the designer in each design process. In the Abstract/ 
Instrumentalising methodology the designer's role is reduced as the logic of the diagram drives the project's development, whereas in the Analytic/Literal methodology input from the designer forms a more significant component of the project's development.

\section{Conclusion Two: Different unconventional urban design outcomes}

The second conclusion is that different types of diagrammatic practice produce different outcomes for their architecture and subsequently different unconventional urban design outcomes. This conclusion is supported by case studies of four key diagrammatic practitioners and a design execution of each type of diagrammatic practice. It also refers back to the unconventional urban design principles identified in the literature review.

The architectural outcomes of the Abstract/Instrumentalising diagrammatic design methodology are typically geometrically complex, featuring curved and sloping surfaces requiring relatively non-conventional constructional techniques. The most significant unconventional urban design outcomes of this type of practice are the minimisation of the distinction between built form and open space, public and private, and typically horizontal and vertical elements. Circulation and an emphasis on continuity and connection typically form the basis for projects developed in this way, resulting in built forms which physically integrate with their urban surroundings, minimising the threshold between building and open space and integrating horizontal circulation with vertical and inhabitable surface with enclosure.

The architectural outcomes of the Analytic/Literal diagrammatic design methodology are typically relatively geometrically simple. This type of diagrammatic practice is more concerned with the generation of a project's organisation rather than form, producing buildings which are largely realised in conventional building elements, however do feature aspects of formal and constructional complexity. The most significant unconventional urban design outcome of this type of practice is an ambiguity between the building's inside and outside, creating a prolonged sense of public urbanity within the typically private built volume. A primary concern for programme and a strict functional logic typically form the basis for projects developed in this way, resulting in architectural solutions which oppose convention and create unusual programmatic organisations and spaces.

\section{Conclusion Three: Contribution of diagrammatic design methodologies in the realisation of unconventional urban design outcomes}

The third conclusion relates to the specific contributions that diagrammatic design methods make towards the realisation of non-conventional urban design outcomes. The conclusion is composed of three subsidiary findings for 
the contribution of diagrams: Abstract Development, Managing Complexity, and Powers of Rhetoric. Practice studies of four key diagrammatic practitioners and a design execution of each type of diagrammatic practice support these findings and conclusion.

\section{Abstract Development:}

The first subsidiary finding is that diagrammatic design methods contribute to the realisation of non-conventional urban design outcomes by prolonging the virtualities of the project, allowing it to develop in an abstract manner with minimal concern for architectural convention. Unconventional urban design outcomes are conceived in abstract diagrammatic space as the bi-products of an overriding functional logic. Architectural conventions such as built form and open space, public and private and interior and exterior space do not exist within the non-physical, non-contextual space of the diagram, resulting in unconventional relationships between the project's elements once transposed to site and realised in architectural terms.

\section{Managing Complexity:}

The second subsidiary finding is that diagrammatic design methods allow control of a high degree of complexity in the design process, often common for the realisation of non-conventional urban design outcomes. Diagrams manage the complex process of optimisation and confrontation of a project's constraints which concern both form and function. The project's constraints are combined with a single operational tool, allowing them to be effectively managed to facilitate the realisation of more complex organisational and formal architectural solutions.

\section{Powers of Rhetoric:}

The third subsidiary finding is that diagrammatic design methods contribute to the realisation of non-conventional urban design outcomes by presenting the often unusual design as the outcome of an underlying functional logic. Diagrammatic design methods are not the only way unconventional urban design outcomes are achieved, however these methods present the unconventional outcome as the logical result of an underlying functional rigour, providing a persuasive, defensible and clearly articulated rhetoric for the unusual architectural outcome.

\section{Limitations and Further Research}

It would be useful to conduct further research into the public spaces and built form/open space relationships produced by diagrammatic design methodologies. This research focused on identifying the unconventional and emergent outcomes produced by the methodologies and examined how they 
were conceived. With a focus on difference, the urban quality of the architectural outcomes was not of principle concern - the outcomes were different, but were they better? Further analysis into the quality of the architectural outcomes could provide significant insight into the applicability of diagrammatic design methodologies in the design of urban architecture and public space, and would also provide a broader, more general insight into the applicability of recent emergent urban design trends.

Further research into the application of the diagrammatic design methodologies for different programmes, scales and in different contexts would also be useful. This research could address whether certain types of diagrammatic practice are more applicable for certain programmes or contexts. It is interesting to note that between the design proposals the Abstract/Instrumentalising method imparted more influence on the lower public floors of the building, whereas the Analytic/Literal method engaged with the building's private upper floors to a higher degree. Further research could also engage with the possibility of combining the two types of diagrammatic practice within a single diagrammatic strategy, exploiting the most valuable aspects of each methodology.

One of the obvious barriers to the realisation of urban buildings which challenge conventional urban design principles is the cost of construction as significant areas of non-standard construction are required. Feasibility studies of the design proposals would be useful to comment on the feasibility of the buildings produced. Both proposals provide outdoor public space and areas for a covered market; programmes which contribute positively to the surrounding urban environment. Because of this, it could be possible that local councils would subsidise part of the development, increasing the likelihood of the projects' feasibility.

\section{Final Conclusion}

New conceptions of the relationships between built form and open space represent a contemporary emerging trend in urban design which minimises many of the conventional distinctions typical in urban architecture projects, promoting hybridity, connectivity and porosity in their place. Diagrams provide a useful tool to engage with these new and evolving relationships in the design of urban architecture projects. Instrumentalising diagrams in the design process generates new possibilities for the future relationships between built form and urban open space, and develops the often unconventional architectural outcome on the basis of an underlying functional logic. With further research and effective use, diagrams could play a more important role in the generation of yet to be conceived solutions for urban architecture projects. 


\section{Bibliography}

Adam, H. (2002). Stacking and Layering. In MVRDV: 1997-2002: Stacking and Layering (pp. 30-38). Madrid, Spain: El Croquis Editorial.

Alison, J., Jones, M., Spiller, N., \& Vaughan, L. (Eds.). (2006). Future City: Experiment and Utopia in Architecture. London, United Kingdom: Thames $\&$ Hudson Ltd.

Allen, S. (1997). Artificial Ecologies: the Work of MVRDV. In Maas vanRijs deVries 1991-1997: MvRdV (pp. 26-33). Madrid, Spain: El Croquis Editorial.

Allen, S. (1998). Diagrams Matter. ANY , 23, 16-29.

Attali, J. (2003). Vertical Labyrinths. In Reading MVRDV (pp. 72-81). Rotterdam: NAi Publishers.

Berkel, B. v., \& Bos, C. (1998). Diagrams - Interactive Instruments in Operation. ANY, 23, 19-23.

Berkel, B. v., \& Bos, C. (2010). Diagrams. In M. Garcia (Ed.), The Diagrams of Architecture (pp. 222-227). Chichester, United Kingdom: John Wiley \& Sons Ltd.

Berkel, B. v., \& Bos, C. (2007). UNStudio: After Images. Beijing: United Asia Art \& Design Cooperation.

Berkel, B. v., \& Bos, C. (2006). UNStudio: Design Models: Architecture Urbanism Infrastructure. London, United Kingdom: Thames \& Hudson.

Betsky, A. (2002). Landscrapers: Building with the Land. New York, USA: Thames \& Hudson Inc.

Buchanan, P. (1988). A Report from the Front. In M. Carmona, \& S. Tiesdell (Eds.), Urban Design Reader (pp. 204-207). Oxford, United Kingdom: Architectural Press.

Carmona, M., \& Tiesdell, S. (2007). The Morphological Dimension. In M. 
Carmona, \& S. Tiesdell (Eds.), Urban Design Reader (pp. 59-62). Oxford, United Kingdom: Architectural Press.

Carmona, M., Tiesdell, S., Heath, T., \& Oc, T. (2010). Public Places, Urban Spaces: The Dimensions of Urban Design. Oxford, United Kingdom: Architectural Press.

Commission for Architecture and the Built Environment. (2000). By Design: Urban Design in the Planning System: Towards Better Practice. London, England: Commission for Architecture and the Built Environment.

Confurius, G. (2000). Editorial. Daidalos , 74, 4-5.

Deen, W., \& Garritzmann, U. (2010). Diagramming the Contemporary: OMA's Little Helper in the Quest for the New. In M. Garcia (Ed.), The Diagrams of Architecture (pp. 228-235). Chichester, United Kingdom: John Wiley \& Sons Ltd.

Ellin, N. (2006). Integral Urbanism. New York: Routledge.

Garcia, M. (2010). The Diagrams of Architecture. Chichester, United Kingdom: John Wiley \& Sons Ltd.

Gargiani, R. (2008). Rem Koolhaas, OMA: The Construction of Merveilles. Oxford, United Kingdom: Routledge.

Gehl, J. (2010). Cities For People. Washington, United states of America: Island Press.

Kleinman, A. (2006). Interview with Farshid Moussavi. X-TRA , 8 (4).

Kubo, M., \& Prat, R. (Eds.). (2005). Seattle Public Library: OMA / LMN. Barcelona: bActar.

Llewelyn-Davies. (2007). Urban Design Compendium. London, United Kingdom: English Partnerships and the Housing Corporation.

Lootsma, B. (1998/1999, December/January). Reality Bytes: The Meaning of Research in the Second Modern Age. Daidalos , 69/70, pp. 8-21.

Lootsma, B. (1997). Towards a Reflexive Architecture. In Maas vanRijs deVries 1991-1997: MvRdV (pp. 35-42). Madrid, Spain: El Croquis Editorial.

Mass, W., van Rijs, J., \& Richard, K. (Eds.). (1998). FARMAX: Excursions on Density. Rotterdam: 010 Publishers. 
Maas, W., de Vries, N., \& van Rijs, J. (1997). mvrdv Maas vanRijs deVries 1991-1997. Croquis , 86.

Mallgrave, H. F., \& Goodman, D. (2011). An Introduction to Architectural Theory: 1968 to the Present. West Sussex, United Kingdom: John Wiley \& Sons Ltd.

Mansilla, L. M., \& Tunon, E. (1997). The Space of Optimism: A Conversation with Winy Maas, Jacob van Rijs and Nathalie de Vries. In Maas vanRijs deVries 1991-1997: MvRdV (pp. 6-25). Madrid, Spain: El Croquis Editorial.

Moussavi, F., \& Zaera Polo, A. (2006, January). Foreign Office Architects. Architectural Review , 219 (1307), p. 61.

Moussavi, F., \& Zaera-Polo, A. (2002). The Yokohama Project: Foreign Office Architects. Barcelona, Spain: Actar.

Moussavi, F., \& Zaera-Polo, A. (2004, May/June). Types, Style and Phylogenesis. Architectural Design , 74 (3), pp. 34-39.

Salazar, J. (Ed.). (1999). MVRDV at VPRO. Barcelona: Actar.

Schumacher, P. (1999). Rational in Retrospect: Reflections on the Logic of Rationality in Recent Design. AA Files , 38, pp. 32-36.

Somol, R. E. (2010). Dummy Text, or the Diagrammatic Basis of Contemporary Architecture. In M. Garcia (Ed.), The Diagrams of Architecture (pp. 88-91). Chichester, United Kindom: John Wiley \& Sons Ltd.

Trancik, R. (2007). What is Lost Space? In M. Carmona, \& S. Tiesdell (Eds.), Urban Design Reader (pp. 63-69). Oxford, United Kingdom: Architectural Press.

Van Sande, H., \& Schoonjans, Y. (2007, January). Interview - Part 2: Research by Design. Architecture and Urbanism, pp. 80-85.

Van Sande, H., \& Schoonjans, Y. (2007, January). Interview - Part 3: Space Transformers. Architecture and Urbanism, pp. 122-123.

Vidler, A. (2004). Diagrams of Utopia: The Activist Drawing. Lotus International , 123, 28-41.

von Meijenfeldt, E., \& Geluk, M. (2003). Below Ground Level: Creating New Spaces for Contemporary Architecture. Basel, Switzerland: Birkhauser. 
Zaera-Polo, A. (2010). Between Ideas and Matters: Icons, Indexes, Diagrams, Drawings and Graphs. In M. Garcia (Ed.), The Diagrams of Architecture (pp. 237-243). Chichester, United Kingdom: John Wiley \& Sons Ltd.

Zaera-Polo, A., \& Moussavi, F. (1998/1999). New Grounds. Scroope , 10, pp. $10-16$.

Zaera-Polo, A., \& Moussavi, F. (1998). Reformulating the Ground. Quaderns , 220, pp. 36-41.

\section{List of Figures}

\section{Chapter 3:}

Figure 3.1. Yokohama International Port Terminal. (n.d.). Retrieved January 26, 2012, from http://www.idesignarch.com/wp-content/uploads/2010/08/ YokohamaInternationalPortTerminal-1.jpg.

Figure 3.2. No Return Diagram. From The Yokohama Project: Foreign Office Architects (p. 10), by Moussavi, F., \& Zaera-Polo, A, 2002, Barcelona, Spain: Actar.

Figure 3.3. Three Dimensional No-Return Diagram. From The Yokohama Project: Foreign Office Architects (p. 41), by Moussavi, F., \& Zaera-Polo, A, 2002, Barcelona, Spain: Actar.

Figure 3.4. Three-Dimensional No-Return Diagram. From The Yokohama Project: Foreign Office Architects (p. 10), by Moussavi, F., \& Zaera-Polo, A, 2002, Barcelona, Spain: Actar.

Figure 3.5. Diagram of Building Structural Strategy. From The Yokohama Project: Foreign Office Architects (p. 15), by Moussavi, F., \& Zaera-Polo, A, 2002, Barcelona, Spain: Actar.

Figure 3.6. Diagram Showing Distribution of Secondary Programme. From The Yokohama Project: Foreign Office Architects (p. 19), by Moussavi, F., \& Zaera-Polo, A, 2002, Barcelona, Spain: Actar.

Figure 3.7. Early Building Development. From The Yokohama Project: Foreign Office Architects (p. 29), by Moussavi, F., \& Zaera-Polo, A, 2002, Barcelona, Spain: Actar.

Figure 3.8. Building Plans Showing Design Evolution. From The Yokohama Project: Foreign Office Architects (p. 55-59), by Moussavi, F., \& Zaera-Polo, A, 2002, Barcelona, Spain: Actar.

Figure 3.9. Yokohama International Port Terminal. (n.d.). Retrieved January 
26, 2012, from http://archis.org/action/2010/01/16/reasoning-with-wavesand-the-diagrams/.

Figure 3.10. Yokohama International Port Terminal. Sayo, M. (Photographer). (2008). Retrieved January 28, 2012, from http://www.flickr.com/photos/ lilmissayo/3164457942/

Figure 3.11. Arnhem Central Design Proposal. UN Studio (n.d.). Retrieved January 26, 2012, from http://www.unstudio.com/projects/arnhem-centralmasterplan.

Figure 3.12. Scaled Diagram of Programme Floor Areas. From UNStudio: Design Models: Architecture Urbanism Infrastructure (p. 275), by Berkel, B. v., \& Bos, C, 2006, London, United Kingdom: Thames \& Hudson.

Figure 3.13. Diagram Showing Separation of Bus Services. From "Rational in Retrospect: Reflections on the Logic of Rationality in Recent Design," by Schumacher, P, 1999, AA Files , 38, p. 33.

Figure 3.14. Network Graph. From "Rational in Retrospect: Reflections on the Logic of Rationality in Recent Design," by Schumacher, P, 1999, AA Files , 38, p. 33.

Figure 3.15. Network Graph Transposed onto the Site. From "Rational in Retrospect: Reflections on the Logic of Rationality in Recent Design," by Schumacher, P, 1999, AA Files , 38, p. 33.

Figure 3.16. 'Branching Figure' Diagram. From "Rational in Retrospect: Reflections on the Logic of Rationality in Recent Design," by Schumacher, P, 1999, AA Files, 38, p. 34.

Figure 3.17. Schematic Matrix. From UNStudio: Design Models: Architecture Urbanism Infrastructure (p. 275), by Berkel, B. v., \& Bos, C, 2006, London, United Kingdom: Thames \& Hudson.

Figure 3.18. Three Dimensional Branching Diagram. From "Rational in Retrospect: Reflections on the Logic of Rationality in Recent Design," by Schumacher, P, 1999, AA Files, 38, p. 34.

Figure 3.19. Three Dimensional 'Cone' Diagram. From "Rational in Retrospect: Reflections on the Logic of Rationality in Recent Design," by Schumacher, P, 1999, AA Files, 38, p. 35.

Figure 3.20. Single Surface Diagram. From "Rational in Retrospect: Reflections on the Logic of Rationality in Recent Design," by Schumacher, P, 1999, AA Files, 38, p. 35 .

Figure 3.21. Klein Bottle Diagram. From UNStudio: Design Models: Architecture Urbanism Infrastructure (p. 274), by Berkel, B. v., \& Bos, C, 2006, London, United Kingdom: Thames \& Hudson.

Figure 3.22. Hybrid Diagram. From UNStudio: Design Models: Architecture 
Urbanism Infrastructure (p. 274), by Berkel, B. v., \& Bos, C, 2006, London, United Kingdom: Thames \& Hudson.

Figure 3.23. Diagram of Design Models. From UNStudio: Design Models: Architecture Urbanism Infrastructure (p. 274), by Berkel, B. v., \& Bos, C, 2006, London, United Kingdom: Thames \& Hudson.

Figure 3.24. Arnhem Central Design Proposal. UN Studio (n.d.). Retrieved January 26, 2012, from http://www.unstudio.com/projects/arnhem-centraltransfer-hall

Figure 3.25. Arnhem Central Design Proposal. UN Studio (n.d.). Retrieved January 26, 2012, from http://www.unstudio.com/projects/arnhem-centraltransfer-hall

Figure 3.26. The Villa VPRO. Leng, J. (Photographer). (2008). Retrieved January 26, 2012, from http://www.flickr.com/photos/ettubrute/2357171915/

Figure 3.27. Graph of Daily Work Activities. From MVRDV at VPRO (p. 47), by Salazar, J. (Ed.), 1999, Barcelona: Actar.

Figure 3.28. Building Volume Study. From MVRDV at VPRO (p. 48, 49), by Salazar, J. (Ed.), 1999, Barcelona: Actar.

Figure 3.29. Plan Layout Study. From FARMAX: Excursions on Density (p. 684, 685), by Mass, W., van Rijs, J., \& Richard, K. (Eds.), 1998, Rotterdam: 010 Publishers.

Figure 3.30. Precision Bombardment Diagram. From MVRDV at VPRO (p. 51), by Salazar, J. (Ed.), 1999, Barcelona: Actar.

Figure 3.31. Conceptual Diagram. From mvrdv Maas vanRijs deVries 19911997 (p. 88), by Maas, W., de Vries, N., \& van Rijs, J, Croquis , 86.

Figure 3.32. Diagrams Showing Spatial Moulding. From MVRDV at VPRO (p. 66, 67), by Salazar, J. (Ed.), 1999, Barcelona: Actar.

Figure 3.33. Diagrammatic Break-down of Programmed Floor Areas. From MVRDV at VPRO (p. 70), by Salazar, J. (Ed.), 1999, Barcelona: Actar.

Figure 3.34. Distribution of Programme. From MVRDV at VPRO (p. 72), by Salazar, J. (Ed.), 1999, Barcelona: Actar.

Figure 3.35. Rose Window Effect. Leng, J. (Photographer). (2008). Retrieved January 26, 2012, from http://www.flickriver.com/photos/ettubrute/tags/ netherlands/

Figure 3.36. The Villa VPRO. Leng, J. (Photographer). (2008). Retrieved January 26, 2012, from http://www.flickr.com/photos/ettubrute/2358017442/ sizes/z/in/photostream/

Figure 3.37. The Villa VPRO. Leng, J. (Photographer). (2008). Retrieved January 26, 2012, from http://www.flickr.com/photos/ettubrute/2358004198/ 
Figure 3.38. Seattle Public Library. (n.d.). Retrieved January 26, 2012, from http://plusmood.com/2008/09/seattle-public-library-rem-koolhaas-oma/

Figure 3.39. Conceptual Diagram Showing Organising Principles. From Seattle Public Library: OMA / LMN (p. 16, 17), by Kubo, M., \& Prat, R. (Eds.), 2005, Barcelona: bActar.

Figure 3.40. Floor Area Proportions of Programme. From Seattle Public Library: OMA / LMN (p. 18), by Kubo, M., \& Prat, R. (Eds.), 2005, Barcelona: bActar.

Figure 3.41. Unstable Compartments Pushed Out. From Seattle Public Library: OMA / LMN (p. 18), by Kubo, M., \& Prat, R. (Eds.), 2005, Barcelona: bActar.

Figure 3.42. Offset Stacking of Programmatic Compartments. From Seattle Public Library: OMA / LMN (p. 22), by Kubo, M., \& Prat, R. (Eds.), 2005, Barcelona: bActar.

Figure 3.43. Flexible Spaces Between Compartments. From Seattle Public Library: OMA / LMN (p. 26), by Kubo, M., \& Prat, R. (Eds.), 2005, Barcelona: bActar.

Figure 3.44. Influences of View and Sun Requirements. From Seattle Public Library: OMA / LMN (p. 30), by Kubo, M., \& Prat, R. (Eds.), 2005, Barcelona: bActar.

Figure 3.45. View-shafts. From Seattle Public Library: OMA / LMN (p. 30), by Kubo, M., \& Prat, R. (Eds.), 2005, Barcelona: bActar.

Figure 3.46. Seattle Public Library. (n.d.). Retrieved January 26, 2012, from http://pcj.typepad.com/planning_commissioners_jo/2008/05/downtownlibrar.html

Figure 3.47. Seattle Public Library. Norsworthy, S. (Photographer). (2011). Retrieved January 26, 2012, from http://www.flickr.com/photos/ scottnorsworthy/6490546513/.

Figure 3.48. Analysis Diagrams. Adapted from previously referenced images (Figures 3.12, 3.14, 3.15, 3.27, 3.33, 3.40).

Figure 3.49. Datascape Diagrams. Adapted from previously referenced images (Figures 3.28, 3.29, 3.44, 3.45).

Figure 3.50. Organisational Diagrams. Adapted from previously referenced images (Figures 3.2, 3.13, 3.16, 3.18, 3.34, 3.42, 3.43).

Figure 3.51. Operational Diagrams. Adapted from previously referenced images (Figures 3.3, 3.19, 3.20, 3.22, 3.30, 3.32).

Figure 3.52. Conceptual Diagrams. Adapted from previously referenced images (Figures 3.31, 3.39)

Figure 3.53. Abstract Diagrams. Adapted from previously referenced images (Figures 3.21, 3.41) 
Figure 3.54. Diagram Use Comparison Between the Different Practices.

Figure 3.55. Areas of Unconventional Diagram Use

Figure 3.56. Areas of Common Unconventional Diagram Use

\section{Chapter 4:}

Figure 4.1. Wellington Arial View. Adapted from Google Earth.

Figure 4.2. Wellington City Contours. Adapted from Google Earth and Koordinates.com.

Figure 4.3. Wellington City Grid. Adapted from Google Earth and Koordinates. com.

Figure 4.4. Wellington City Building Footprints. Adapted from Google Earth and Koordinates.com.

Figure 4.5. Wellington City Districts. Adapted from Google Earth and Koordinates.com.

Figure 4.6. Arial View of Site. Adapted from Google Earth.

Figure 4.7. Site Figure-Ground Diagram. Adapted from Koordinates.com.

Figure 4.8. Height Restrictions. Adapted from Koordinates.com.

Figure 4.9. Vehicle Network. Adapted from Koordinates.com.

Figure 4.10. Transport Infrastructure. Adapted from Koordinates.com.

Figure 4.11. Pedestrian Network. Adapted from Koordinates.com.

Figure 4.12. Photograph of Existing Building. Photograph by Author, 2011.

Figure 4.13. Photograph of Existing Building. Photograph by Author, 2011.

Figure 4.14. Photograph of Existing Building. Photograph by Author, 2011.

Figure 4.15. Photograph of Existing Building. Photograph by Author, 2011.

Figure 4.16. The Oaks Sectional Perspective. Wellington City Archives, accessed 2011.

Figure 4.17. The Oaks Ground Floor Plan. Wellington City Archives, accessed 2011.

Figure 4.18. Proposed Wellington Laneway Development. From WGTN2040: Reshaping Wellington's Future, Wellington City Council, 2011, Retrieved from http://www.wellington2040.co.nz/sites/default/files/attachments/WCC9663_ WN2040\%20Project\%20Single\%20Cards.pdf

Figure 4.19. Cross-site Connection Diagram. Adapted from Koordinates.com.

Figure 4.20. Proposed Te Aro Park Development. From WGTN2040: Reshaping Wellington's Future, Wellington City Council, 2011, Retrieved 
from http://www.wellington2040.co.nz/sites/default/files/attachments/

WCC9663_WN2040\%20Project\%20Single\%20Cards.pdf

\section{Chapter 5:}

Figure 5.1. Circulation Diagram. Image by Author.

Figure 5.2. Scaled Surfaces Diagram. Image by Author.

Figure 5.3. Three-Dimensionally Manipulated Diagram. Image by Author.

Figure 5.4. Three Dimensional Diagram Manipulated within Site Constraints.

Image by Author.

Figure 5.5. Resulting Form. Image by Author.

Figure 5.6. Resulting Form in Context. Image by Author.

Figure 5.7. Site Plan. Image by Author.

Figure 5.8. Perspective Image. Image by Author.

Figure 5.9. Perspective Image. Image by Author.

Figure 5.10. Perspective Image. Image by Author.

Figure 5.11. Perspective Image. Image by Author.

Figure 5.12. Perspective Image. Image by Author.

Figure 5.13. Perspective Image. Image by Author.

Figure 5.14. Perspective Image. Image by Author.

Figure 5.15. Perspective Image. Image by Author.

Figure 5.16. Plan. Image by Author.

Figure 5.17. Plan. Image by Author.

Figure 5.18. Plan. Image by Author.

Figure 5.19. Plan. Image by Author.

Figure 5.20. Plan. Image by Author.

Figure 5.21. Massing Logic Diagram. Image by Author.

Figure 5.22. Diagram showing Floor Area Proportions. Image by Author.

Figure 5.23. Sunlight and Shading Study. Image by Author.

Figure 5.24. Compactness and Cross-site Connection Study. Image by Author.

Figure 5.25. Additional Space Requirement Diagram. Image by Author.

Figure 5.26. Abstract Diagrammatic 'Pushing Out' Operation. Image by Author.

Figure 5.27. Precision Push Diagrammatic Operation. Image by Author. 
Figure 5.28. Subtracted Voids Diagram. Image by Author.

Figure 5.29. Configuration of Voids. Image by Author.

Figure 5.30. Resulting Form. Image by Author.

Figure 5.31. Resulting Form in Context. Image by Author.

Figure 5.32. Site Plan. Image by Author.

Figure 5.33. Perspective Image. Image by Author.

Figure 5.34. Perspective Image. Image by Author.

Figure 5.35. Perspective Image. Image by Author.

Figure 5.36. Perspective Image. Image by Author.

Figure 5.37. Perspective Image. Image by Author.

Figure 5.38. Perspective Image. Image by Author.

Figure 5.39. Perspective Image. Image by Author.

Figure 5.40. Perspective Image. Image by Author.

Figure 5.41. Perspective Image. Image by Author.

Figure 5.42. Plan. Image by Author.

Figure 5.43. Plan. Image by Author.

Figure 5.44. Plan. Image by Author.

Figure 5.45. Plan. Image by Author.

Figure 5.46. Plan. Image by Author.

Figure 5.47. Plan. Image by Author.

Figure 5.48. Public/Private Diagram. Image by Author.

Figure 5.49. Figure/Ground Diagram. Image by Author.

Figure 5.50. Warped Surface Diagram. Image by Author.

Figure 5.51. Horizontal/Vertical Diagram. Image by Author.

Figure 5.52. Permeable Edge Diagram. Image by Author.

Figure 5.53. Wave Diagram. Image by Author.

Figure 5.54. Warped Surface of Public Space. Image by Author.

Figure 5.55. Urban Extension Diagram. Image by Author.

Figure 5.56. Topographical Variation Diagram. Image by Author.

Figure 5.57. Permeable Edges Diagram. Image by Author.

Figure 5.58. Elevated Public Space Diagram. Image by Author. 